Running Head: SPED MATH ELLS

\title{
THE INVESTIGATION OF THE SELF-EFFICACY OF SPECIAL EDUCATION TEACHERS WHO TEACH MATHEMATICS TO ENGLISH LANGUAGE LEARNERS WITH DISABILITIES
}

A Dissertation presented to the Faculty of the Graduate School of Special Education at the University of Missouri-Columbia

by JESSICA COLLINS KAMURU

Dr. Delinda van Garderen-Anderson, Dissertation Supervisor

JULY 2020 
The undersigned, appointed by the dean of the Graduate School have examined the Dissertation entitled:

THE INVESTIGATION OF THE SELF-EFFICACY OF SPECIAL EDUCATION TEACHERS WHO TEACH MATHEMATICS TO ENGLISH LANGUAGE LEARNERS WITH DISABILITIES,

Presented by, Jessica Collins Kamuru, A candidate for the degree of Ph.D. in Special Education, and hereby certify that, in their opinion, it is worthy of acceptance.

Professor- Dr. Delinda van Garderen-Anderson [Chair]

Professor- Dr. Erica Lembke [Committee Member]

Professor- Dr. Melissa Stormont [Committee Member]

Professor- Dr. Zandra de Araujo [Committee Members] 


\section{DEDICATION}

First, I would like to thank God, who works everything out for my good. Next, I would like to thank my husband, Mash, who supported me in both my course work and through this dissertation process by selflessly staying in our home and living with roommates. A special thank you to my children, Jasmine and Jacob who moved to Columbia and went on the journey of my graduate program with me. They are the two best kids that anyone could ask for. I would like to thank my mother, Gladys Collins, for her never ending love and support; and for not allowing me to quit. We made it, mama! To my brother and sisters, Ronnie, April and Yvette, thank you so much for being there for me. To my Kenyan parents-in-law, and Stephen thank you for your love and support, and coming to the USA to visit and give your encouragement. To my brother and sistersin-law, Evans, Edith, Charles and Penny, and thank you for your love, encouragement and support, and especially for a place to stay, when my house was occupied by roommates. To Karen and Emma, thank you for your cards, support, love and days out to have fun. To Tracey and Christina, thank you for the yoga and brunch sessions. Frances, thank you for visiting me from Germany and for the care packages. To Nick, Frances (again), Mikko and Petteri "Pete", where would my life be without you in it? Thank you for love, friendship and support... and for allowing me to retreat to Europe just get to some much needed rest. I'll never forget how your friendships got me through this. To Seth, thank you for visiting Columbia, and for showing my friend and I around when we attended the Minneapolis CGI conference. To my rest of my family and friends, I am 


\section{SPED ELLS MATH}

extremely grateful for the calls, cards, letters, packages, and visits...especially

Thanksgiving Dinners at my house. Finally, to the other doctoral students in both special education and mathematics education, thank you for your support and comraderie. If I have forgotten anyone, please charge it to my head, and not my heart.

I would like to give a very special thank you to the students whom I had the privilege to teach as a special education teacher in the inner city of Kansas City, Missouri. Many of whom were English Language Learners from Mexico, Guatemala, Burma, Vietnam and Somalia. All of my students had documented disabilities, and many of them lived in poverty, spoke a different home language, and had to learn how to navigate the American school system — which was not created with their needs in mind. Yet, my students were resilient, adaptable people who thrived. They were the "roses who grew from the cracks of the concrete" and my greatest teachers. Likewise, I am grateful for and inspired by all of the teachers and staff who continue to stand in the gap, and do their best to create more equitable learning opportunities for all of their students. 


\section{ACKNOWLEDGEMENTS}

This dissertation would not been possible without my advisor, Dr. Delinda van Garderen and my committee members, Dr. Erica Lembke, Dr. Melissa Stormont, and Dr. Zandra de Araujo. Thank you so much for your guidance, patience, encouragement and belief in my ability. I also want to acknowledge and thank the following people for their advice and assistance with my study: Dr. Diane Rodriguez of Fordham University, New York; Dr. Oneyda Paneque of Miami Dade College, Florida; Dr. Antonio Castro, University of Missouri- Columbia, Missouri; Heather Lindfors- Navarro, University of Missouri-Columbia, Missouri; Laura Avery, University of Missouri- Columbia, Missouri and Hyejim Shim, University of Missouri-Columbia, Missouri.

Last, but certainly not least, I am very grateful and indebted to the teachers in my study who took the time to fill out surveys, and give interviews to help me craft this study. 


\section{TABLE OF CONTENTS}

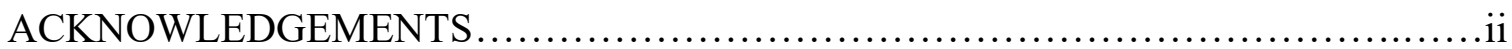

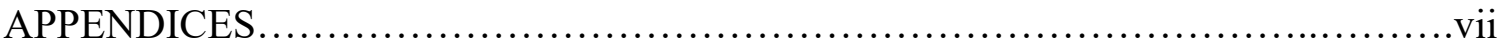

LIST OF TABLES and FIGURES .......................................... viii

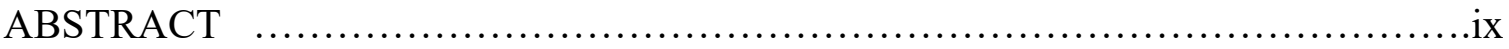

CHAPTERS

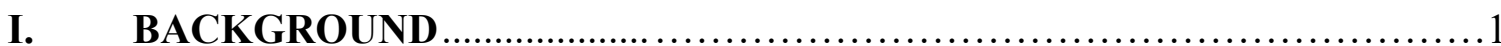

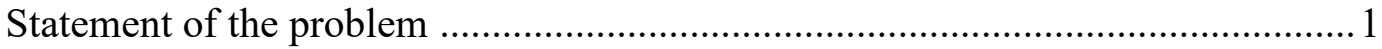

Teaching Mathematics to ELLs with Disabilities................................4

Mathematics Interventions for ELL students with Disabilities ........................... 4

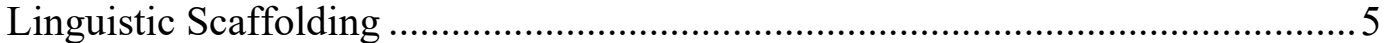

Cultural Competence and Responsiveness ........................................................ 5

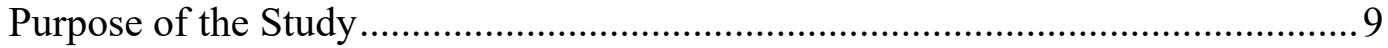

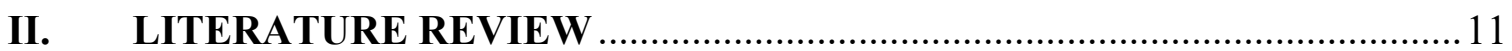

Theoretical Framework/Bandura's Theory of Self-Efficacy ................................ 11

Teacher Self-efficacy and Student Achievement Outcomes ............................. 13

Teacher Self-Efficacy and Teacher Expectations of Students .................15

Teacher Self-Efficacy Impact on Student Self-Efficacy.......................15

Outside Influences of Teacher Self-Efficacy................................ 17

Teacher Self-Efficacy for Teaching Mathematics...........................18

Teacher Self-Efficacy for Teaching ELL Students............................21 
Self-Efficacy for Teaching ELLs with Disabilities ........................22

Factors that Impact Teaching ELL students with Disabilities in Mathematics....24

Significance and Purpose of the Current Study ............................................ 27

Research Questions .............................................................................. 28

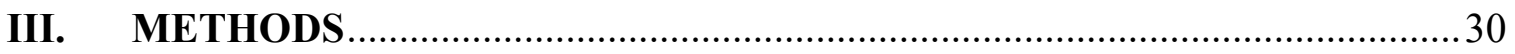

Participants........................................................... 30

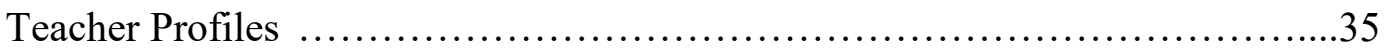

Teacher Beliefs and Self-Efficacy Survey.................................. 37

Survey Development ................................................ 38

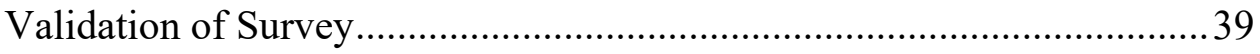

Survey for Current Study................................................................44

Semi-Structured Interview Protocol ...................................46

Survey and Semi-Structured Interview Implementation Procedure .................. 47

Survey Implementation ..........................................................4 47

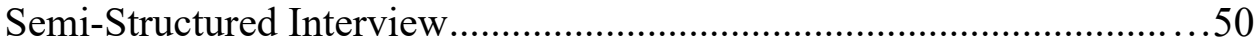

Selection Procedures for Semi-Structured Interview...................50

Quantitative Data Analysis ............................................................51

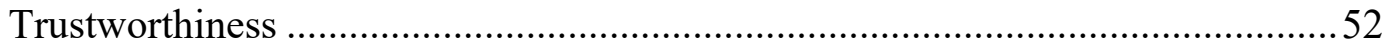

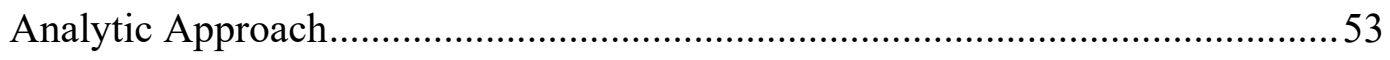

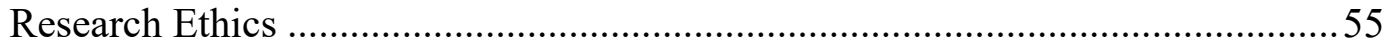

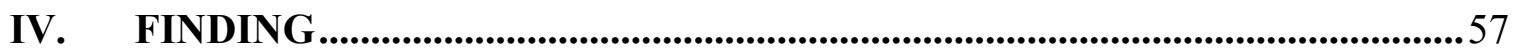

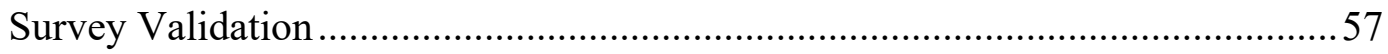

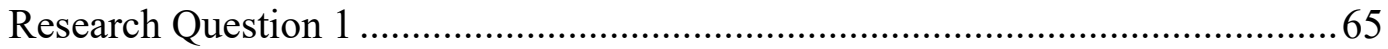


Between Test Comparisons …............................................66

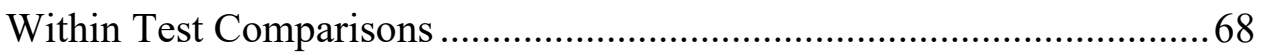

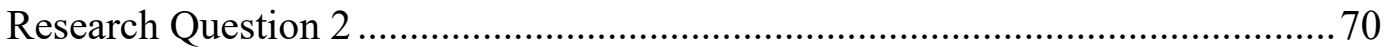

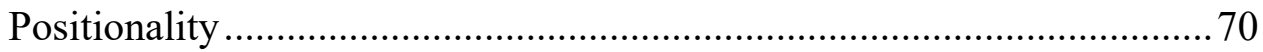

Factors that are Helpful or Harmful to Self-Efficacy for Teaching Mathematics..... 71

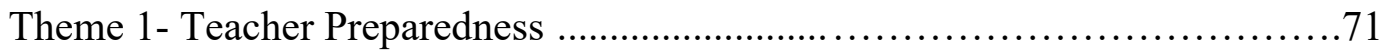

Helpful Factors- Teacher Preparedness ...................................................71

Harmful Factors- Lack of Preparation......................................................73

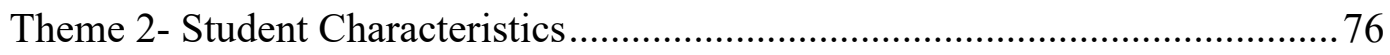

Helpful Factors due to ELL Characteristics ...............................................76

Harmful Factors due to ELL Characteristics ..............................................76

Helpful Factors due to Disability Status.....................................................79

Harmful Factors Related to Disability Status ..............................................79

Harmful Factors- ELL vs. Special Education Concerns .............................81

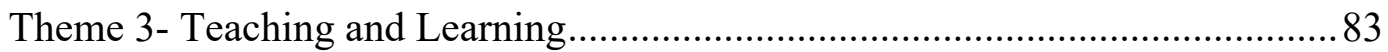

Helpful Factors Related to Teaching Methods .......................................... 83

Harmful Factors Related to Superficial Teaching Strategies ......................86

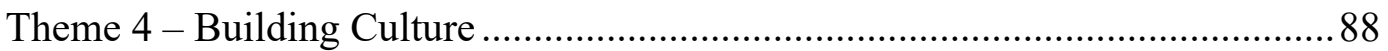

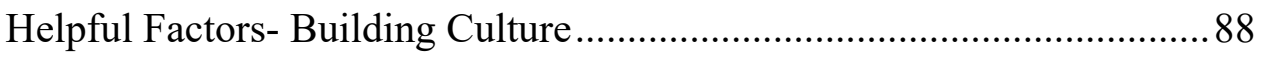

Harmful Factors- Building Culture …………………............................. 90

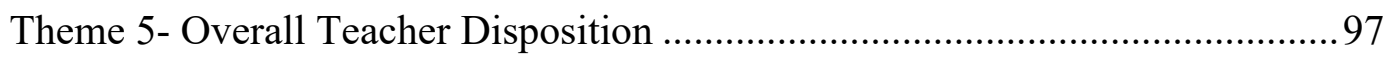

Helpful Factors- Empathy and Positive Regard ........................................97

Harmful Factors- Negative Regard for Students .......................................99 
Theme 6 -Culturally Responsive Pedagogy 100

Helpful Factors- Cultural and Linguistic Responsiveness Awareness .. 100 Harmful Factors- Lack of Cultural and Linguistic Responsive Teaching 101

Theme 7-Teacher Expectations of Student Outcomes

Helpful Factors- High Expectations in Mathematics for ELLs with Disabilities

Harmful Factors- Special Education Teachers Deferring Mathematics

Teaching to Other Teachers

V. DISCUSSION 107

Limitations and Future Research

Survey Response Rate

Survey Concerns

Interview Participants

Implications for Future Research

Implications for Teacher Preparation

Implications for K-12 Administrators

Conclusion

VI. REFERENCES

VII. VITA 


\section{APPENDICES}

1. Appendix (A): New MTEBI/ELL Responsive Measure (Survey instrument)- Current study

2. Appendix B: Cronbach's Alphas for each item in the MTEBI/ ELL Responsive Survey Instrument organized by latent variable (as identified by the pilot study)

3. Appendix C- Interview Question Protocol

4. Appendix D- Interview Code Book, with accompanying categories and codes

5. Appendix E- Recruitment Letter for Administrators.

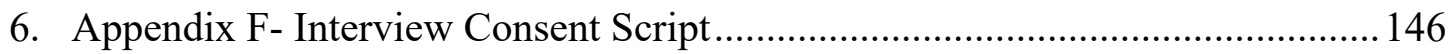

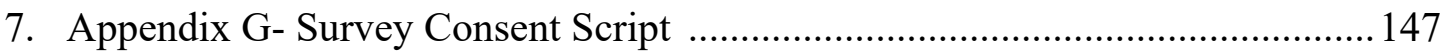

8. Appendix H- Recruitment Letter for Teachers

9. Appendix I- Survey Descriptives for each question asked on

10. the (current study) survey (means, median, standard deviation, range)

11. Appendix J- MTEBI EFA Latent Factor Table (variances)

12. Appendix K- ELL Responsive Factor Loadings Variances

13. Appendix L- MTEBI CFA Graph

14. Appendix M-ELL Responsive CFA Graph

15. Appendix N- CFA Psychometric Properties for the latent variables of the MTEBI and ELL Responsive Measure 


\section{LIST OF TABLES and FIGURES}

1. TABLE 1- Teacher Demographic Information from Survey Participants.......... 31

2. TABLE 2- Teacher Demographic Information from Interview Participants........ 35

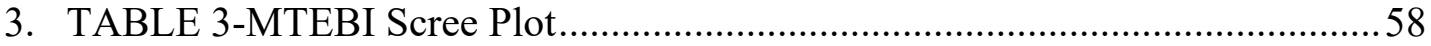

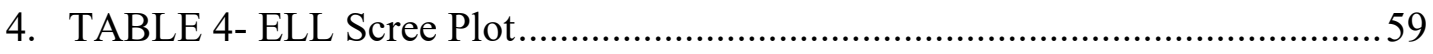

5. FIGURE 1- Survey Participants Flow Chart..................................................59

6. TABLE 5- Cronbach's Alpha Table for Each Latent Variable in the Full Survey..

7. TABLE 6- Correlation Matrix of Latent Variables Between the MTEBI and ELL Responsive Measure of the total survey....

8. TABLE 7- Survey Questions Used for the CFA Model ...................................62

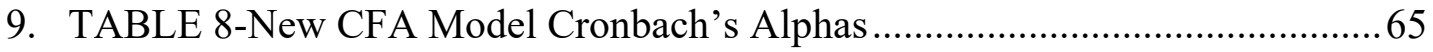

10. TABLE 9-Average Sub-Factors in MTEBI and ELL Responsive Measures ...... 70

11. TABLE 10-Summary of Factors That Were Helpful or Harmful to Teacher's Self-Efficacy 


\begin{abstract}
Of the English Language Learners (ELLs) in USA K-12 schools, 665,000 are identified as having a disability. In mathematics, ELLs with disabilities have significantly lower outcomes than English dominant, and non-disabled peers. Numerous studies over four decades have linked student outcomes to teacher self-efficacy (i.e. belief in ability to perform a task for expected outcomes). Considering many ELLs with disabilities receive mathematics instruction from special education teachers, there are questions about the self-efficacy of these teachers to provide quality instruction, since there are few studies focused specifically on preparing or supporting special education teachers to teach mathematics to ELLs with disabilities. The purpose of this dissertation is to examine in-service special education teachers' overall self-efficacy in teaching mathematics in teaching any student with a disability and in teaching ELLs with disabilities in culturally and linguistically responsive ways. One hundred seventeen special education teachers from 9 states were recruited for this study which utilized surveys and follow up interviews. Six participants, chosen for having low or high selfefficacy in teaching mathematics to any student with a disability or in teaching mathematics to ELLs with disabilities, were interviewed about factors which were helpful or harmful to their self-efficacy. Themes from the data included (a) teacher preparedness, (b) student characteristics, (c) teaching pedagogy, (d) building culture, (e) overall teacher disposition and (f) culturally responsive pedagogy.
\end{abstract}

Key Words: English Language Learners, disabilities, mathematics, self-efficacy 


\section{CHAPTER 1 \\ BACKGROUND}

\section{Statement of the Problem}

In the United States the population of English Language Learners (ELLs) in public schools is steadily growing. Some researchers believe that by the year 2025, onefourth of all students enrolled in American K-12 schools will identify as ELL, at least initially (Diaz-Rico \& Weed, 2006). Some, although not all ELLs are first or second generation immigrants, but many are. Seventy-seven percent of ELLs identify as Hispanic/Latinx and many live in low socio-economic status. Of all the ELLs in K-12 schools, 665,000, or 13.8\%, have been identified as having a disability (McFarland, Hussar \& deBrey, 2017).

According to the 2017 National Assessment of Educational Progress (NAEP), fourth-grade and eighth-grade ELLs with disabilities have significantly lower outcomes in mathematics than English dominant peers, non-disabled peers, and those who identify as both English dominant and non-disabled (de Brey et al., 2019). This gap in student outcomes is concerning not only at the elementary school level, but also at the high school level. Regardless of disability status, ELLs (particularly those who are Hispanic/ Latinx) drop out of high school 2.5 times more frequently than white, English dominant peers (Cramer, Gonzalez \& Pellegrini-Lafont, 2014). This is problematic because the negative implications of dropping out of school include fewer career opportunities, poverty, and an increased risk of incarceration (Cardimona, 2018; Cramer, Gonzalez,\& Pellegrini-Lafont, 2014; NCES, 2019). 
Special education teachers, like general education teachers, are expected to offer high-quality mathematics instruction to all of their students. The Individuals with Disabilities Education Improvement Act (2004), and the Every Students Succeeds Act (ESSA, 2015), have mandated that special education teachers, along with general education teachers, are required to be culturally competent by using culturally and linguistically responsive, relevant and sustaining pedagogy, and provide high quality, equitable mathematics instruction to all of their students, including ELL students with disabilities.

For special education teachers educating ELLs with disabilities in mathematics may be a challenging task. The instructional needs of ELLs with disabilities are multifaceted and complicated. English Languge Learners learn content in a language in which they are not proficient, and then are assessed by measures that do not differentiate between their language acquisition level and their content knowledge, making it possible that these assessment measures actually provide confusing information about student learning (Abedi, 2004; Abedi \& Gándara, 2006; Abedi \& Herman, 2010). Adding to these concerns, for special education teachers who teach ELLs with disabilities, there may also be confusion about what constitutes a language acquisition concern and what pertains to a learning disability (Roberts, 2009). As a result, studies have found that ELLs, regardless of ability status, underperform in mathematics due to language barriers in accessing the technical vocabulary of mathematics and the complexity of word problems. Additionally, ELLs may have difficulty understanding the cultural context of mathematics and may lack the ability to meaningfully model mathematics with their own visual representations (Abedi \& Herman, 2010; Martiniello, 2008; Martiniello, 2009). 
ELLs with disabilities may also experience additional concerns related to cognitive processes such as working memory, executive functioning, and processing speed (Bull \& Lee, 2014; Geary, Hoard, Nugent \& Bailey, 2012; Toll, van der Ven, Kroesbergen, \& van Luit, 2011).

Although there are particular concerns to consider, ELLs with disabilities are not "broken" students and in need of fixing (de Araujo, Smith, \& Sakow, 2016). These students come to school with a wealth of "funds of knowledge" (Moll, Amanti, Neff, \& Gonzalez, 1992) - meaning that they have knowledge, including their language, that comes from their home culture and upbringing that is a useful resource for teachers to use. Mathematics education authors have emphasized using the cultural aspects of students" "funds of knowledge" to build mathematics lessons from everyday life that students can relate to, such as basketball and gardening (Civil \& Khan, 2001; Nasir, Hand, \& Taylor, 2008).

Even though ELLs (with or without disabilities) are capable students, they do need specific support. Mathematics education literature gives some direction to help teachers know how to support language acquisition in the classroom. Moschkovich (2002, 2005), for example, found that it is important for ELLs to have opportunities to speak in the mathematics classroom. In considering how support ELLs in mathematics, Moschkovich (2013) gave clear ideas to guide the implementation of the Common Core State Standards, which include offering students (a) highly rigorous tasks, (b) more than one way to demonstrate their understanding including gestures and various forms of visual representations, (c) attending to student mathematic reasoning beyond their actual language accuracy, (d) the teachers should explicitly teach language use taught including 
scaffolds as needed, and (e) everyday home language should be treated as a resource not an obstacle to more formal academic language. The goal is to include students in mathematical discourse, and to give them encouragement to make conjectures and test them in the mathematics classroom.

\section{Teaching Mathematics to ELLs with Disabilities}

Within the field of special education, there are few studies to guide teachers who teach mathematics to ELL students with disabilities. Twenty years ago, acknowledging the changing demographic of the United States which was including more ELLs with disabilities, Gersten and Baker (2000), completed a qualitative study based upon interviews of five workgroups of teachers from the United states to better understand practices that special education teachers from elementary and middle grades identified as effective instruction for ELLs with disabilities. This study was non-content specific. The authors of this study analyzed the special education teacher recommendations in light of the contemporary literature of that time, and found five instructional principles that all teachers should use when teaching ELLs with disabilities. They included (a) utilizing vocabulary as an "anchor" of curriculum, (b) utilizing visuals to emphasize and explain vocabulary and concepts, (c) using highly structured peer strategies, (d) strategic use of native language in the classroom, and (e) adjusting either cognitive and/or language demands. Given the limited research available at that time, Gersten and Baker (2000) called for further research for ELLs with disabilities; some of these recommendations included stronger research design, more valid studies, and more research which focuses on groups of practitioners to better understand the needs of ELLs with disabilities.

\section{Mathematics Interventions for ELLs with Disabilities}


Since Gersten and Baker (2000), there have been some research that examines mathematics interventions specifically for ELLs with disabilities. At the time of this writing, eleven studies have been identified. Most existing studies focus on interventions in mathematics word problem-solving and include many of the previously advocated tenets such as a focus on linguistic or cognitive adjustment, vocabulary, peer strategies, and use of home language. A few examples of existing intervention studies are shared below.

\section{Linguistic Scaffolding}

In agreement with Moschkovich's studies $(2002,2005)$ on language support, a key tenet in the literature regarding ELLs who are at risk for math disabilities is the notion of linguistic scaffolding that addresses the need that Gersten and Baker (2000) recommend in adjusting instruction for cognitive and linguistic needs of the students. Orosco and colleagues (Orosco, Swanson, O’Connor, \& Lussier, 2013; Orosco, 2014; Swanson, Orosco, \& Lussier, 2014) used a linguistic scaffold to support students according to their linguistic and mathematics needs. The linguistic scaffold intervention was designed to explicitly teach vocabulary needed to solve word problems, as well as linguistically modify word problems according to sentence complexity. The intervention allowed students to access the information on their level of linguistic ability, until they were ready to solve more linguistically complex word problems.

\section{Cultural Competence and Responsiveness}

In agreement with tenets in mathematics education literature related to building upon students' funds of knowledge and using home culture in the classroom, studies such as Driver and Powell (2017), Kim et al., (2015), and Verzosa and Mulligan (2013) 
stressed the importance of posing culturally-relevant situations (situations that related to the students' home life and background) in word problems for ELLs at risk for disabilities. In Driver and Powell (2017), culturally and linguistically responsive pedagogy was incorporated into a Schema Based intervention for ELLs with disabilities by (a) clearly communicating measurable objectives, (b) encouraging open student discourse with by the interventionist and each other, (c) encouragement of the use of home language, (d) use of graphic organizers and manipulatives to further communicate meaning, and (e) intentionally using students' own ideas and life experiences. The findings suggested that basic strategy instruction together with culturally responsive teaching, improved word problem performance.

Although the above studies in both mathematics education and special education have provided some information to give direction to support teachers, studies that attend to specifically support teaching mathematics to ELLs with disabilities are few in number, and there are questions regarding how well research has actually been translated into practice. Furthermore, since existing research on ELLs with disabilities has focused on interventions and strategies, there is an scarcity of research focused on how special education teachers perceive their self-efficacy, and factors that impact their instruction in teaching mathematics to ELLs with disabilities. Turning our attention to teachers is important because teachers influence student outcomes. There are clear connections between teacher knowledge, disposition, and particularly teacher self-efficacy beliefs and their instruction and outcomes for students (Darling-Hammond, 2016; DarlingHammond, Chung, \& Frelow, 2002; Dinham, 2006; McLeskey et al., 2017). 
Teacher self-efficacy beliefs as defined by Bandura (1993, 1997), is the belief that one has in their ability to perform a task and the subsequent expectations of the task outcomes have been linked to student outcomes, in not only achievement, but also in motivation and engagement (Bandura, 1997). Therefore, for example, if a special education teacher with high self-efficacy in teaching mathematics to ELLs with disabilities, there is an expectation that these teachers will demonstate more effective teaching strategies that in turn impact student outcomes more favorably (Bandura, 1997; Darling-Hammond, 2016).

When considering the tenets that would make special education teachers who teach mathematics to ELLs with disabilities effective teachers, The High-Leverage Practices in Special Education suggests that special education teachers who are effective mathematics teachers have a deep understanding of both the curriculum and the developmental sequence by which students learn. Special education teachers are able to use this knowledge to craft meaningful mathematic tasks for their students. Additionally, effective special education teachers use evidence and professional judgment to support decisions for students (McLeskey et al., 2017).

To illustrate how quality special education teaching leads to student outcomes, in a study, Griffin, Jitendra, and League (2009) examined the practices of novice, preservice special education teachers as they taught the mathematics component of their student teaching requirements. Those teachers with the highest performing students offered more than the required curriculum, helping students to make meaning by using manipulatives, exploratory strategies, while posing questions to prompt more explicit explanations. These authors concluded, "It is evident that special education students' mathematics 
performance is improved when teachers both understand the mathematics content they are teaching and apply certain instructional practices" (p. 333).

In considering the needs of students who are ELLs with disabilities, McLeskey et al., (2017) also strongly advocate for the use of culturally and linguistic responsive pedagogy as an effective high leverage practice for special education teachers. Being a culturally and linguistically responsive teacher, means using relevant curricula and materials to the students' life experience in their teaching, and working to sustain the language and culture of their students (Gay, 2002; Ladson-Billings, 1995; Paris, 2012). Teachers accomplish being culturally responsive by using students' home language and culture in the classroom as a resource to help students make meaning of the instruction offered, by giving students a voice in the curriculum and help their students use education to empower themselves and their communities. Furthermore, some research has found that teaching in a culturally responsive manner has also been connected to higher outcomes for students in not only academic achievement outcomes, but also in motivation and engagement (Aronson \& Laughter, 2016).

Aronson and Laughter (2016) reviewed the literature from the previous 10 years and found articles grounded in culturally-relevant pedagogy and culturally-responsive teaching and termed it culturally-responsive education. Their literature review included articles and in some cases dissertations that had not been published as articles — all of which connect culturally-responsive education to student outcomes-including achievement, motivation and engagement. Although some literature such as Choi (2013), Duncan-Andrade (2007), and Hubert (2013) directly connect culturally-responsive education to positive achievement test scores, there were substantial gains in other 
“affective domains" such as student motivation, engagement, interest, participation and students seeing themselves as capable.

Effective special education teachers of students who are culturally and linguistically diverse, such as ELLs with disabilities, embrace student diversity and find ways to build on students' experiences and home culture in the classroom. However, many teachers are not prepared to teach in a culturally-relevant manner (Sleeter, 2012). Some teachers view culturally-competent education as "cultural celebration," by focusing on superficial aspects of culture such as holidays, rather than making connections between students'culture and their academic learning. Some teachers are also not able to see how traditional teaching practices, including assessments, could be biased against ELLs with disabilities. Teachers may look at culturally competent teaching as steps to be checked off on a checklist, and not realize that true cultural competent teaching has to do more with a cultural awareness and an understanding of student need -including building relationships with the students - rather than discrete, superficial aspects of cultural awareness (Gutiérrez, 2002; Sleeter, 2012).

\section{Purpose of the Study}

Given the relationship of teacher self-efficacy and achievement outcomes, the self-efficacy of the special education teachers who teach mathematics to ELLs with disabilities is worthy of investigation. More than 40 years of research have positively associated teacher self-efficacy with student outcomes in not just achievement scores, but in student higher goals set for students, and improved student self-efficacy (Allinder, 1995; Ashton \& Webb, 1986; Bandura, 1997; Hattie \& Yates, 2013; Holzberger, Philipp, \& Kunter, 2013). A teacher's self-efficacy impacts their practice (Bandura, 1997). 
Special education teachers with higher self-efficacy are likely to have more effective practices in teaching mathematics to any student with a disability, and in teaching mathematics to ELLs with disabilities including in a culturally and linguistically responsive manner. However, if special education teachers tend to have low self-efficacy in teaching mathematics to ELLs with disabilities, or in teaching mathematics to ELLs with disabilities in a culturally and linguistically responsive manner, this information may identify a need in the field of special education, in terms of teacher preparation and professional development.

Along with understanding teacher self-efficacy, it is also useful to understand which factors in the school environment teachers report as helpful or harmful in their practice of teaching mathematics to ELLs with disabilities. Teacher self-efficacy in their ability to teach their students does not happen in a vacuum and is impacted by other influences, including internal factors such as their own experience and prior training, as well as external factors such as administration, peers, and building culture (Bandura, 1997). By better understanding how these factors impact special education teachers who teach ELLs with disabilities, it may be possible to determine what additional supports are needed to help these teachers do their jobs. 


\section{Chapter 2}

\section{LITERATURE REVIEW}

This study focuses on the self-efficacy of special education teachers who teach mathematics to ELLs with disabilities. In this section, I will discuss Bandura's theory of self-efficacy and summarize the literature to better explain what is known about teacher self-efficacy that may lead to insight to help explain teacher effectiveness and achievement outcomes for ELLs with disabilities, and factors that impact the teaching practice of these teachers.

\section{Theoretical Framework/Bandura's Theory of Self-Efficacy}

In Bandura's theory of self-efficacy, from Social Cognitive Theory, self-efficacy is the belief that one can successfully complete a task required to enact a particular outcome and this belief determines their ability to persevere and cope with circumstances and the expected outcome of the task (Bandura, 1977, 1986). The belief in being able to successfully complete a task (self-efficacy) and the expected outcome of the task are related concepts, but they are not the same. Outcome expectations may differ from one's level of self-efficacy because other factors such as a person's past performance and outside environmental factors may impact the outcome. Bandura (1997) states:

The difference is between self-efficacy and outcome expectation is that selfefficacy is the "judgement of one's ability to organize and execute given types of performances, whereas an outcome expectation is a judgement of the likely consequence such performances with produce.” (p.21)

Self-efficacy is more closely aligned to personal judgment of a person's ability than to the anticipation that any particular event will happen. Many factors impact overall 
self-efficacy and include: (a) history of situations connected to past performance, (b) perceived task difficulty, (c) amount of effort needed, (d) level of support received, (e) situations where the task must be performed, and (f) mental and physical being (Bandura, 1986). Expectations of how much a person aspires to accomplish (i.e., outcome expectations) also affects how much effort they will put into their performance, with higher outcome expectations leading to higher effort.

Bandura (1993) posits that those with higher self-efficacy are focused more on achievement and mastery. When things do not work out in a desired manner, those with high self-efficacy attribute the lack of achievement to lack of effort on their part and seek opportunities to grow in their abilities, including asking for help from others. However, those with lower self-efficacy tend to attribute lower achievement to having lower ability and may choose to just give up rather than learning from the past. Low self-efficacy is linked to believing that one's ability cannot change. Therefore, those with low selfefficacy may believe that their mistakes are due to their ability and their intelligence.

The next few sections will focus on how levels of teacher self-efficacy have impacted students who are (a) culturally and linguistically diverse, from low socioeconomic areas or have disabilities, (b) how teacher self-efficacy impacts students in terms of their own self-efficacy and outcome expectations, and (c) outside factors that influence teacher self efficacy. Then I will conclude by summarizing the literature that examines teacher self-efficacy in mathematics, teacher self-efficacy in teaching ELLs with disabilities and the reason for this study.

\section{Teacher Self-efficacy and Student Achievement Outcomes}


For four decades, measures of teacher self-efficacy have indicated a strong relationship to student achievement outcomes (Armor et al., 1976; Brookover, Beady, Flood, Schweitzer, \& Wisenbaker, 1979). More interestingly, some studies have found that this significance is stronger for students who are taught in low SES, who are culturally and linguistically diverse (such as ELLs), and those who have disabilities than it is for students who are taught in high SES identify as middle or high class, white, and are non-disabled (Armor et al., 1976; Ashton \& Webb, 1986; Brookover et al., 1979; Caprara, Barbaranelli, Steca, \& Malone, 2006; Moore \& Esselman, 1994).

The research supporting the significant relationship between teacher self-efficacy for teaching in particular content areas and domains, and student achievement outcomes of culturally and linguistically diverse students in content areas began in the 1970's. Armor et al., (1976), in conducting a longitudinal study on student progress of black and Mexican students in federally funded program in California, examined student outcomes and school characteristics. Two questions related to teacher self-efficacy were significantly related to the achievement outcomes of both demographics of students. The authors found that the most effective teachers were those who had a high self-efficacy or strong sense of their abilities to reach students who may have additional internal or environmental challenges.

Similar to the study by Armor et al.(1976), Brookover et al., (1979) studied school level factors that impacted student achievement in schools in Michigan. Schools in this study were divided into low SES and high SES, and into schools with mostly white students and schools with mostly "black and brown" students. For those who taught in schools with low SES or had a high population of black and brown students, the 
correlation between teacher self-efficacy and student achievement outcomes was significantly higher than it was for teachers who taught in schools that had high SES or in schools with a majority of white students. This meant that if teachers had high selfefficacy and taught in schools with low SES, or black and brown students, the students were more likely to have higher achievement scores. Also, for the same students, if a teacher had low self-efficacy it was likely that the student would have more dismal outcomes. In comparision, for students in high SES, or in white majority schools, this relationship between teacher self-efficacy and student outcomes was not as strong.

For students who may have disabilities, teacher self-efficacy continues to be a pertinent aspect in student achievement, and this is particularly true in the area of language and mathematics. For example, Ashton and Webb (1986) examined the relationship between students who were placed in remedial classes based upon their previous standardized testing scores and the self-efficacy of their teacher. Among other variables, data was collected on the self-efficacy of teachers and student achievement. When student beginning levels of achievement scores were controlled for, teacher selfefficacy significantly predicted student achievement outcomes of both mathematics and language post-test scores of students. When teachers experienced higher levels of selfefficacy, the students experienced more growth on achievement assessments. Additionally, for students who were placed into special education, the self-efficacy of their teacher was related to high stakes decisions made on behalf of the student. In another example, Allinder (1994) found a positive relationship between special education teacher self-efficacy in mathematics, goals set for students using curriculum-based measurement probes, and the level of growth their students attained. Taken together, 
these articles support the idea that for students who are culturally and linguistically diverse, from lower SES, or who have a disability — such as many ELLs with disabilities - teacher self-efficacy in teaching is significantly related to the level of students' academic achievement.

\section{Teacher Self-Efficacy and Teacher Expectations of Students}

Only considering the level of a teacher's self-efficacy is not enough to explain the relationship to student achievement outcomes. Some researchers have found that the teachers' expectations of their students, of themselves, and their subsequent behavioral practices mediate teacher self-efficacy relationship to student outcomes (Allinder 1994; Kim \& Seo, 2018; Podell \& Soodak, 1993). Brookover et al. (1979) found that teacher expectations of their students' achievement scores were correlated with the students' actual achievement on standardized assessments. Teachers with high self-efficacy believe that it is the teacher's responsibility to reach students who are difficult to teach, and that the teacher needs to provide extra effort and better techniques (Bandura, 1977; 1986; 1997). Both Allinder (1994) and Ashton and Webb (1986) agree that teachers with high self-efficacy take more responsibility for their students' learning, set higher expectations of their students, and these behaviors are actually closely related to student outcomes.

\section{Teacher Self-Efficacy Impact on Student Self-Efficacy}

Similar to academic achievement outcomes, the relationship between teacher selfefficacy and a student's self-efficacy for learning is particularly even more significant for students who are culturally and linguistically diverse, from low SES, and who may be at risk for having disabilities (Holzberger et al., 2013; Midgley, Feldlaufer, \& Eccles, 1989). For example, in a study that measured student the relationship between student self- 
efficacy and teacher self-efficacy, Midgley, Feldlaufer, and Eccles (1989) found that students who had a teacher with high self-efficacy in elementary school, but then had a teacher with low self-efficacy in junior high - experienced a significant drop in their own self-efficacy from elementary school to junior high. Additionally, student selfefficacy also changed within the same school year based upon the level of self-efficacy of their teachers. Even more striking, teacher efficacy beliefs had an even higher correlation to changes in the self-perceptions of students who were low-achieving in mathematics as compared to students who were higher achieving. These authors believed that this impact would have been even more pronounced if this study had limited its' parameters to "remedial classrooms." This may suggest that teacher self-efficacy has a higher impact on the students who are in need of the most educational assistance, such as students with learning disabilities.

More recently, Holzberger, Phillip and Kunter (2013) investigated the reciprocal nature of self-efficacy beliefs by measuring both teacher and student ratings of instructional quality at two measurement points over the course of two years. Teachers with initial measures of high self-efficacy had students who reported higher self-efficacy than their peers a year later. The self-efficacy of teachers has a strong and lasting effect on the self-efficacy that students have in their own learning. If teachers have low selfefficacy in teaching, the effects could be negative and long lasting. In addition to impacting student self-efficacy, teacher self-efficacy also has a direct impact on student engagement and motivation (Mojavezi \& Tamiz, 2012; Schiefele \& Schaffner, 2015; Van Uden, Ritzen, \& Pieters, 2013). 


\section{Outside Influences of Teacher Self-Efficacy}

Studies have suggested that different factors impact teacher self-efficacy such as student demographics (including SES) (Hoy \& Spero, 2005; Midgley et al., 1989; Téllez \& Manthey, 2015). Teachers who teach in schools with low SES tend to have lower selfefficacy than those who teach in schools with high SES (Moore \& Esselman, 1994; Paneque \& Barbetta, 2006; Siwatu, 2007; Téllez \& Manthey, 2015). However, peer teachers and administration support can influence this trend. For example, Hoy and Spero (2005) prepared master's education students to teach in low SES urban areas. During their first year of teaching, the self-efficacy of teachers declined from the first of the year to mid-year. This decline in self-efficacy could have been due to the level of support that teachers reported having in the way of peers and administration. Caprara et al., (2006), also found that the contribution of peers, and positive relationships including rapport with other staff members, and community members influenced teacher self-efficacy. To further support how crucial a positive environment is for the self-efficacy of teachers, Kim and Kim (2010) in investigating early childhood educators, found that school climate was more strongly related to teacher self-efficacy than interpersonal teacher characteristics, such as depression. Within the school environment, administrative support that enhances teacher self-efficacy includes allowing teachers to have access to educational resources and giving teachers the autonomy to have ownership of curricular decisions (Ashton \& Webb, 1986; Moore \& Esselman, 1994).

To summarize, teacher self-efficacy is very imporant to understanding the achievement outcomes of ELLs with disabilities in mathematics because studies have demonstrated stronger, more significant relationships between self-efficacy and student 
outcomes for students who are culturally and linguistically diverse, those from lower socio-economic background or those with a disability. The reasons for this strong relationship, particularly for these groups of students, may be because teachers with high self-efficacy have higher expectations of students, and may teach in ways that lead students to have higher-self efficacy in their own abilities. However, teacher selfefficacy, whether high or low does not happen in a vacuum, and there are other environmental factors which may impact teacher self efficacy. These factors include the SES of the school, adminstrators, peers and even outside influences such as parents and community. When considering teacher self-efficacy, these environmental factors may be very important to better understand why a teacher may rate their self-efficacy in a particular way.

In the next section, I will summarize what is known in the literature about the self-efficacy of teacher who teach mathematics, and in self-efficacy in teaching ELLs with disabilities. Then I will discuss the rationale for this study.

\section{Teacher Self-Efficacy for Teaching Mathematics}

Most research studies that center around teacher self-efficacy in teaching mathematics feature preservice teachers. Research supports that self-efficacy during preservice training is the highest, and the most malleable (Hoy \& Woolfolk, 1990; Midgely, Anderman, \& Hicks, 1995). The principles that can be learned from studies involving the self-efficacy of preservice teachers in mathematics may be associated to ideas related to the self-efficacy of in-service teachers as well. Pre-service teachers in early childhood and elementary education teachers tend, overall, to rate themselves high in self-efficacy to teach mathematics (Bates, Latham, \& Kim, 2011; Giles, Byrd, \& Bendolph, 2016; 
Zuya, Kwalat, \& Attah, 2016). When comparing measures where preservice teachers have to rate their self-efficacy for teaching mathematics and demonstrate their actual knowledge of solving mathematics problems, teachers who have higher self efficacy in teaching mathematics tend to have with higher abilities to perform mathematics problems (Bates et al., 2011). Pre-service teachers who have higher self-efficacy in teaching mathematics tend to believe that students should be taught in an open endedconstructivist manner, with an emphasis on meaning and demonstrate the ability to explain mathematical problems in a more conceptual way (Giles et al., 2016; Hinton, Burton, Flores, \& Curtis, 2015). This belief was particularly true for special education preservice teachers. Hinton et al. (2015) examined special education preservice teachers' preparation for effectively teaching mathematics by using a teaching self-efficacy survey and open-ended questions regarding how the teachers would teach a basic mathematical computation problem involving regrouping. These authors found that teachers who explained how to solve the problem using a conceptual explanation, tended to score higher on the teaching self-efficacy measure, in comparison to those who explained how to solve the problem using a memorized procedure.

There are limited studies focused on the self-efficacy of in-service special education teachers who teach mathematics to students with disabilities. However, there are existing studies that compare special education and general education teacher selfefficacy in teaching mathematics to students with disabilities. Findings from these studies suggest that special education teachers have equal or higher self-efficacy in teaching mathematics to students with disabilities at the elementary and middle school level as 
compared to their general education mathematics teacher peers (Ekstam, Korhonen, Linnanmäki, \& Aunio, 2018; Flores, Thornton, Franklin, \& Hinton, 2014).

It is worth mentioning that Ekstam, Korhonen, Linnanmäki, and Aunio (2018) found that although special education and general education teachers have similar levels of self-efficacy, which was high overall, there were differences in between the two groups of teachers. Specifically, general education teachers who taught mathematics had higher self-efficacy in teaching content whereas the special education teachers had higher self-efficacy in teaching students with disabilities. Additionally, teacher interest in mathematics strongly predicted teacher self-efficacy (Ekstam, Korhonen, Linnanmäki, \& Aunio, 2017; Ekstam, Korhonen, Linnanmäki, \& Aunio, 2018). However, none of these studies examined differences of the self-efficacy of special education teachers who teach mathematics to culturally and linguistically diverse students such as ELLs, or students with disabilities, whose unique characteristics together with content, may impact teacher self-perception of their abilities.

When thinking about the self-efficacy for teachers in teaching mathematics to ELLs students, Ross (2014) examined in-service general education teacher self-efficacy in teaching mathematics to ELL, and non-ELL students. In this study teachers selfreported lower self-efficacy in teaching students who are ELL relative to those who are not ELL. Additionally, teachers were assessed in their knowledge and use of professional development opportunities. Those who self-reported engaging in professional opportunities to learn ways to work with ELL students also had higher scores in teaching self-efficacy. There was also a positive correlation between a teacher's 
professional development involvement in and higher student engagement, management and instruction of ELLs.

\section{Teacher Self-Efficacy for Teaching ELL Students}

Teacher self-efficacy in teaching students who are ELLs is typically lower than in teaching other students. Although teachers tend to rate their self-efficacy as high in building relationships with their students, they rate their self-efficacy as lower in using aspects of the students' language and culture in the classroom to make meaning (MaloJuvera, Correll, \& Cantrell, 2018; Siwatu, 2007, 2011). Siwatu (2007) created a measure called the Culturally Responsive Teaching Self-Efficacy (CRSTE) and the Culturally Responsive Teaching Outcome expectancy (CRSTOE) to assess preservice teacher selfefficacy in teaching culturally and linguistically diverse students (including ELLs) in a culturally and linguistically responsive manner. After validating the measure, Siwatu found that preservice teachers felt lower self-efficacy in using students' home language in the classroom, and felt higher self-efficacy in building positive student relationships. Later, Siwatu, (2011) examined the influences that school has on the self-efficacy of preservice teachers. This study found that although preteachers had higher self-efficacy in teaching in suburban rather than in urban contexts, they had lower self efficacy in teaching ELL students in meaningful ways.

Similarly, Malo-Juvera, Correll, and Cantrell, (2018) used a mixed methods investigation to examine in service teacher's self-efficacy for culturally responsive instruction. These authors investigated 26 in service elementary school teachers using the Culturally Responsive Teaching Self-Efficacy (CRSTE) portion of Siwatu's measure. This portion only measured teacher self-efficacy, but not outcome measures. Then, at the 
beginning of a professional development, meant to educate teachers on culturally responsive instruction, all 26 teachers were interviewed. Teachers in this study had low self-efficacy for implementing culturally responsive instruction. Particularly, they had a lack of understanding of what culturally responsive instruction means, and how to make connections to the students' home life to the curriculum that they were using. Teachers self-reported low self-efficacy in working with students who were ELL. One reason reported is that teachers could not distinguish whether students had a language acquisition problem or concerns related to their learning ability. Lastly, these authors found that teachers also had low self-efficacy in working with parents. These teachers believed that ELL parents were less concerned about academic matters as other parents, and ELL parents may even be a hinderance to their students' education.

\section{Teacher Self-Efficacy for Teaching ELLs with Disabilities}

There are very few studies that have examined teacher self-efficacy for teaching students who are ELLs with disabilities. Paneque and Barbetta (2006) investigated the self-efficacy of special education teachers who teach ELLs with disabilities. In this study, the majority of the teachers were multi-lingual (mostly speaking both Spanish and English). They found that, overall self-efficacy in teaching ELLs was high among the teachers. But, teacher self-efficacy was significantly related to the ability of teachers to access the home language of the students. However, in the qualitative portion of the study, barriers to teacher self-efficacy were noted. These barriers included the availability of resources such as enough teachers, disposition of teachers, teacher preparation and language skills of those who were not proficient in the language of the students. Understanding the barriers to special education teachers' self efficacy in 
teaching ELLs with disabilities, may give some clues to why ELLs with disabilities are underperforming in mathematics, as well.

Chu and Garcia (2014) adapted the CRSTE and CRSTOE survey from Siwatu (2007) for use specifically for in-service special education teachers who work with culturally and linguistically diverse students with disabilities (including ELLs with disabilities). This survey assessed special education teachers' self-efficacy in teaching in a manner that incorporated questions that attended to teacher cultural competence in teaching culturally and linguistically diverse students. Teachers were assessed in their self-efficacy in teaching pedagogy which (a) incorporates students' cultural backgrounds into curriculum and instruction, (b) considers cultural needs in classroom management, (c) allows students multiple methods to demonstrate understanding, and (d) gives students access and tools to function in the dominant culture as well as helping them to retain their cultural identity. The authors of the study examined how personal characteristics, teaching assignments, and professional preparation predicted special education teachers' selfefficacy in teaching in a culturally and linguistically responsive manner. They found that special education teachers with the highest self-efficacy included those who taught in resource or self-contained classes with students with mild/moderate disabilities, were nonwhite, spoke more than one language, and held certification in bilingual/ ESL education, received six or more sessions of "highly effective" professional development that focused on how to work with diverse populations. The researchers hypothesized that teachers who teach in self-contained classrooms may have a greater locus of control which is their belief about their control in a situation, Bandura (1997). For teachers who have the ability to speak more than one language (though the study did not focus on teachers speaking the 
same home language as their students), their self-efficacy may be due to their better understanding of language acquisition.

\section{Factors That Impact Teaching ELL Students with Disabilities in Mathematics}

Understanding special eduation teacher self-efficacy is important to better comprehend the mathematics outcomes of ELLs with disabilities. However, it is also important to understand the factors and nuances that may impact teaching mathematics to ELLs with disabilities. Research on the actual in classroom practice of special education teachers teaching ELL students is quite scant. To better understand this practice, I will draw from two qualitative studies by Orosco and Adulrahim (2017a; 2017b).

In this first example, these authors explored the teaching practices of a successful special education teacher to ELL students with disabilities in literacy. Although the content area was not mathematics, aspects of her teaching may be helpful in mathematics as well. Orosco and Abdulrahim (2017a) conducted a case study on one special education teacher, Ms. Estrella, who taught ELL students (all of whom were Latinx) who had learning disabilities. The students in this case, however, had disabilities specifically in reading comprehension. Nominated by her administration, Ms. Estrella was regarded as being effective at teaching her students. Although her own self-efficacy was not in question, her behaviors in working with the students are worth noting.

Ms. Estrella used direct explicit instruction, broke down tasks related to teaching into smaller steps and consistently checked in with her students to guage their level of understanding. In addition, three themes emerged from the data. The first theme related to the value of American diversity. Ms. Estrella used culturally relevant curricula to teach literacy to her students intentionally because she recognized that American schooling 
often devalued the culture and linguistic identity of the students. The second theme related to culture mattering in special education. Ms. Estrella recognized that the field of learning disabilities has never had a strong "culture consciousness", in minding the perceived gap, Ms. Estrella understood the importance of using students' culturally experiences in her instruction. She specifically gave the students opportunites to filter their new knowledge through their own experiences. Lastly, Ms. Estrella allowed students to use their home culture that centered around collaboration by allowing students to work together in collaborative groups in the classroom.

Though this case study gave rich nuance of the teaching of one special education teacher who taught ELLs in literacy, the level of self-efficacy of special education teachers who teach mathematics to ELLs with disabilities is unknown. Furthermore, for those special eduation teachers who teach mathematics to ELLs with disabilities, it is unknown to what extent they use culturally and linguistically responsive practices. Orosco and Adulrahim's (2017a) study of Ms. Estrella identified the nuances of how one special education teacher successfully taught ELLs with disabilities in a culturally and linguistically responsive manner.

In the second case study, Orosco and Adulrahim (2017b) studied one special education teacher who taught Latino ELLs with mathematics disabilities. They examined her teaching through a culturally responsive teaching framework, focusing on the teacher's pedagogy and how her instruction changed once she had professional development. This study was centered around Ms. Casemiro. Ms. Casemiro explained that her training regarding teaching mathematics, was different from the needs that ELL students had in solving mathematics word problems. Specifically, she was trained to 
teach her students how to increase their mathematics fact fluency, however, she did was not taught the tools to teach word problems to her students in a meaningful way. She held a master's degree, applied ESL training, was bilingual and had cross-cultural language and academic development and had taught students who were ELLs with mathematics disabilities for 9 years.

School administrators chose her because she was a good teacher, but the school admitted not providing her with enough professional development in the area of teaching mathematics. By her own admission Ms. Casemiro said that she needed help in teaching her students word problems. Specifically, she requested help for connecting higher basic mathematics skills with higher order thinking skills. The researchers provided her with professional development focused on concepts and vocabulary, teaching the strategies, collaborative learning opportunities for students. Ms. Casemiro explicitly taught students how to say vocabulary with different sounds in English than exist in Spanish. For teaching strategies related to decoding the word problem, Ms. Casemiro explained the words in the problems that the students may not know-such as food could be stored in a bin as well as a shelf - and she drew what a bin looked like. In teaching the conceptual meaning of the problems, Ms. Casemiro connected the problem to the students' background, and allowed students to use a variety of strategies to solve the problem. She even demonstrated two visual representations of the word problem. She also used mathematics strategies such as questioning, checking for understanding and giving targeted feedback. The authors concluded that the improvement of ELL students in word problem solving may be dependent upon how well teacher training is related to word solving comprehension. 
These two examples of good special education teachers of ELLs with disabilities highlight what good teaching could look like for these students, by using explicit instruction, attending to the students' linguistic needs, building from student background, as well as questioning, peer collaboration and checking with students for meaning. In the case of the last study, professional development targeted for mathematics was useful in helping this teacher be successful in using researched based strategies. What is unknown is how well the findings from these two studies can be applied to other special education teachers who teach mathematics to ELLs with disabilities. Furthermore, what other factors maybe other factors in the school that could be helpful or harmful to a special education teacher's practice in teaching mathematics to ELLs with disabilities.

\section{Significance and Purpose of the Current Study}

When considering the outcomes of ELLs with disabilities on the NAEP assessment in grades 4 and 8, better Understanding the nature of teacher self-efficacy as well as what factors may impact teaching mathematics to ELLs with disabilities may provide information in predicting teacher effectiveness, that may, in turn, help inform teacher education programs as well as professional development programs for special education teachers who teach ELLs with disabilities.

Studying self-efficacy is important because teachers who have high self-efficacy in teaching tend to teach in more conceptual ways focused on developing meaning over procedures (Hinton et al., 2015). Teachers who teach in a culturally and linguistically responsive manner teach above the curriculum and use the home language and culture of the students to also develop meaning (Aronson \& Laughter, 2016). These behaviors have been known to positively impact student outcomes. In terms of self-efficacy, special 
education teachers tend to have the same or more self-efficacy as general education teachers in teaching mathematics to students with disabilities (Ekstam et al., 2017, 2018). However, when considering teaching ELL students, particularly in a culturally and linguistically responsive manner, teachers have overall self-reported low self-efficacy (Malo-Juvera et al., 2018; Ross, 2014).

When considering the barriers that teachers report in teaching ELLs with disabilities, such as preparation and knowledge of how to teach these students, and access to the language of the students (Chu \& Garcia, 2014; Paneque \& Barbetta, 2006), there are questions about how teachers rate their self-efficacy in teaching mathematics ELLs with disabilities.

Lastly, teaching self-efficacy and student outcome expectations does not only reside within the person, but these constructs are impacted by outside factors in the environment in terms of peers, curriculum, administration, and parent relationships (Bandura, 1997). It is important to understand which environmental factors teachers report as helpful or harmful to their practice of teaching mathematics to English Language Learners with disabilities. In doing this, it may be possible to better understand what may or may not impact teacher self-efficacy for teaching mathematics to ELL students with disabilities.

\section{Research Questions}

The following questions are guiding this study:

1) How do special education teachers self-report the self-efficacy beliefs and outcome expectations in teaching mathematics to (a) any student with a disability, 
(b) ELLs with disabilities, and (c) ELLs with disabilities in a culturally and linguistically responsive manner?

2) What factors do teachers report as helpful or harmful in teaching mathematics to ELLs with disabilities? 


\section{Chapter 3}

\section{METHODS}

The research design of this mixed-methods study involved the use of survey along with follow up semi-structured interviews of selected special education teachers. Both the survey and interview data were used to answer question 1, and only interview data was used to answer question 2.

\section{Participants}

Participants were 117 elementary, middle and high school special education teachers who teach mathematics to ELLs with mild/moderate disabilities. The teachers came from Arkansas, California, Colorado, Florida, Illinois, Kansas, Missouri, Nevada, and Texas. In this sample of participants, $45 \%$ were from urban school districts, $38 \%$ were from suburban districts, and 13\% were from rural districts. Seventy-eight percent of the participants were white, $10 \%$ were Hispanic/Latinx, and 5\%Black, $2 \%$ were Asian, and 3\% were multi-racial. Eighty-eight percent of the participants were female, and $12 \%$ were male. In terms of ages, $25 \%$ were in the age range of twenty-one to thirty, $27 \%$ were in the age range of thirty one to forty, $31 \%$ were in the age range of forty one to fifty, and $25 \%$ were fifty-one and above. Seventy-eight percent of the participants were mono-lingual, where $22 \%$ spoke more than one language. The highest degree obtained by participants included 27\% had a Bachelor's Degree, 57\% held a Master's Degree, $8 \%$ held an Educational Specialist Degree and 3\% held a Ph.D. or ED. Twenty-six percent of teachers reported having TESOL certification and 73\% reported not having TESOL certification. 
For more information regarding the demographics of teachers, please see See

Table 1 below for demographic information:

Table 1

Teacher Demographic Information from Survey Participants

\begin{tabular}{|c|c|c|}
\hline & $\begin{array}{l}\text { Number of participants } \\
\text { who answered each } \\
\text { question } \\
\qquad N=117\end{array}$ & Percentages of the total \\
\hline \multicolumn{3}{|l|}{ States } \\
\hline Arkansas & 6 & $5 \%$ \\
\hline California & 7 & $6 \%$ \\
\hline Colorado & 3 & $3 \%$ \\
\hline Florida & 11 & $9 \%$ \\
\hline Illinois & 4 & $3 \%$ \\
\hline Kansas & 10 & $9 \%$ \\
\hline Missouri & 44 & $38 \%$ \\
\hline Nevada & 15 & $13 \%$ \\
\hline Texas & 15 & $13 \%$ \\
\hline Unknown & 2 & $2 \%$ \\
\hline \multicolumn{3}{|c|}{ Urban, Sub-urban, Rural } \\
\hline Urban & 53 & $45 \%$ \\
\hline Sub-urban & 44 & $38 \%$ \\
\hline Rural & 15 & $13 \%$ \\
\hline Other & 2 & $2 \%$ \\
\hline I'm not sure & 3 & $2 \%$ \\
\hline \multicolumn{3}{|l|}{ SES status of school } \\
\hline High/Upper Class & 2 & $2 \%$ \\
\hline High Middle Class & 7 & $6 \%$ \\
\hline Lower Middle Class & 21 & $18 \%$ \\
\hline Lower/Poverty class & 59 & $51 \%$ \\
\hline Other & 7 & $6 \%$ \\
\hline No answer & 21 & \\
\hline \multicolumn{3}{|l|}{$\begin{array}{l}\text { Racial status of the } \\
\text { teacher }\end{array}$} \\
\hline Asian & 2 & $2 \%$ \\
\hline Black & 6 & $5 \%$ \\
\hline Latino/a/x- Hispanic & 12 & $10 \%$ \\
\hline
\end{tabular}




\begin{tabular}{|lll|}
\hline White & 91 & $78 \%$ \\
Multi-racial & 3 & $3 \%$ \\
Prefer not say & 2 & $2 \%$ \\
No answer & 1 & $1 \%$ \\
\hline Gender of teacher & & \\
\hline Female & 103 & $88 \%$ \\
Male & 14 & $12 \%$
\end{tabular}

\section{Age range of teacher}

21-30

$31-40$

41-50

36

$51+$

25

$25 \%$

$27 \%$

$31 \%$

$25 \%$

\section{Other languages spoken}

by the teacher

$\begin{array}{lll}\text { Zero } & 91 & 78 \% \\ \text { One to two } & 14 & 20 \% \\ \text { Three or more } & 2 & 2 \%\end{array}$

\section{Grades taught (multiple} could be chosen)

$\begin{array}{ll}\text { K-5 } & 58 \\ \text { K-8 } & 5 \\ \text { K-12 } & 2 \\ \text { Sixth to eighth } & 30 \\ \text { Sixth to twelfth } & 2 \\ \text { Ninth- twelfth } & 14 \\ \text { Other } & 6\end{array}$

\section{Highest Level of}

Education

Bachelor's Degree

Master's Degree

5

2

30

2

14

6

Educational Specialist

Ph.D or E.D.

Other

31

67

9

4

6
$27 \%$

$57 \%$

$8 \%$

$3 \%$

$5 \%$ 


\begin{tabular}{|lr|}
\hline $\begin{array}{l}\text { Certification- multiple } \\
\text { could be chosen }\end{array}$ \\
\hline Cross categorical Mild & 83 \\
Moderate- & \\
General Education & 17 \\
Other & 8 \\
Secondary General & 4 \\
education & \\
Secondary Special & 5 \\
\hline
\end{tabular}

Education

\section{TESOL Certification}

$\begin{array}{lll}\text { No } & 86 & 73 \% \\ \text { Yes } & 30 & 26 \% \\ \text { No answer } & 1 & 1 \%\end{array}$

\begin{tabular}{|lll|}
\hline Years taught in Career & & \\
\hline $0-1$ & 4 & $3 \%$ \\
$2-5$ & 22 & $19 \%$ \\
$6-10$ & 30 & $25 \%$ \\
$11+$ & 61 & $52 \%$ \\
No answer & 1 & $1 \%$
\end{tabular}

Years of teaching in Special Education

$\begin{array}{lll}0-1 & 6 & 5 \% \\ 2-5 & 32 & 27 \% \\ 6-10 & 22 & 19 \% \\ 11+ & 56 & 48 \% \\ \text { No answer } & 1 & 1 \%\end{array}$

Years of teaching in ELLs

with Disabilities

\begin{tabular}{lll}
\hline $0-1$ & 13 & $11 \%$ \\
$2-5$ & 40 & $34 \%$ \\
$6-10$ & 31 & $27 \%$ \\
$11+$ & 27 & $23 \%$ \\
No answer & 6 & $5 \%$ \\
\hline $\begin{array}{l}\text { Ethnicities of ELLs with } \\
\text { Disabilities- }\end{array}$ & \\
\hline $\begin{array}{l}\text { Having Hispanic/Latinx } \\
\text { with others }\end{array}$ & 105 & $90 \%$ \\
\hline
\end{tabular}




\begin{tabular}{|lll|}
\hline $\begin{array}{l}\text { Having Only Other } \\
\text { ethnicities (African, Asian, } \\
\text { European) }\end{array}$ & 12 & \\
& & \\
\hline $\begin{array}{l}\text { Years Teaching Students } \\
\text { with mathematics } \\
\text { disabilities }\end{array}$ & \\
\hline $0-1$ & 10 & \\
$2-5$ & 29 & $9 \%$ \\
$6-10$ & 32 & $25 \%$ \\
$11+$ & 46 & $27 \%$ \\
& & $39 \%$ \\
\hline Hours of Professional & & \\
Development & 42 & \\
\hline 0 hours & 34 & $36 \%$ \\
$1-4$ hours & 12 & $29 \%$ \\
5-10 hours & 29 & $10 \%$ \\
$11+$ hours & & $25 \%$ \\
& & \\
\hline
\end{tabular}

For the semi-structured interview of the study, 6 special education teachers from Missouri and Kansas who had participated in the pilot study (see details below regarding this study), were selected to participate. To choose participants, the MTEBI and the ELL Responsive Measure were examined separately. By examining quartiles of the scores on each measure, teachers were chosen if they scored in the upper $25^{\text {th }}$ percentile or the lower $25^{\text {th }}$ percentile on either the MTEBI or the ELL responsive measure teachers who met this criteria were interviewed. Teachers were strategically chosen according to their scores on the survey to better understand environmental factors that teachers with both high and low self-efficacy reported that were common to their teaching practice. Please see Table 2 below for teacher demographic information. 
Table 2

Teacher Demographic Information from Interview Participants

\begin{tabular}{|c|c|c|c|c|c|c|}
\hline Teacher & $\begin{array}{l}\text { Score on } \\
\text { the } \\
\text { Survey } \\
\text { measures }\end{array}$ & Ethnicity & Age & School SES & $\begin{array}{l}\text { Years of } \\
\text { experience } \\
\text { teaching } \\
\text { ELLS } \\
\text { with } \\
\text { disabilities }\end{array}$ & Certifications Held \\
\hline Margaret & $\begin{array}{l}\text { Low self- } \\
\text { efficacy- } \\
\text { MTEBI }\end{array}$ & $\begin{array}{l}\text { White } \\
\text { female }\end{array}$ & 55 & $\begin{array}{l}\text { Low SES- } \\
\text { poverty/urban }\end{array}$ & Two years & $\begin{array}{l}\text { Low incidence and } \\
\text { Mild/Moderate Cross } \\
\text { Categorical K-12 }\end{array}$ \\
\hline Robyn & $\begin{array}{l}\text { Low self- } \\
\text { efficacy } \\
\text { MTEBI }\end{array}$ & $\begin{array}{l}\text { White } \\
\text { female }\end{array}$ & 54 & $\begin{array}{l}\text { High Middle } \\
\text { Class/suburban }\end{array}$ & $\begin{array}{l}\text { Twenty- } \\
\text { five years }\end{array}$ & Severely disabled \\
\hline Michelle & $\begin{array}{l}\text { Low self- } \\
\text { efficacy - } \\
\text { ELL } \\
\text { responsive }\end{array}$ & $\begin{array}{l}\text { White } \\
\text { female }\end{array}$ & 61 & $\begin{array}{l}\text { Lower middle } \\
\text { class/rural }\end{array}$ & $\begin{array}{l}\text { More than } \\
\text { eleven } \\
\text { years }\end{array}$ & $\begin{array}{l}\text { Mild/Moderate Cross } \\
\text { Categorical K-12/ Social } \\
\text { Studies }\end{array}$ \\
\hline Abigail & $\begin{array}{l}\text { High self- } \\
\text { efficacy- } \\
\text { MTEBI }\end{array}$ & $\begin{array}{l}\text { White } \\
\text { female }\end{array}$ & 48 & $\begin{array}{l}\text { Middle } \\
\text { Class/rural }\end{array}$ & $\begin{array}{l}\text { More than } \\
\text { eleven } \\
\text { years }\end{array}$ & $\begin{array}{l}\text { Mild/Moderate Cross } \\
\text { Categorical K-12/Social } \\
\text { Studies/ } \\
\text { TESOL/mathematics/Ed. } \\
\text { Specialist }\end{array}$ \\
\hline Amanda & $\begin{array}{l}\text { High self- } \\
\text { efficacy - } \\
\text { MTEBI/ } \\
\text { High Self- } \\
\text { Efficacy } \\
\text { ELL } \\
\text { responsive }\end{array}$ & $\begin{array}{l}\text { White } \\
\text { female }\end{array}$ & 45 & $\begin{array}{l}\text { Lower poverty } \\
\text { class/urban }\end{array}$ & $\begin{array}{l}\text { More than } \\
\text { eleven } \\
\text { years }\end{array}$ & $\begin{array}{l}\text { Mild-Moderate Cross } \\
\text { Categorical K-12, } \\
\text { general education } \\
\text { certificate }\end{array}$ \\
\hline Cheyanne & $\begin{array}{l}\text { High self- } \\
\text { efficacy- } \\
\text { ELL } \\
\text { responsive }\end{array}$ & $\begin{array}{l}\text { White } \\
\text { female }\end{array}$ & 49 & $\begin{array}{l}\text { Lower } \\
\text { poverty/ }\end{array}$ & $\begin{array}{l}\text { More than } \\
\text { eleven } \\
\text { years }\end{array}$ & $\begin{array}{l}\text { Certified Cross } \\
\text { Categorical K-12 }\end{array}$ \\
\hline
\end{tabular}

\section{Teacher Profiles}

Margaret, was a 55-year- old white female teacher who scored in the lower 25

percentile of the MTEBI (which means that she had overall low self-efficacy in teaching mathematics to any student with a disability). Margaret held a low incidence and 
mild/moderate K-12 certification, and taught in an urban setting with students who are classified mostly in lower SES-poverty class. She taught two ELLs with disabilities in mathematics in a "class within a class" setting within a high school for two years. Before becoming a faculty member at her school, she was a substitute teacher.

Robyn, was a 54-year-old white female who also scored in the lower 25 percentile of the MTEBI, and she taught in a suburban school which is in a high-middle class neighborhood. She held a teaching certificate for severely developmentally disabled and had a master's degree. In total, she taught students with disabilities for a total of 25 years. At the time of this interview, Robyn taught students in grades K-5, and had taught ELLs with disabilities for more than eleven years. She taught 2 ELLs with disabilities in mathematics with intermediate English proficiency. She agreed to take the survey and participate in the interview because some of her ELL students were on the ASD spectrum and had mild/moderate disabilities. Robyn also self-reported having low self-efficacy in teaching mathematics, and explained that she had a speech-language background — which she taught for four years.

Michelle, who is a white female who was 61 years old, scored in the lower 25 percentile on the ELL-Responsive measure of the survey. This means that she rated herself as having overall low self-efficacy in teaching mathematics to ELL students. Michelle taught high school in a co-teaching setting, in a rural school set within a lower middle-class neighborhood. She held a bachelor's degree, and was certified in Cross Categorical K-12 mild/moderate disabilities and Social Studies. She had taught ELLs with disabilities for more than eleven years, but had taught mathematics 2 to 5 years. Her 
students were mostly Hispanic/Latinx, Vietnamese and Hmong, and had beginning levels of English proficiency.

Abigail, was a 48-year-old white female scored in the top 25 percentile on the MTEBI, meaning that she self-reported having high self-efficacy in teaching mathematics to any student with a disability. She taught eight students, in junior high school, who were ELLs with disabilities in a rural- middle class neighborhood. The ethnicities of her students are Hispanic/ Latinx and European. Her students are at the beginning and intermediate levels of proficiency.

Amanda scored in the top 25 percentile on both the MTEBI/ ELL responsive measure, meaning that she had overall high self-efficacy in both teaching mathematics to any student with a disability and in teaching mathematics to ELLs with disabilities. Amanda taught 3 ELLs with disabilities in mathematics in K-5 in an urban- lower poverty school.

Cheyenne scored in the top 25 percentile of the ELL responsive measure, meaning that she rated herself as having high self-efficacy in teaching mathematics to ELLs with disabilities. At the time of the interview, she taught students in $\mathrm{K}-2^{\text {nd }}$ grade. She had more than eleven years of teaching experience, but 3 to 5 years in teaching students wo are ELLs with disabilities. Her students mostly identified as Hispanic/ Latinx, and are at beginning levels of English proficiency. She reported that her school has a "high" ELL population.

\section{Teacher Beliefs and Self-Efficacy Survey}

To identify the self-efficacy beliefs of teachers who teach ELL students with disabilities, and answer research question 1, one online survey was used and sent through 
electronic mail using Qualtrics. The survey combined questions from two existing surveys: Mathematics Teacher Efficacy Beliefs Instrument (MTEBI) and ELL Responsive Measure. In this study, I kept the name "MTEBI", but changed the CRSTE/CRSTOE to "ELL Responsive Measure". The next section describes the combined survey and how it was validated for use in the current study.

\section{Survey Development}

The Mathematics Teacher Efficacy Beliefs Instrument (MTEBI) (Enochs, Smith, \& Huinker, 2000), measures self-efficacy and student outcome expectations for teaching mathematics. Enochs et al., (2000) created the MTEBI as a combination of questions related to teacher personal mathematics teaching efficacy (PMTE) and mathematics teaching outcome expectancy of the students (MTOE). They surveyed 324 elementary preservice mathematics teachers to validate this measure. For the PMTE, the measure of internal consistency measured by the Cronbach's alpha coefficient was .88 , and the MTOE had a Cronbach's alpha coefficient of .77. Both coefficients were over .70, which are considered acceptable (George \& Mallery, 2003).

The Culturally Responsive Self-Efficacy and Outcome Expectancy Measure (CRSTE/CRSTO), measures self-efficacy in teaching students and expectations of student outcomes in special education - content non-specific - in a culturally/linguistically responsive manner (Chu \& Garcia, 2014). Chu and Garcia (2014) surveyed 344 in-service special education teachers from 10 large urban districts. The culturally responsive self-efficacy (CRSTE) had a Cronbach's alpha coefficient of .95 and the culturally responsive self-efficacy outcome expectancy survey (CRSTO) had a 
Cronbach's alpha coefficient of .92 (Chu \& Garcia, 2014), both reliabilities were considered excellent (George \& Mallery, 2003).

\section{Validation of Survey}

To validate the survey in the current study, the following steps were taken. First, the MTEBI and CRSTE/CRSTOE were combined (hereafter the MTEBI/ELL Responsive Measure) and additional demographic questions added related to the teachers' age, ethnicity, years of teaching, certification areas, number of ELL students and ethnicities in a manner similar to other studies (Chu \& Garcia, 2014;Paneque \& Barbetta, 2006; Paneque, 2004; Siwatu, 2007; van Garderen, Scheuermann, Poch, \& Murray, 2018). Where necessary, the survey questions were modified to take out any references to parents, and the language of the ELL responsive portion was changed to include ELLs with disabilities.

Second, Drs. Delinda van Garderen (advisor) whose research interests focuses on students with learning disabilities, struggling learners, and teachers in the content areas of mathematics and science, Zandra de Araujo (committee member) whose work centers around mathematics education of English language learners, and Melissa Stormont (committee member) whose research interests include characteristics associated with risk and success in school and exploring teachers' knowledge and use of specific instructional practices for children at risk as well as Bilingual Special Education professors, Drs. Diane Rodriguez research interest is the intersection of special education, bilingual and multicultural education, and teacher preparation and Oneyda Paneque whose work centers around ELLs in special education, and bilingual education, reviewed the survey. Drs. Rodriguez and Paneque were consulted as outside experts due to having written 
similar studies regarding ELLs in Special Education. Examples of advice given from each professor included to craft demographic questions with a more natural flow, and to have more language consistency, such as using the term "ELLs with disabilities" throughout the survey.

Third, a pilot study was conducted. For this study, 66 in-service special education teachers from different demographics and settings in Missouri and Kansas who teach mathematics to students who are English Language Learners (ELLs) with mild or moderate disabilities were targeted. Ninety-four percent of participants in this study were female (compared to national average of 89\%), 79.52\% were white (compared to the national average of 80\%) (U.S. Department of Education National Center for Education Statistics, 2015-2016). Additionally, $80 \%$ of the participants were mono-lingual, $82 \%$ teachers had taught more than 6 years, $86 \%$ had a Master's degree or higher, and $43 \%$ had received 0 to 1 hour of professional development in teaching ELLs with disabilities in mathematics. Teachers answered demographic questions and then 42 questions related to teaching mathematics to students with disabilities, and teaching mathematics to ELLs with disabilities.

An exploratory factor analysis (EFA) was used to determine how many, and the nature of latent variables present in this survey. By examination of the eigenvalues, two latent variables were identified for the MTEBI, and three latent variables were identified for the ELL responsive survey. The latent variables for the MTEBI were (a) teaching efficacy and (b) student outcome expectation.

The variable teaching efficacy is how a teacher perceives their ability to teach students, and has more to do with their self-perception of themselves more than their 
perception of students. Questions on the MTEBI which captured this construct include the following examples:

- MTEBI 8, which says, "I generally teach mathematics ineffectively. (reverse coded)

- MTEBI 16, which says, "I am not sure if I have the necessary skills to explain to students why mathematics work. (reverse coded)

- MTEBI 18, which says, "When a student has difficulty understanding mathematics concept, I am usually at a loss as to how to help the student understand. (reverse coded).

Teaching efficacy matched MTEBI Items 4,9,10,12,13. Student outcomes characterizes the expectations that teachers have of their students as a result of the teacher's actions. According to Bandura (1997), performance efficacy and outcome expectations are related in some aspects, but are not the same construct because outside factors may also play a role. Examples of student outcome expectations on the MTEBI include:

- MTEBI 4, which states, "When the mathematics grades of students improve, it is often due to their teacher having found a more effective approach to teaching."

- MTEBI 12, which states, "The teacher is generally responsible for the achievement of students in mathematics."

- MTEBI 13, which states, "Students' achievement in mathematics is directly related to their teacher's effectiveness in mathematics teaching."

Each of these statements relates to the teacher's expected outcome of students because each statement highlights what the teacher thinks will happen as a result of their teaching.

For the "ELL Responsive Measure" portion of this survey, factors loaded on three latent variables. The first latent variable on the ELL Responsive Measure was Teacher Self-efficacy in Teaching Mathematics to ELLs with Disabilities. Questions that address this construct include items such as:

- ELL 5, which states, "In mathematics, I am able to develop appropriate Individual Education Plan (IEP) goals for English Language Learners with disabilities." 
- ELL 18, "In mathematics, I am able to help my English Language Learners with disabilities develop positive interactions with their peers."

- ELL 15, "In mathematics, I am able to create a supportive environment for my English Language Learners."

Teacher self-efficacy in teaching mathematics to ELLs with disabilities was measured by the following questions: (ELL Efficacy: 1,2,3,5, 6,9,10,15,17,18,19).

The second latent variable was Outcome Expectation of ELLs in Mathematics, (ELL Outcome: 20:26). Outcome Expectations were classified by what teachers believe the outcomes of ELLs with disabilities will be in mathematics. Questions that reflect this are the following:

- ELL 21, "In mathematics, I believe students' learning becomes meaningful when teachers are aware of the linguistic needs of their English Language Learners with disabilities."

- ELL 22- "In mathematics, I believe that using culturally relevant examples motivates students' learning."

- ELL 25- "In mathematics, I believe that changing learning environments to be compatible with students' home culture increases students' motivation to learn."

The third latent variable was Culturally/Linguistically Responsiveness (CLR)Efficacy in teaching ELLs also labeled ELL-CLR (CLR:4,7,8,11,12,13,14,16).

This latent variable differs from the variable ELL teachers' self-efficacy in that it specifically addresses how teachers perceive themselves as teachers of mathematics to ELLs with disabilities in a culturally and linguistically responsive manner. Culturally/ Linguistically responsive efficacy refers to how much self-efficacy teacher have toward teachers students who are different linguistic and cultural backgrounds using the students' language and home-culture in the classroom (as a way to make mathematics tasks have meaning for students, and learning more relevant) (Ladson-Billing, 1995; Gay, 2002). The following questions reflect this idea: 
- ELL 8, which states "In mathematics, I am able to critically examine the curriculum to determine whether it appropriately represents people from different linguistic/ cultural backgrounds."

- ELL 12, which states, "In mathematics, I am able to use culturally specific context to make mathematics meaningful to students who are English Language Learners with disabilities."

- ELL16, which states "In mathematics, I am able to assist my students to be successful in mathematics by supporting the native language of my students with disabilities who have limited English proficiency."

Following the EFA, Cronbach's alpha testing was conducted on each of the latent variables. The results are were as follows: MTEBI efficacy- $(\alpha=.87,95 \% \mathrm{CI}=[.83-.90])$, MTEBI outcome- $(\alpha=.81,95 \% \mathrm{CI}=[.76-.86])$, ELL-CLR (culturally/linguistically responsiveness $)(\alpha=.83,95 \% \mathrm{CI}=[.79-.87])$, ELL teaching efficacy- $(\alpha=.85,95 \%$ $\mathrm{CI}=[.81-.88])$, ELL outcome- $(\alpha=.86,95 \% \mathrm{CI}=[.83-.89])$.

Because the internal consistency was high implying that both survey instruments provided reliable measurement of each factor, a confirmatory factory analysis (CFA) was performed to determine how well each survey item represented the latent variable (also called model fit). The factors with the highest loadings, and the theory of self-efficacy and outcome expectations were used until the best CFA model fit was found.

For the MTEBI, the two factor CFA model exhibited acceptable fit to the sample data with a TLI of .904 and RMSEA of $.08,90 \%$ CI $(.029, .124)$. The two-factor solution also exhibited a good fit to the sample data $\left(\chi^{2}(.026)=62.734, \mathrm{df}=43, \mathrm{p}<.05\right)$. For the ELL Responsive Portion of the Survey, the CFA model also exhibited a good fit to the data with a TLI of 0.908 and RMSEA of $0.070,90 \%$ CI (.032-0.100). Retaining three factors also exhibited good fit to the data $\left(\chi^{2} .016=133.80, \mathrm{p}<.05\right)$. For this survey, all 
factors showed positive factor loadings with standardized coefficients ranging from 0.357 to 0.890 .

The new standardized Cronbach's Alpha for the total measure of the new MTEBI and ELL Responsive measure combined was .86 ( $\alpha=.86,95 \% \mathrm{CI}=[.8-.88])$. Standardized alphas for each of latent variables were the following: MTEBI- Total $(\alpha=$ $.75,95 \% \mathrm{CI}=[.69-.82])$, MTEBI Outcome $(\alpha=.79,95 \% \mathrm{CI}=[.73-.84])$, MTEBI Efficacy $(\alpha=.82,95 \% \mathrm{CI}=[.78-.87])$, ELL Responsive Total $(\alpha=.8,95 \% \mathrm{CI}=[.75-.85]), \mathrm{ELL}$ Outcome $(\alpha=.85,95 \% \mathrm{CI}=[.81-.89])$, ELL Efficacy $(\alpha=.78,95 \% \mathrm{CI}=[.72-.84])$ and cultural /linguistic efficacy $(\alpha=.81,95 \% \mathrm{CI}=[.76-.86])$. Although each of the Cronbach's alphas were lower than the original survey, each alpha was considered either “good" or "acceptable" (George \& Mallery, 2003).

\section{Survey for Current Study}

The current survey (MTEBI/ELL Responsive Measure) was composed of 27 out of the original 42 questions, and included questions representing each of the five latent variables. In the pilot study, using all 42 questions did not lead to a good CFA model fit. Only questions with the highest factor loadings were used, ensuring that atleast 3 questions were used for each latent variable, until a good model fit was found. The use of twenty seven questions with the highest factor loading lead to the best model fit. Based on the CFA model from the pilot study, the internal consistency and reliability of the survey ranges, the Cronbach's alpha for each latent variable ranged from .75 to .85 . In the combined survey, 14 items ( 7 from MTEBI and 7 from ELL Responsive measure) relate to efficacy for teaching, 8 items ( 4 from MTEBI and 4 from ELL Responsive measure) relate to student outcome expectation, and 5 items relate to cultural and 
linguistic self-efficacy from the ELL Responsive Measure. All items were Likert scale items on a 0 to 10 scale. Each question was presented with a sliding scale where 0 means strongly disagree, 5 is neutral, and 10 means strongly agree. The current scale differed from the pilot study, which had a Likert Scale with items 0 through 100, where 0 meant strongly disagree, 50 was neutral and 100 was strongly agree. This change was made because teachers may be more familiar with smaller numbers such as 0 to 10 where 5 is considered neutral. When considering the comparisons between the pilot study and the current study, it is important to note this change in scale.

The questions relating to the outcome variable of the ELL Responsive Measure portion of the survey were adjusted to reflect teacher expectations of students' learning outcomes as opposed to engagement, motivation, and self-esteem. The reason for this change was to make the ELL Responsive learning outcome variable more compatible with the MTEBI outcome variable. The outcome variable of the MTEBI was focused on learning outcomes. Whereas, the previous ELL Responsive outcomes variable focused on student self-esteem, motivation and learning outcomes. The ELL Responsive outcome variable was changed to focus on only learning outcomes, to make it more compariable with the MTEBI outcome variable. For this reason, the information interpreted from this survey data may not be exactly like the information interpreted from the pilot data. An example of this change from the pilot study to the the current study is as follows:

Pilot Study- ELL 25, In mathematics, I believe that English Language Learners with disabilities' self-esteem can be enhanced when their native languages/ cultures are valued by teachers.

Current Study- ELL 25, In mathematics, I believe that English Language Learners with disabilities' learning outcomes can be enhanced when their native languages/ cultures are valued by teachers. 
In addition to the survey items, teacher demographic information was collected. The demographic information included: the size and socio-economic status of the community in which the teachers teach, teacher gender, ethnicity, languages spoken, grades taught, highest level of education, professional licenses held - including TESOL certification, years taught, number of ELLs and their ethnicities, and professional development hours related to teaching ELLs with disabilities. The entire MTEBI/ELL Responsive survey instrument (including demographics) is found in Appendix A and Cronbach's alpha of each individual question, can be found in Appendix B. The survey took respondents approximately 15 minutes to take.

\section{Semi-Structured Interview Protocol}

To answer both research question numbers 1 and 2, six teachers were interviewed following a semi-structured protocol adapted from Orosco and Abdulrahim's (2017a) interview protocol. The questions break down into two main ideas. First, there are questions regarding teachers' own background knowledge and experience in working with ELLs with disabilities in mathematics. Second, in terms of outside influences such as professional development opportunities, administrator support, peer support, and curriculum, teachers were asked to share what factors have or have not helped in building their self-efficacy in teaching ELLs with disabilities in mathematics.

Teachers were asked questions such as:

a. Please tell me your experiences with teaching ELLs with disabilities.

b. How prepared do you feel that you are to teach ELL students with learning disabilities in mathematics? What has led or not led to this level of preparedness?

c. What methods of supporting your ELL students who are struggling with mathematics do you find most effective? 
The full protocol can be found in Appendix C- Interview Protocol which includes all interview questions as well as follow up questions.

To ensure validity of the measure, the interview questions in this protocol were sent to Dr. Delinda van Garderen, Dr. Zandra de Araujo (from the University of Missouri-Columbia), Dr. Melissa Driver (Special Education professor from Kennesaw State University- whose work centers around ELLs), and Dr. Antonio Castro (Social Studies professor from University of Missouri-Columbia whose work centers around ELLs). Each professor gave advice which led to clearer questions and better overall flow from one question to another. One example of advice was to start with general questions such as, "Tell me your experience for teaching ELLs with disabilities.", and then narrowing down each question to elicit more details such as, "Please talk to me about how prepared that you were to teach mathematics to ELLs with disabilities. How does this compare to other content areas."

\section{Survey and Semi-Structured Interview Implementation Procedures}

Survey Implementation. School districts were targeted if there were at least 20 percent ELL students, or for smaller districts at least 50 students who were ELL. Based upon the power analysis of the pilot study, to obtain the same level of effect size (.30), the current target number of participants needed was 79 special education teachers.

Special education teachers who taught in states with a high number of ELLs were targeted for this study. According the NCES (2019), in fall of 2017, the following states were among the states with the highest number of ELL students: California- 19.2\%, Nevada - 17.1\%, Texas- 18\%, Florida- 10.1\%, Illinois- $11.3 \%$, Kansas- $10.3 \%$, Colorado- $11.9 \%$. Arkansas also had a sizeable percentage at $8.3 \%$, . Missouri was 
included because this author had access to all email addresses of special education teachers in Missouri because of the relationship the university had with the state education department.

In total, 4,696 emails were sent to teachers directly, and 134 were sent to administrators with the request to pass the survey on to eligible teachers (see Figure 1) This sample of teachers was reached through a purposive sample. Although this survey was sent to select districts in these states that had a high number of ELL students, some districts did not want to participate in this study, or required additional IRB requirements that would take longer than the allotted time for this research study. Examples of districts not in the study include San Francisco, and Los Angeles. Other districts with less regulations were targeted.

Once eligible districts were found, emails were gathered by going through the state education websites or the school website of each school in each district. In the letters to both administrators and special education teachers, participants were asked to open the survey only if they were special education teachers, who taught mathematics to students who were English Language Learners who had mild or moderate disabilities. Out of 134 administrators, 4 agreed to pass along the survey. For the surveys that were sent to teachers directly, 618 emails were returned as undeliverable. Eighty-five teachers responded that they did not meet all of the criterion to take the survey because they either taught ELLs in reading but not in mathematics or did not have any ELLs on their case load this year. Others responded that they were speech therapists or behavior interventionists and did not teach mathematics. Still others taught students with severe disabilities, as opposed to those with mild or moderate disabilities. This left a count of 
approximately 3,993 teachers who may have been eligible to take the survey. Other than the count of returned emails, and the emails of teachers who wrote back, it is unknown exactly how many teachers met the criterion who could have possibly taken this survey.

From the teachers who were targeted, 205 of the teachers opened the survey. Some were not able to get past the screening questions. Still others fatigued and did not answer enough of the questions in the demographics and the survey to provide usable data. The number of eligible teachers who could have taken the survey was 3,993, and 205 actually opened the survey. The response rate is $205 / 3993$ or $5 \%$. Please see Figure 1 for a flow chart of chosen participants for this study.

A final participant count of 117 was used for the quantitative analysis. Despite only 117 completed surveys, this study met the power analysis requirement which was 79 participants.

\section{Figure 1}

Survey Participants Flow Chart

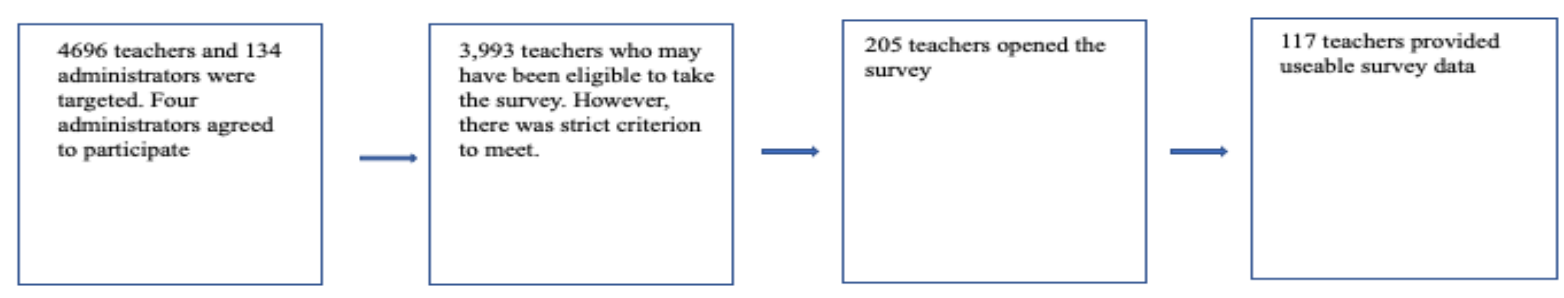

As an incentive to take the survey, teachers were entered into a raffle, and 10 teachers won $\$ 25.00$ for taking the survey. Surveys were sent to teachers in the different states from Nov. 20 to Feb.15, and this time frame included one invitation email and 2 
reminder emails sent at intervals of approximately every two weeks, once school resumed from the winter holidays. On February 20, the survey was closed, and used for analysis.

Semi-Structured Interviews. The purpose of interviewing teachers who met this criteria was to better understand the nuances of their experience as special education teachers who teach mathematics to English Language Learners in terms of what was helpful or harmful. Merriam and Tisdell (2016) make the case for qualitative research to serve such purposes by this statement, "In qualitative research, a single case or a small nonrandom, purposeful sample is selected precisely because the researcher wishes to understand the particular in depth, not to find out what is generally true of the many." (p.254).

Selection Procedures for Semi-Structured Interview. There were 23 teachers from the pilot study who met the above criteria and had also given consent to be contacted for a follow up interview. All 23 teachers were emailed an invitation for an interview, with the assurance of a guaranteed Amazon $\$ 25.00$ gift card, those who did not respond the first time were invited two more times for an interview. After 3 invitations, six teachers agreed to be interviewed. These interviews took place by phone, from November 26, 2019 to December 7, 2019 in the evenings after the teachers' work day, and on the weekends during times that was most convenient for them. Each interview lasted 30 to 45 minutes. All interviews were audio recorded, and then transcribed by the primary investigator, and one other researcher. The interviews were semi-structured and, 
where necessary, the teachers were probed for more information. Each participant was contacted the first week of May, 2020 for follow-up member checks.

Quantitative Data Analysis. This quanitative portion of this study was designed explore the differences between latent variables. The primary purpose of the survey was to conduct between test comparisons of the MTEBI and the ELL Responsive Measure. This included first comparing the mean scores of both of the entire surveys. Then, similar latent variables were compared, the self efficacy variable on the MTEBI was compared to the self-efficacy variable on the ELL Responsive Measure. The outcome expectation variable on the MTEBI was compared to the outcome variable on the ELL Responsive Measure.

Secondary analyses included within tests analyses. On the MTEBI, this included comparing the teaching self-efficacy latent variable with the student outcome variable. On the ELL responsive, this included comparing ELL teaching self-efficacy, ELL student outcome expectations and ELL teaching self-efficacy in a culturally and linguistically responsive (CLR) manner. Before comparison testing, reliability testing had to be conducted, and the steps to determine reliability and comparison testing are outlined below.

To analyze quantitative statistical analyses R-Studio packages Psych (Revelle, 2015) and Lavaan (Rosseel, 2012) in the R-statistical software environment (Team, 2018) were used. Post analysis was conducted using $\mathrm{G}^{*}$ Power (Faul, Erdfelder, Lang \& Buchner, 2007). Descriptive analyses were used to calculate demographic information, and determine the means, medians, standard deviations, and ranges of teacher selfreported scores on the MTEBI/ ELL Responsive Measure. 
The survey was tested for reliability by the use of the Cronbach's alpha testing. Then, a screen plot analysis was performed to check if the same number of latent variables from the pilot study were present. After seeing that the variables were the same by the use of the Varimax rotation and cut-off of .3, a confirmatory factor analysis (CFA) was conducted. The questions with the highest factor loadings signifying the questions that best represented the latent variables and had the best CFA fit were used for comparison testing in the current study.

Once the best CFA fit was found, the means of both measures were compared. Then, the latent variables of teaching self-efficacy and student outcome expectations between the two measures were compared by T-tests. Then secondary analysis included within test comparisons. The within test comparison of the MTEBI was conducted using T-tests. The within test comparison of the three latent variables within the ELL Responsive Measure (ELL teacher self-efficacy, ELL student outcome, ELL teaching self-efficacy in a culturally and linguistically responsive manner) was conducted using General Linear Modeling (GLM) instead of an ANOVA. General Linear Modeling was chosen because ANOVA assumes that the variables are independent of each other. Since one person answered the questions related to these three latent variables on each survey, these variables are not independent of each other. General Linear Modeling does not work upon the assumption of independence and allows the comparisons of three variables by using a system of regressions instead (Fields, Miles, Field, 2012).

Qualitative Data Analysis Trustworthiness. In order to ensure trustworthiness of the data, the interviewees were given an opportunity to validate tentative findings through member checks. Summaries of each interview were written, and each participant 
was called for a 10 to 15 minute follow up interview, to confirm that their words had been interpreted correctly. All six participants agreed on the written summaries.

However, there were a few places where more information was added. For example, one participant was asked about a program that called "Near-Pod" that she mentioned in her interview. The participant supplied more details, and explained that it was a computer program that she uses to teach her students. Additionally, the primary investigator and another researcher examined the transcripts, the codes and the final analysis of the interviews.

Analytic Approach. The six phases of thematic analysis promoted by Braun \& Clarke, (2006). This analysis was chosen because although the thematic analysis allows for a great deal of flexibility in the interpretation of qualitative data, this six phase thematic analysis gives clear and concise guidelines. Braun and Clark (2006) argue that "Thematic analysis should be seen as a foundational method for qualitative analysis. It is the first qualitative method of analysis that researchers should learn, as it provides core skills that will be useful for conducting many other forms of qualitative analysis" (p.78) .

Phase 1 of Braun and Clarke's (2006) thematic analysis is familiarizing oneself with the data by transcription. For each interview, the speaker feature of a cellular telephone, and an I-Pad's recorder were used to record each interview. To transcribe the interviews, the TEMI app (Chicola \& Neubecker, 2017) was used. TEMI-Transcription Software (Retrieved from https://www.temi.com/ ) to transcribe each interview. Once the transcriptions were complete, each recording was listened to and any places that were not picked up accurately by the app were corrected by one of two researchers. 
Phase 2 of the thematic analysis involved "generating initial codes." Each transcript was read through and meaningful statements by the teachers were tagged. After reading through the interviews, tags were identified that occurred all 6 of the interviews. From those tags, codes were formed and organized into categories.

To ensure the reliability of the codes, another researcher from mathematics education - who has experience in working and research with ELL students - co-coded data. She did not have experience with special education, and needed some coaching on some aspects of special education such as student placement (self-contained, class within a class, and coteaching) as well as characteristics of special education categories. Once she was coached on these aspects, she and the primary investigator coded one interview separately using the code book that the primary investigator made. For 25 statements, there were 52 codes. There was agreement on 49 out of the 52 codes, for an initial reliability of $94 \%$ agreement. Both investigators talked through the codes and made adjustments to the code book. Since the first interview had high agreement, the second interview was not coded for reliability, but rather used to further adjust the the code book. Codes were discussed again in a third meeting, and was further refined by deciding that any time a student's ethnicity was mentioned, it did not mean necessarily reflect the code of SES/ demographics of the school. The codes for each category can be found in Appendix D- Interview Code Book.

Phase 3 of thematic analysis involved searching for themes across the coding. Both researchers looked across the interviews to see recurring ideas that seemed to go together. For example, the expectations of teacher autonomy, working with peers, and relationships with administrators was combined into one theme called "Building 
Culture". The rest of the time was spent looking for emerging themes between the two interviews. One example of an emergent theme, is the decision to collapse the codes of math pedagogy, ELL pedagogy and student learning needs into one bigger theme “Teaching and Learning".

Phase 4 of the thematic analysis involved checking to see if the themes generated still worked in relationship to the extracts that were coded, as well as the rest of the data. An Excel spread sheet was created to identify each theme, relevant codes and participant statements. Once the excel spread sheet was analyzed and organized according to themes, we looked over the themes to ensure that the organization still fit the intended goals of the data, which is to look at examples of factors that impact teacher's self-efficacy. The fifth step included ongoing analysis, themes were written and examples supplied to support the theme. The other researcher read through samples of the writing and asked some questions about the bigger meanings of what the data was telling us. For example, one participant who had low self-efficacy in teaching mathematics, however, she reported using a variety of ways to teaching her students.

Finally, the sixth step of the thematic analysis involved writing the themes, giving a final clarification of the bigger meaning of the teachers' spoken statements, and adding vivid and compelling examples of quotes to support the interpretations. Then, relating these themes and spoken statements back to what is known in the existing literature.

\section{Research Ethics}

The University of Missouri Institutional Review Board (IRB) approved this study on March 13, 2019. Necessary IRB documents included a recruitment letter for administrators, and recruitment letter for teachers, which will be electronically mailed 
along with the survey. The survey consent script was embedded into the survey and unlocked access to the survey. The interview consent script was read aloud to the participants, and their verbal consent was taken before any interview was conducted. The documents can be found in the in the following appendices:

Appendix E- Recruitment Letter for Administrators

Appendix F- Interview Consent Script

Appendix G- Survey Consent Script

Appendix H- Recruitment Letter for Teachers 


\section{Chapter Four}

\section{FINDINGS}

\section{Survey Validation}

Quantitative statistical analyses were performed using psych (Revelle, 2015) and lavaan packages (Rosseel, 2012) in the R statistical software environment (Team, 2018). First, descriptive statistics were used to find the mean, median, standard deviation and range of each item on the surveys of the MTEBI and ELL Responsive. (Please see Appendix I). This was to determine overall trends in the data. To determine the internal consistency of this measure, Cronbach's alpha was used on the MTEBI portion, and the ELL Responsive Measure separately. For the total MTEBI, Cronbach's alpha was .76 with a $95 \%$ confidence interval of $.67-.81(\alpha=.76,95 \% \mathrm{CI}=[.67-.81])$. For the ELL Responsive survey, the Cronbach's alpha was .90 standard score, with a 95\% confidence interval of .87-.92. $(\alpha=.90,95 \% \mathrm{CI}=[.87-.92])$. The MTEBI Cronbach's alpha was considered acceptable and the ELL Responsive Survey Cronbach's alpha was considered excellent (George \& Mallery, 2003). Consistency was not calculated together because surveys were two different survey measures.

From a previous pilot study, an Exploratory Factor Analysis had determined that the MTEBI survey measure had two latent factors, (a) teacher self-efficacy in teaching mathematics to any student with a disability (MTEBI-teacher efficacy) and (b) student outcome expectations of any student with a disability in mathematics (MTEBI- student outcome). In the current study, a parallel analysis scree plot verified these latent 
variables were the same. Please see Table 3. (In order to read a scree plot, count how many triangles appear above the bottom red line.)

\section{Table 3}

MTEBI Scree Plot

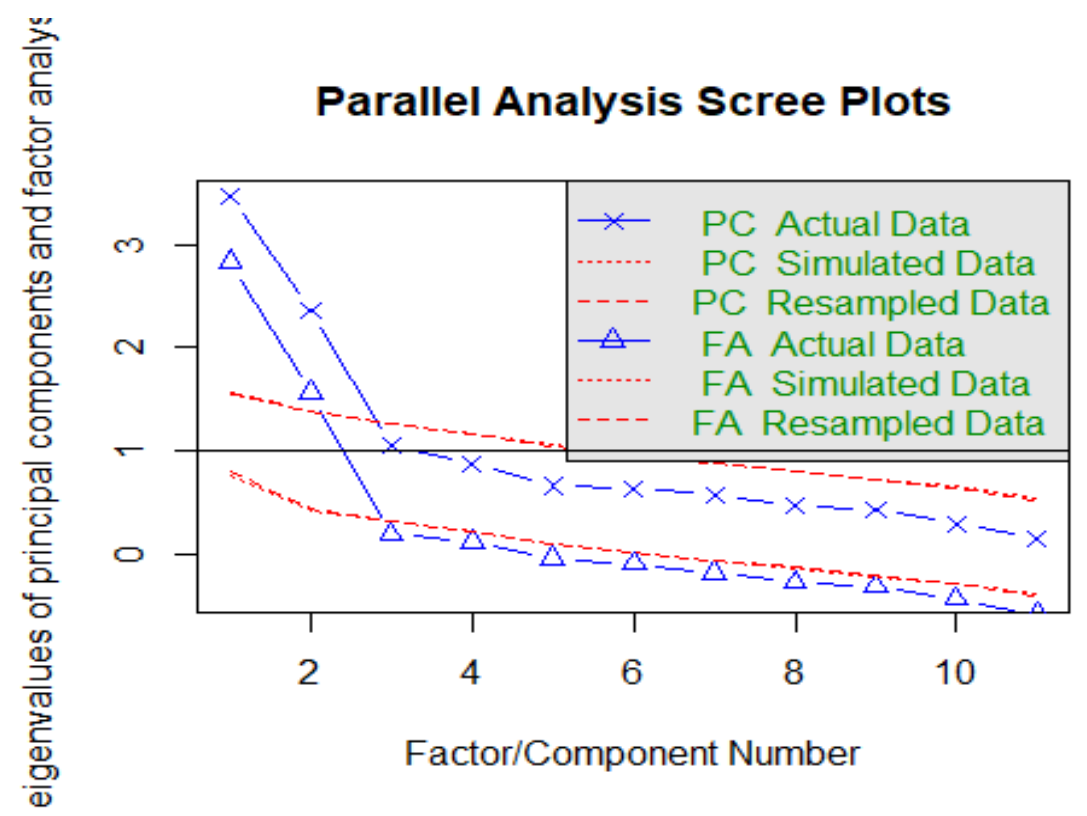

For the ELL Responsive measure, the pilot study revealed three latent variables that were (a) teacher self-efficacy in teaching ELLs with disabilities in mathematics (ELL-self-efficacy), (b) student outcome expectations for ELLs with disabilities in mathematics (ELL-student outcome), and (c) teacher self-efficacy in teaching mathematics to ELLs with disabilities in a culturally and linguistically responsive manner (ELL-CLR efficacy). A parallel analysis screen plot confirmed three latent variables in the current study. Please see Table 4. 


\section{Table 4}

\section{ELL Scree Plot}

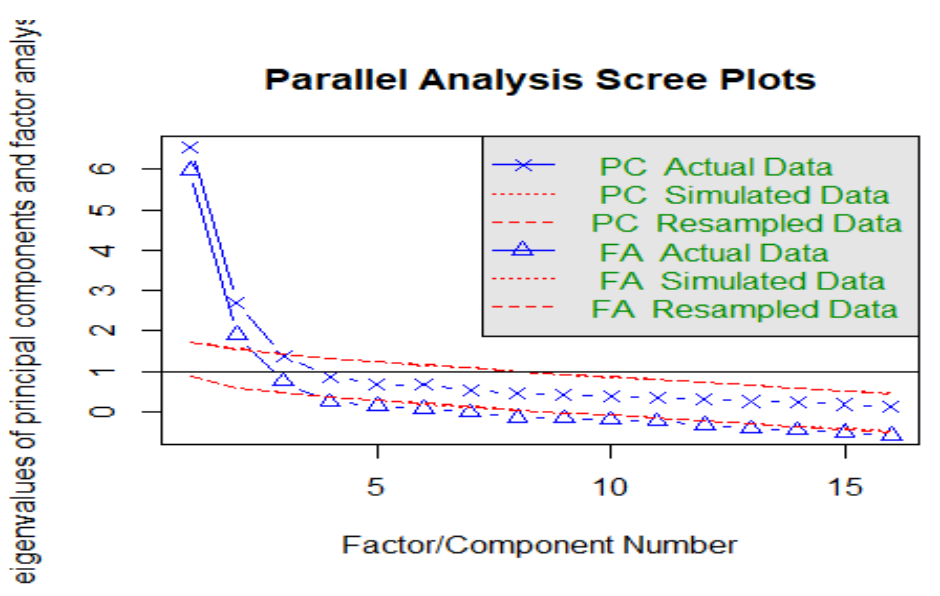

By examining the scree plots and the eigenvalues, it was determined the two survey measures had the same number of latent variables as the pilot study.

Next, reliability analysis for each latent variable was performed. For the MTEBI, the latent variable of teacher self-efficacy had a Cronbach's alpha of .78, with a 95\% confidence interval of .73-.84. $(\alpha=.78,95 \% \mathrm{CI}=[.73-.84])$. The Cronbach's alpha of the latent variable of MTEBI-student outcome was .67, with a $95 \%$ confidence interval of $.57-.77,(\alpha=.67,95 \% \mathrm{CI}=[.57-.77])$. For the ELL Responsive measure, for the latent variable of ELL-self-efficacy, the Cronbach's alpha was .84, with a 95\% confidence interval of .77 to $.87,(\alpha=.84,95 \% \mathrm{CI}=[.77-.87])$. The Cronbach's alpha for ELLstudent outcome was .84 , with a $95 \%$ confidence interval of $.79-.88,(a=.84,95 \% \mathrm{CI}=$ [.79-.88]). Lastly, the Cronbach's alpha for ELL- CLR (culturally linguistically responsive) efficacy was .89 , with a $95 \%$ confidence interval of $.86-.92(\alpha=.89,95 \% \mathrm{CI}$ $=[.86-.92])$. According to George and Mallery, (2003), Cronbach's alpha scores at or above .70 are considered acceptable, and scores at or above .90 are considered to be 
excellent. Since the MTEBI-outcome variable was close to .70 , this variable was still considered for further analyses. Please see Table 5.

\section{Table 5}

Cronbach's Alpha Table for each Latent Variable in the Full Survey

\begin{tabular}{|lcc|}
\hline \multicolumn{1}{|c}{ Latent Variable } & Cronbach's Alpha & Confidence interval \\
MTEBI-efficacy & .76 & $.67-.81$ \\
MTEBI- outcome & .78 & $.73-.84$ \\
Total ELL Responsive & .67 & $.57-.77$ \\
ELL- self-efficacy & .90 & $.87-.92$ \\
ELL- outcome & .84 & $.77-.87$ \\
ELL-CLR efficacy & .84 & $.79-.88$ \\
\end{tabular}

Scores $\geq .70$ are considered acceptable, $\geq .80$ are considered good, and $\geq .90$ are considered excellent (George \& Mallery, 2003).

Because the internal consistency was acceptable for each total measure, and implied that both survey instruments provided reliable measurement of each factor, a correlation matrix (Table 6) was created to compare sub-latent factors on both the MTEBI and the ELL responsive measure. 


\section{Table 6}

Correlation Matrix of the Latent Variables of the MTEBI and ELL Responsive Measures of the Total Survey

\begin{tabular}{|llllll|}
\hline & $\begin{array}{l}\text { MTEBI } \\
\text { efficacy }\end{array}$ & $\begin{array}{l}\text { MTEBI } \\
\text { outcome }\end{array}$ & $\begin{array}{l}\text { ELL } \\
\text { Efficacy }\end{array}$ & $\begin{array}{l}\text { ELL } \\
\text { outcome }\end{array}$ & $\begin{array}{l}\text { ELL CLR- } \\
\text { efficacy }\end{array}$ \\
\hline MTEBI efficacy & 1.00 & & & & \\
MTEBI outcome & 0.15 & 1.00 & & & \\
ELL efficacy & 0.38 & 0.22 & 1.00 & & \\
ELL outcome & 0.10 & 0.26 & 0.23 & 1.00 & 1.00 \\
ELL CLR-efficacy & 0.20 & 0.21 & 0.72 & 0.23 & \\
\hline
\end{tabular}

The purpose of the correlation matrix was to examine how the variables correlated with each other. Since similar constructs were being measured on the two survey measures, some correlation is to be expected. According to, Field, Miles, and Field, (2012), typically correlations are to be near 0.30 . Most correlations in this matrix measure between 0.20 to 0.40 , with the exception of MTEBI efficacy and MTEBI outcome $(\mathrm{R}=$ $0.15)$ and MTEBI efficacy and ELL outcome $(\mathrm{R}=0.10)$. From Bandura's theory of selfefficacy (Bandura, 1997), it is noted that self-efficacy and outcome expectations may indeed be independent constructs. Another purpose of the correlation matrix is to determine if any variables are highly related to each other, thus suggesting multicollinearity (Field et al., 2012). Multicollinearity may be a problem for any variables that correlate too highly, such as $\mathrm{R}>0.80$, as this may suggest that the variables are actually measuring the same idea. In this correlation matrix, ELL self-efficacy and ELL CLR-efficacy are more highly correlated than other variables, $(\mathrm{R}=0.72)$, but since this was not more than 0.80 , these variables were considered as separate and used for further analysis. 
The next step was to conduct a confirmatory factor analysis (CFA) on both the MTEBI and ELL Responsive surveys to determine which questions had the highest factor loadings to be used for additional analyses. The purpose of a CFA was to determine which questions in the survey best represented the latent variables, and only use those questions answer Question 1. Even though in the pilot study, all 27 items led to a good model fit, this was not the case in the current study. Using all of the twenty-seven questions in the CFA model did not lead to a good model fit. For this reason, for both the MTEBI and the ELL Responsive surveys, models were created by using factors with the highest loadings that also made sense in light of the theory of self-efficacy and outcome expectations, and then other factors were added one by one, being sure to include at least 3 survey questions per latent variable, until the best CFA model fit was found. Only the factors that had loadings more than 0.30 were used, and all factors were positive and significant $(\mathrm{p}<.05)$. (Please see Appendix $\mathrm{J}$ for factor loading variances for the MTEBI, and Appendix K for factor loading variances for the ELL Responsive). Although twentyseven questions were included in the entire survey, sixteen were used for the CFA model. Please see the Table 7 below for survey questions that were used in the current CFA model.

\section{Table 7}

Survey Questions Used for the CFA Model.

\begin{tabular}{|l|l|l|}
\hline Latent Variable & Question number & Question \\
\hline MTEBI Efficacy & MTEBI 8 & $\begin{array}{l}\text { I generally teach mathematics } \\
\text { ineffectively. (reverse coded) }\end{array}$ \\
\cline { 2 - 3 } & MTEBI 14 & $\begin{array}{l}\text { I find it difficult to use manipulatives to } \\
\text { explain to students why mathematics } \\
\text { work. (reverse coded) }\end{array}$ \\
\hline
\end{tabular}




\begin{tabular}{|c|c|c|}
\hline & MTEBI 16 & $\begin{array}{l}\text { I am not sure if I have the necessary } \\
\text { skills to teach mathematics. (reverse } \\
\text { coded) }\end{array}$ \\
\hline & MTEBI 18 & $\begin{array}{l}\text { When a student has difficulty } \\
\text { understanding a mathematics concept, I } \\
\text { am usually at a loss as to how to help } \\
\text { the student understand. (reverse coded) }\end{array}$ \\
\hline \multirow[t]{3}{*}{ MTEBI Outcome } & MTEBI 4 & $\begin{array}{l}\text { When the mathematics grades of } \\
\text { students improve, it is often due to their } \\
\text { teacher having found a more effective } \\
\text { approach to teaching. }\end{array}$ \\
\hline & MTEBI 12 & $\begin{array}{l}\text { The teacher is generally responsible for } \\
\text { the achievement of students in } \\
\text { mathematics. }\end{array}$ \\
\hline & MTEBI 13 & $\begin{array}{l}\text { Students' achievement in mathematics } \\
\text { is directly related to their teacher's } \\
\text { effectiveness in mathematics teaching. }\end{array}$ \\
\hline \multirow[t]{3}{*}{ ELL Efficacy } & ELL 17 & $\begin{array}{l}\text { In mathematics, I am able to identify } \\
\text { how mathematics standardized tests } \\
\text { may be biased against students who are } \\
\text { English Language Learners with } \\
\text { disabilities. }\end{array}$ \\
\hline & ELL 18 & $\begin{array}{l}\text { In mathematics, I am able to help my } \\
\text { English Language Learners with } \\
\text { disabilities develop positive interactions } \\
\text { with their peers. }\end{array}$ \\
\hline & ELL 19 & $\begin{array}{l}\text { In mathematics, I am able to gather } \\
\text { information about how my English } \\
\text { Language Learners with disabilities } \\
\text { learn best. }\end{array}$ \\
\hline \multirow[t]{4}{*}{ ELL Outcome } & ELL 23 & $\begin{array}{l}\text { In mathematics, I believe that using } \\
\text { culturally relevant examples enhances } \\
\text { the learning outcomes of English } \\
\text { Language Learners with disabilities. }\end{array}$ \\
\hline & ELL 24 & $\begin{array}{l}\text { In mathematics, I believe encouraging } \\
\text { the use of the native language of } \\
\text { English Language Learners with } \\
\text { disabilities will enhance their learning } \\
\text { outcomes. }\end{array}$ \\
\hline & ELL 26 & $\begin{array}{l}\text { In mathematics, I believe that changing } \\
\text { learning environments to be compatible } \\
\text { with students' home culture increases } \\
\text { the learning outcomes of English } \\
\text { Language Learners with disabilities. }\end{array}$ \\
\hline & ELL7 & $\begin{array}{l}\text { In mathematics, I am able to use various } \\
\text { types of assessments that are matched to }\end{array}$ \\
\hline
\end{tabular}




\begin{tabular}{|l|l|l|}
\hline ELL- CLR & $\begin{array}{l}\text { the proficiency of English Language } \\
\text { Learners with disabilities. }\end{array}$ \\
& ELL8 & $\begin{array}{l}\text { In mathematics, I am able to critically } \\
\text { examine the curriculum to determine } \\
\text { whether it appropriately represents } \\
\text { people from different linguistic/ cultural } \\
\text { backgrounds such as English Language } \\
\text { Learners with disabilities. }\end{array}$ \\
\hline ELL12 & $\begin{array}{l}\text { In mathematics, I am able to use } \\
\text { culturally specific context to make } \\
\text { mathematics meaningful to students } \\
\text { who are English Language Learners } \\
\text { with disabilities. }\end{array}$ \\
\hline
\end{tabular}

For the MTEBI, the two factor CFA model exhibited acceptable fit to the sample data with a TLI of .980, CFI of .988 and RMSEA of $.03,\left(X^{2}(.33)=14.61, \mathrm{df}=13, \mathrm{p}>.05\right)$. (Please see Appendix L for MTEBI CFA graph). For the ELL Responsive Portion of the Survey, the CFA model exhibited good fit to the data with a TLI of 0.963, CFI of .975 and RMSEA of $0.063,\left(X^{2}(.091)=33.65, \mathrm{p}>.05\right)$. For both surveys, all factors showed positive, significant factor loadings. Please see Appendix M for ELL Responsive CFA graph, and Appendix $\mathrm{N}$ for the CFA Psychometric descriptive properties for the MTEBI and ELL Responsive Measures.

After the CFA, a new Cronbach's Alpha was conducted for each of latent variables to determine the internal consistency of the latent variables using only the questions that were used in the CFA. Because some questions are omitted, and less were used to create the model, this lead to lower overall reliabilities. The new Cronbach's alphas were the following: MTEBI- Total MTEBI: $(\alpha=.62,95 \% \mathrm{CI}=[.55-.74]), \mathrm{MTEBI}$ Outcome $(\alpha=.67,95 \% \mathrm{CI}=[.57-.77])$, MTEBI Efficacy: $(\alpha=.81,95 \% \mathrm{CI}=[.77-.86])$, ELL Responsive Total: $(\alpha=.83,95 \% \mathrm{CI}=[.78-.87])$,ELL Outcome: $(\alpha=.82,95 \%$ 
$\mathrm{CI}=[.76-.88])$, ELL Efficacy: $(\alpha=.71,95 \% \mathrm{CI}=[.63-.8])$ and ELL CLR- efficacy: $(\alpha=$ $.83,95 \% \mathrm{CI}=[.77-.88])$. Please see Table 8.

\section{Table 8}

New CFA Model Cronbach's Alphas

\begin{tabular}{|lll|}
\hline Latent Variable & Cronbach's & Confidence interval \\
& Alpha & \\
\hline Total MTEBI & .62 & $.55-.74$ \\
MTEBI-efficacy & .81 & $.77-.86$ \\
MTEBI- outcome & .67 & $.57-.77$ \\
Total ELL Responsive & .83 & $78-.87$ \\
ELL- self-efficacy & .71 & $.63-.80$ \\
ELL- outcome & .82 & $.76-.87$ \\
ELL-CLR efficacy & .83 & $.77-.88$ \\
\hline
\end{tabular}

Although the total MTEBI had an alpha score that was lower than .70, the latent variables within both measures demonstrated sufficient reliability to conduct further analyses.

\section{Research Question 1}

The first research question was: How do special education teachers self-report the self-efficacy beliefs and outcome expectations in teaching mathematics to (a) any student with a disability, (b) ELLs with disabilities, and (c) ELLs with disabilities in a culturally/linguistically responsive manner? To answer these questions, normality testing was conducted before differences between means were examined. Normality testing and means testing results are presented together. 
Between Test Comparisons. The primary purpose of this study was to compare similar latent variables between the two measures (i.e. teaching self-efficacy and student outcome expections on both measures). In attempt to be thorough, the means of the total measures of both the MTEBI and the ELL Responsive Measure were compared first. To compare the total distribution of scores between the total MTEBI and the total ELL Responsive Measure, a Shapiro-Wilk's normality test revealed that the distribution was normal and non-significant $(\mathrm{W}=0.98, \mathrm{p}>.05)$. A dependent $\mathrm{t}$-test revealed that there were no significant differences in the total scores of the MTEBI $(M=7.37, \mathrm{SD}=1.19)$ and the ELL Responsive Measure $(M=7.29, \mathrm{SD}=1.35)(t(112)=0.52, \mathrm{p}>.05, \mathrm{~d}=0.05)$. In both measures the means were near 7 . On average, participants rated themselves as having overall high self-efficacy in both teaching mathematics to any student with a disability and in teaching ELLs with disabilities in a culturally/linguistically manner.

Next, between measure comparisons were conducted to compare similar latent variables on each measure. The first latent variable to be compared was self-efficacy. MTEBI self-efficacy and ELL Responsive efficacy were compared. A Shapiro Wilk's test was conducted to examine normality. The distribution of average scores on Efficacy on the MTEBI and the ELL Responsive Measure were not normal and significant (W= $.92, \mathrm{p}<.05)$. This means that the ways in which participants answer questions on each measure followed different distribution trends. For the MTEBI efficacy, the scores were left skewed. This means that the mean was less than the median. This may be because three teachers had average scores on the self-efficacy variable as low as 1.9, 2.0 and 2.0 respectively. While the majority of other teachers rated their self-efficacy on the MTEBI between 7 and 10. These three low scores may be outlier. Or, this may be a subset of 
teachers who represent a demographic of teachers with extreme low self-efficacy in teaching mathematics. This may be an area of further research. On the ELL Responsive Measure, the distribution of scores followed a more normal curve with scores ranging from 3 to 10 . Because normality was violated, a Wilcoxon T-test was conducted to compared the medians of self-efficacy scores on the MTEBI-efficacy $(\mathrm{Mdn}=8.5)$ and ELL Responsive Measure- efficacy $(\mathrm{Mdn}=7.67)$. There were significant differences found between MTEBI-efficacy and ELL Responsive-Efficacy, with a very small effect $(p=.02, d=0.11)$. Participants rated themselves as having significantly more self-efficacy in teaching mathematics to any student with a disability than they did to teaching mathematics to ELLs with disabilities.

The next between test comparisons were between the MTEBI-outcome, and the ELL Responsive Measure were normal and non-significant $(\mathrm{W}=0.97, \mathrm{p}>.05)$. A paired t-test was conducted to compare the average scores of the outcome variables on the MTEBI-outcome $(M=6.9, \mathrm{SD}=1.32)$ and the ELL Responsive Measure- outcome $(M=7.64, \mathrm{SD}=1.70)$. Significant differences were found, with outcomes expectations scoring higher on the ELL Responsive Measure than the MTEBI-outcome measure with a small effect $(\mathrm{t}(111)=-4.19, \mathrm{p}<0.01, \mathrm{~d}=0.40)$. This means that participants self-reported that they expected ELL students with disabilities to have higher learning outcomes in mathematics (if their language and culture were attended to), compared to the mathematics outcomes of any student with a disability. 
Within Test Comparisons. Within test comparisons are secondary analyses for the current study. The purpose of the within test comparisons was to explore other differences to consider in follow-up studies. The first within comparisons were conducted with the two latent variables that composed the MTEBI, specifically, a dependent T-test was conducted on the two sub-factors, MTEBI-efficacy and MTEBI- outcomes. The variables within the MTEBI were examine for normality using the Shapiro-Wilk test. The distribution was significantly non-normal, this was most likely due to the three very low scores on the MTEBI-efficacy variable previously mentioned $(\mathrm{W}=0.96, \mathrm{p}<0.01)$.

Because normalcy was violated, a Wilcoxon Signed Paired T-test was conducted to compare the median scores of the MTEBI efficacy average, and the MTEBI outcome average. The MTEBI efficacy $(\mathrm{Mdn}=8.5)$ was significantly higher than the MTEBI outcome average $(\mathrm{Mdn}=7),(\mathrm{p}<.001, \mathrm{~d}=.52)$. Participants rated themselves as having higher self-efficacy in teaching mathematics to any student with disabilities than they did in their outcome expectations for any of their students with disabilities.

To compare means within the ELL Responsive Measure, General Linear Modeling was used because it is better suited to compare the means of dependent measures than ANOVA. Field, Miles and Field (20120 explain it in the following quote:

In short, a multi-level model is simply a regression or linear model that considers dependency in the data... A multi-level model is an extension of regression that handles dependent data by explicitly modeling the dependency. It is, therefore, very well suited to repeated measures experimental design. (p. 573)

By examining Simultaneous Tests for General Linear Hypotheses - Multiple Comparisons of Means: Tukey Contrasts, it was found that there were significant differences in ELL teaching efficacy $(M=7.66, S D=1.53)$ and ELL-CLR efficacy $(M=6.59, S D=2.03)$ with a large effect $(z=5.76, \mathrm{p}<.001,95 \%$ CI $[.63-1.50], \mathrm{d}=0.84)$, 
with ELL teaching efficacy scoring higher. This means that participants rated their selfefficacy in teaching mathematics to ELLs with disabilities as higher than their selfefficacy in teaching ELLs with disabilities in a culturally and linguistically responsive manner.

There were also significant differences between ELL outcome expectancies $(M=7.64, \mathrm{SD}=1.70)$ and ELL-CLR efficacy with a near moderate effect $(M=6.59, \mathrm{SD}$ $=2.03)(z=5.61, \mathrm{p}<.001,95 \%$ CI- [.60- 1.48], $\mathrm{d}=0.45)$, with ELL outcome expectancies scoring higher. This means that participants rated their expectations of ELL learning outcomes as higher than their self-efficacy in teaching ELLs with disabilities in a culturally and linguistically responsive manner.

When comparing teacher self efficacy in teaching mathematics to ELLs and their learning outcome expectations for ELLs, there were no significant differences between teacher self-efficacy in teaching ELL students $(M=7.66, \mathrm{SD}=1.53)$ and ELL outcome expectancies $(M=7.64, \mathrm{SD}=1.70)(z=-0.138, \mathrm{p}=.98,95 \%[\mathrm{CI}-0.46-0.40], \mathrm{d}=0.009)$. Teacher self-efficacy in teaching ELL students in a culturally and linguistically responsive manner was significantly below self-efficacy in teaching ELL students in mathematics, and significantly below ELL student outcome expectations. Please see Table 9 below. This table provides a visual representations of the comparisons. The 
average scores are plotted on the graph. The MTEBI is in blue and the ELL Responsive Measure is in red.

\section{Table 9}

Average Sub-Factor Scores in the MTEBI and ELL Responsive Measure.

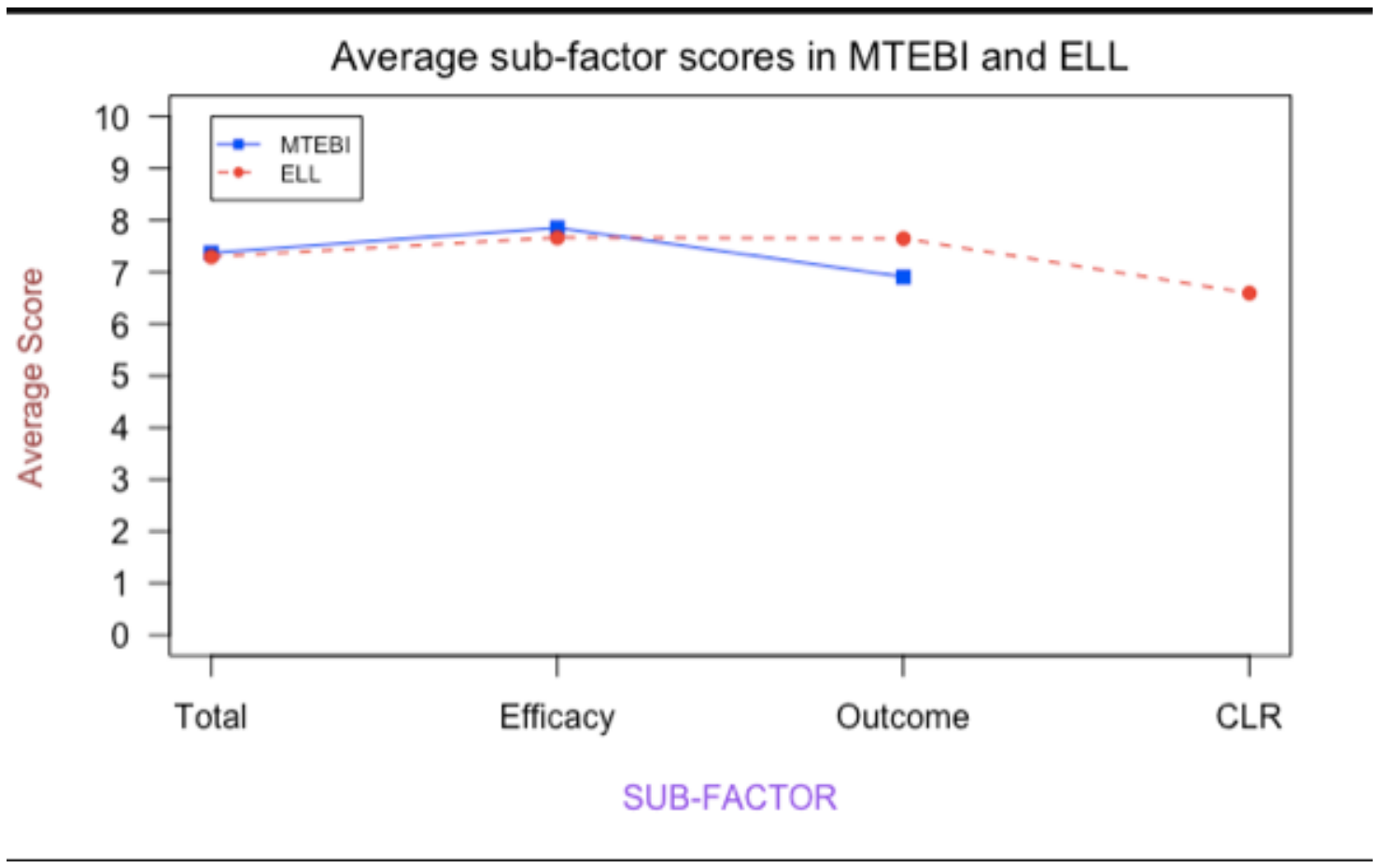

\section{Research Question 2}

The qualitative data, semi-structured interviews, was used to answer Question 2: What factors do teachers report as helpful or harmful in teaching mathematics to ELLs with disabilities?

Positionality. The primary investigator for this study was an African-American woman who taught special education in elementary and middle schools in a Mid-Western urban school district for over 10 years. The secondary researcher was a Latina woman from a South-Western urban school district who also had over 10-years' experience 
teaching mathematics in elementary schools. Both researchers had taught ELL students through-out their careers.

\section{Factors that are Helpful or Harmful to the Practice of Teaching Mathematics to \\ ELLs with Disabilities}

The first part of research question 2 focused on identifying what factors do teachers report are helpful or harmful in teaching mathematics to ELLs with disabilities. Helpful factors are internal or external aspects of teaching that teachers identify as favoriable in helping them teach mathematics to ELLs with disabilities. Harmful factors are the aspects that teachers identify as a barrier to their teaching of mathematics to ELLs with disabilities. Six themes emerged from the data and within each theme, factors that were both harmful and helpful emerged. Themes that emerged from the data related to helpful factors included teacher preparedness by means of university training and ongoing professional development and teaching methods used "favorable" student dispositions, and access to supportive administration and peers. Harmful factors included lack of understanding how to teach mathematics to ELLs with disabilities, time constraints, negative parent relationships and lack of awareness or ability to teach in a culturally responsive manner. A summary of all the findings can be found in Table 10. In this next section, the themes are discussed in more detail.

\section{Theme 1- Teacher Preparedness}

Helpful Factors-Teacher Preparedness. Teacher preparedness refers to any training that teachers received in teaching their students. This training could be university classes, degree programs, certifications or professional development offered by their schools. Overall, the teachers interviewed had various levels of training. Those who 
seemed more comfortable with teaching mathematics to ELLs with disabilities had TESOL certification, content certification, advanced degrees such as Education Specialist or reported having ongoing professional development. These teachers seemed to be the most prepared to teach mathematics to ELLs with disabilities.

Abigail had over eleven years of teaching experience and had taught ELLs with disabilities 2 to 5 years. She held an educational specialist degree as well as certifications in cross categorical mild/moderate disabilities K-12, social studies, TESOL, and mathematics. She expressed that she felt very confident in her mathematics teaching ability because of her certifications and professional development that she has received.

Interviewer: You have these licensures, and so my next question is how prepared do you feel that you are to teach mathematics to English language learners who have disabilities?

Abigail: Well, I am, I'm certified in math, so, so I have the proper certifications, but my focus is on special education, so I'm content certified as well as special education certified, which is unusual.

Interviewer: So you feel very prepared then?

Abigail: I'm good. Yeah. Yeah.

Cheyenne reported that she never received any training in college related to ELLs with disabilities as learning about ELL students was not a requirement of her program, nor does she remember it being offered. However, the school where she taught had a high ELL population and offered "ESOL" endorsement classes.

Cheyenne: I work at a school with ESOL [ELL] students, high ESOL population, um, so I'm currently working on my endorsement for ESOL, This has only been my second year, and I've taught students with ESOL and learning disabled... It's an ESOL school. So most of the staff, they have that endorsement; they have that training. My principal teaches ESOL classes and I am taking those classes with her. If I have a student that struggles, and this is any student in particular, I always know I'll go talk to the principal or somebody in the building. 
Additionally, Cheyenne had professional development sessions every Wednesday where teachers learned a strategy to try with their students. Though she seemed appreciative of this training, and said that is was helpful, she added that she would like classes that teach her basic Spanish, since the majority of her students speak Spanish.

Harmful Factors- Lack of preparation. Teachers who seemed to be the least prepared to teach mathematics to ELLs with disabilities had limited certifications and an absence of regular professional development in teaching students who are ELLs with disabilities. Although these teachers may have held master's degrees, the degree was typically in special education categories and not content or TESOL certification. Additionally, these teachers also reported having no school support in terms of professional development and peer support to aid in their training of helping them learn how to teach these students.

Margaret was certified in low incidence and cross categorical mild/moderate disabilities, and had some experience teaching students who were ELL, but she expressed that she did not feel prepared to teach mathematics to ELLs with disabilities. Although Margaret taught some students with mild/moderate disabilities, she explained that her prior education did not focus on teaching mathematics or teaching students with various linguistic or cultural needs.

Interviewer: How prepared do you feel that you were to teach math to these students, to your ELL students in math?

Margaret: Not at all. I don't feel as far as the schooling that I received to get my master's degree in special ed for low incidence, special ed, they didn't include ELL at all, but they didn't really prepare you at all to work with the students. It was more about paperwork then, you know, and they didn't tell you about the paperwork itself, they just had you do reports. 
Likewise, Robyn had a speech-language background, and was certified in working with students who were severely developmentally disabled. She also held a master's degree. She did not feel prepared to teach mathematics to students who are ELL and have a disability. In her district, when she first started teaching ELLs with disabilities, she did not have any resource to go to - no ELL teachers or paraprofessionals. She taught special education in a resource-pull out classroom setting, and was expected to deliver content to the students. When asked about her experience, this is what she had to say:

Robyn: I have taught, uh, I did speech and language therapy here for about four years and the rest of the time, I guess about 25 years I've been working with students, in special ed who have ESL[ELL] needs. And I think it seems to have increased within the past five or 10 years though. The amount of students that I see that have some type of a language or some type of a disability as well as the ESL services... I don't feel like I was prepared at all...I didn't understand the, you know, the real needs that these kids had especially when it comes to the language and vocabulary.

Michelle said that she felt comfortable with teaching mathematics because she was a mathematics major in college before switching her major to education. However, she felt completely unprepared to teach ELLs with disabilities. She reported that she had one professional development centered around teaching ELLs with disabilities a few years ago, but the professional development had generic strategies, and she could not think of anything specific that she had learned.

Interviewer: So let me ask you, how well do you feel you were prepared to work with these students [ELLs with disabilities]?

Michelle: Oh gosh. I mean, I majored in math for a short time in college and changed majors. I mean, I'm, I'm good in math, so the math part wasn't, wasn't bad. And of-course my certification is in social studies and special ed, so I've got that. But I was never really trained for the ELL students... And with special ed you kind of get put into, you know, wherever they need you, in order to meet their requirements. 
Interviewer: So what you're saying is, you don't feel like you had any university classes that prepared you to teach math to these students, to ELL students with disabilities? Have you had any professional development or anything since you've been teaching these students?

Michelle: Not really. I mean, we've had some over the years a couple of generic ones--how to work with all students and it was more culture-based, you know, expectations and consequently are coming from that. It wasn't specific about, you know, here's what you need to do...

Interviewer: How many professional development sessions have you had?

Michelle: Oh gosh, maybe two or three in the last 19 years.

Although Abigail reported many certifications, and licenses, she also reported that she has never taken a class or had any professional development preparing her to teach ELLs with disabilities, in any content area-including mathematics. She often signed up for ongoing district professional development, as she said, "I've signed up for math specific stuff, but I've also signed up for, of course, special education professional development, but nothing specific to ELLs with disabilities."

Amanda, had also received no professional training through university training or professional development in teaching ELLs with disabilities in mathematics. Amanda said that she felt as if she is learning as she goes and had this to say:

Amanda: We have a saying in education, that we're flying the airplane while we're building it. And that's pretty much what I would say. Discuss my experience? Coming out of college I had no training at all in teaching kids with a disability who were are also ESL [ELL].

Since Amanda had not had any formal training regarding specifically teaching ELLs with disabilities, and particularly in mathematics, she appears to have drawn from her knowledge of students with autism, which she described as a language based disorder. 
Amanda: I also teach students with autism and that's a very similar situation. You know, it could be a difficulty with language to begin with.

She expressed that using strategies to teach vocabulary to students with autism helped her to teach her ELLs with disabilities in mathematics.

Although all six teachers said that they did not have any classes that specifically addressed ELLs with disabilities_ - particularly in mathematics in their university training, teachers with more certifications and trainings seemed to feel like they were better prepared to teach mathematics to ELLs with disabilities. However, there was an overall sense that teachers did not know exactly how to best teach mathematics to these students, as is evidenced by Amanda who had self-reported high self-efficacy in teaching mathematics, and ELLs in mathematics, felt as if she was "building the plane while flying it". In the absence of specific university training in teaching mathematics to ELLs with disabilities, teachers seemed to use the knowledge that they had from other professional training as is evidenced by Abigail who was certified in math, TESOL, social studies as well as special education. Having training in multiple academic areas seemed to give the teachers more tools to teach their ELLs with disabilities. This in turn, may have been helpful to their self-efficacy.

\section{Theme 2- Student Characteristics}

The second theme referred to the characteristics of the students in behavior, the teachers discussed student characteristics related to their ELL status, disability status, disposition toward mathematics and SES status that they either found helpful or harmful to their teaching practice.

Helpful Factors due to ELL status characteristics. Some teachers mentioned that their ELL with disabilities found mathematics the easiest subject for them often due 
to procedural mathematics that was void of vocabulary or because it was "concrete."

Robyn mentioned that compared to other subjects, her ELLs were more interested in mathematics. She explains, "So even if they're not focused and in the other subjects, they are for some reason in math...It's very interesting. I don't know if it's being concrete...But, that's their strength for all three of them."

Although the teachers seemed to see the engagement, and motivation of ELLs with disabilities in mathematics as positive, the emphasis was on procedural mathematics — not mathematics that required vocabulary and technical language. When considering teaching conceptual understanding of mathematics that required specific vocabulary and technical language, teachers shared particular concerns.

Harmful Factors due to ELL characteristics. When considering the characteristics of their students related to their ELL status, a common barrier was the mismatch of language and culture as well as a lack of methods to teach mathematics in a meaningful way. For example, although Amanda's ELLs with disabilities tended to excel at procedural mathematics, many of her students who were ELL's who qualified for special education services in mathematics, qualified for word problem solving-connected to language and vocabulary. She gave an example of a student who struggled with problem solving in mathematics,

Amanda: Um I'm thinking of a student I had last year and his area of disability was problem solving and that's mainly word problems. So as long as I read the word problems can, he could solve them. He had no problem with calculation cause it's just understanding the language of the mechanics and the problems, wanting to know what they, what the words meant and what they do to solve it. Like, if a problem says "in all" you know, are you going to add or subtract or if they say six of the birds left and I can subtract or add, you know, the key words are tricky for some of our kids who are learning English. 
Other teachers mentioned challenges that their students had in comprehension of mathematics because of vocabulary and context. Michelle mentioned the challenge of teaching mathematics terminology in English.

Michelle: When it comes in with the language is how to explain things and using the right terminology for them because you get into, you know, you've got math terminology and then you've got English terminology and getting them to coincide when they [ELL students with disabilities] don't have much English terminology anyway.

Michelle further explained the mismatch between the needs of the students with the curriculum that she was given to use.

Michelle- If you've got a student that has 'languages' and a disability, allowing them to use an English textbook really isn't a whole lot of help, you know.

Abigail, Cheyenne, Margaret and Robyn all agreed that teaching ELLs with disabilities mathematics vocabulary was challenging. Abigail mentioned how the vocabulary was challenging because the technical terminology does not sound like spoken English,

Abigail: But I think when it comes down to just the vocabulary, especially mathematics vocabulary is a challenge because you don't use it in everyday language when you're talking to your friends, you don't talk about sums and differences and products and slopes and intercepts and things like that. So mathematical vocabulary is the biggest challenge and we have to make it understandable to them to where they get it.

Robyn expressed her frustration at teaching word problems to her students.

Robyn:The word "reasoning" cause that's what the word problems are. That's the word they use. And, and my little Chinese boy, he's just like, 'Oh no, I'm not going to be able to do this' before he's ever read it. [pause] I want them to understand it before they leave my room because I will teach the next concept.

Margaret mentioned that one of her students has behavioral concerns because of a lack of communication, which is complicated by limited access to an interpreter in the student's 
home language, Vietnamese. Abigail found the different levels of English proficiency a struggle, with those students who are new to the country being the most difficult to teach.

Cheyenne, also mentioned the frustration of teaching vocabulary, but she readily

had a number of strategies she used to mitigate this frustration.

Cheyenne:They struggle with vocabulary...They don't get the vocabulary part of it, so I provide good hands-on, pictures or whatever to help explain it. I think that makes it a little bit better.

All six teachers reported barriers to their teaching practice in their inability to effectively communicate with their students due to vocabulary and language concerns. Specifically, the teacher's ability to teach mathematics vocabulary and concepts, and the teachers' abilities to understand their students, was the greatest reported need related to ELLs with disabilities student characteristics.

Helpful factors related to disability status. Overall, teachers expressed a certain amount of regard for their job in teaching students with disabilities, such as Abigail, who said, "We're here for the kids, I want to be the best I can be for the babies." Teachers also seemed to be knowledgeable about their students' disability status and their learning needs.

Harmful Factors related to disability status. There was some concern about student characteristics related to their disability that may have impacted teachers self-efficacy. Teachers mentioned the stress of trying to meet the needs of students with various levels in one classroom. For example, Margaret expressed frustration in trying to meet the needs of her students who demonstrated problems with their memory. These difficulties included remembering what had just happened while learning a lesson, as well as retaining information from day to day. 
Margaret: Because you have 14 different little people and they all need different, you know, levels of support. And then they get frustrated. It's also frustrating to the teacher. And, every day is like you haven't taught this to them. How can you not remember this? I just went over this with you. Even five minutes ago. How can you not remember this?

Abigail, had similar concerns as Margaret. However, she added that she felt pressure from having students in the middle grades who are not developmentally ready for the level of mathematics that is expected for their grade level. She felt the stress of trying to teach students in sixth to eighth grade who are struggling with concepts common to students in the third or fourth grade.

Abigail: But those functioning at the third or fourth grade level is what I'm finding is it's very hard for them to advance conceptually. And a lot of the kids in sixth, seventh, and eighth grade, they're still in the concrete phase of learning. And you know, you're supposed to be merging into the abstract phase of learning and they're just not getting it...It's like they're getting further and further behind in mathematics. And I, we don't know what the deal is.

Amanda, found the lack of student background knowledge, which she attributed to their socio-economic status as determined by the free and reduced lunch percentage of the school to be a barrier to her teaching.

Amanda: My difficulty is that some of my students have a lack of background knowledge. Their world is very small. Like I mentioned, our school is I think $80 \%$ free and reduced lunch. And so a lot of those kids going to Walmart, it's like an adventure... That's the farthest they've been from their house. They don't go on family vacations, they don't go on trips, or leave the city, they stay in the city. And so it's harder to talk to them.

Common student disability status related characteristics that teachers reported as barriers to their teaching practice included cognitive development that is behind the expectations of curriculum as well as the development of their peers, and inherent disability related characteristics such working memory challenges. 
Harmful Factors-ELL vs Special Education concerns. Another barrier that teachers identified as harmful to their teaching practice of ELLs with disabilities in mathematics was the ability to differentiate the whether students were having typical language acquistion concerns that would be expected of anyone learning another language, or if students were experiencing true learning difficulties. Both Michelle and Margaret, mentioned difficulty in knowing the difference between language acquisition and learning problems. Michelle believed that the struggles that students have are either a learning concern or a language concern, and it is important to identify which issue the students are struggling with.

Michelle: It is sometimes very difficult to tell where the disability stops and the language issue takes over or vice versa. And you know, I think as a special ed teacher, we're trying to kind of decide is this a language issue? Is this a disability issue? Because it's usually one or the other.

However, Margaret also noticed that for her ELLs with disabilities (in this case autism in particular) it seemed as if their learning problems were not as severe as the other students with disabilities.

Margaret- And a lot of my kids, I don't know if it's autism or what, but they have comprehension problems and retaining that information for more than five minutes. And I mean, I don't know if it's something that parents do at home for the ESOL [ELL] students, or what, but a lot of them retain the information. So, I don't know if their autism isn't quite as bad or what?

However, Amanda explained that she believed that the assessment methods of students with disabilities is getting better at distinguishing a language acquistion concern from a learning disability. As a result, many students in her building who are ELL are not qualifying for special education.

Amanda: I noticed the trends when I first started teaching more that, you know, students that were ESL were being overly identified for special ed because they didn't have the language skills. It seems like the trend is becoming, you know, 
where they were being overly identified for services when I first started teaching, and now they're becoming less. And I think as the ESL [ELL] services have become more defined and more purposeful, I think that's kind of decreased by a bit. But we aren't seeing a lot of kids. Now if they don't have skills, okay, then test them, you know, but it could be very much the language issues.[For some] that was the whole problem to start with.

Overall, teachers mentioned mathematics being easier to teach to ELLs with disabilities because of favorable characteristics of students, such as that their dispositions' toward mathematics, which included engagement and motivation. However, other student characteristics related to ELL status, such as challenges in understanding language and vocabulary were a viewed as negative factors that impacted the teachers' teaching practice. Teachers also mentioned frustration in teaching students the intended curriculum due to inherent disability related qualities such as slower cognitive development and limited working memory.

\section{Theme 3- Teaching and Learning}

Teaching and learning relates to the strategies that the teacher used to teach the students, particularly a variety of strategies and the teacher's view of the success of those strategies. This includes access to curriculum, and resources such as technology. All six teachers reported using similar teaching techniques such as starting with the given curriculum, scaffolding the lesson using direct explicit instruction and modeling and then fading instruction until the students could perform the mathematics on their own. Additionally, Some teachers mentioned using manipulatives, taking frequent breaks, using highlighters to underline important parts of word problems. Where teachers differed in their responses was in how they differentiated their instruction for ELLs with disabilities who may be struggling with learning mathematics concepts. 
When considering factors that were helpful or harmful to the teaching practice of teachers, it is interpreted that helpful teaching strategies included teaching strategies mentioned that included teaching more than the given curriculum required, and using different materials such as manipulatives, and visual representations to make mathematics meaningful. Whereas, either refusing to teach a topic, or teaching in a procedural manner void of conceptual understanding is interpreted as "superficial" and potentially a harmful teaching practice.

Helpful factors related to teaching methods. Amanda, self-reported giving careful thought into how she prepared lessons for her students. She made parallels between her students who are ELL with disabilities and those with autism. Amanda crafted her lessons with her students in mind by bringing in real life objects to teach vocabulary, and using tools such as technology to use in addition to the given curriculum to help students make meaning.

Amanda: A lot of time what I go to is pictures because I also teach students with autism and that's a very similar situation. You know, it could be a difficulty with language to begin with? And so a lot of times, I'll do pictures or I'll bring in artifacts. Um, know, if it's talking about a certain kind of object in the word problem and I know they don't know what that is, I'll bring it in. And when you start to go to objects, so I had to ... making it more hands on or showing a video. You know, I have a student and you know, he didn't know what a "robe" was, so I pulled up a Google image, you know, and just found an image of a robe and showed him what a robe was. But he didn't know what it was because they didn't use robes in their home and something like that. So I just want a video or pictures or hands on, um just purposely teach that vocabulary. I haven't really had any help doing that.

Amanda demonstrated a willingness to spend extra time going out of her way to go above and beyond the curriculum to provide a scaffold to help students understand by bringing in actual artifacts to help students make meaning out of the vocabulary and by using the computer to show pictures of objects used in mathematical problems. 
Cheyenne used a scripted curriculum meant for special education students. For her ELLs with disabilities, she also modified the scripted curriculum by adding visual representations and using technology to make the concepts more meaningful.

Cheyenne: The modified special education curriculum teaches differently because it's like scripted. It does a lot of repetition. I'm not supposed to bring out the manipulatives, and stuff, but I find that even though like with my slower learners, they need that, they need the hundreds chart to start to see how things work or be put together and like, I'm trying to think of visuals for students in the general curriculum, like I'm trying to even thinking of vocabulary right now. If we were working on addition and they're not catching with what it means to add things together, I will show them with the manipulatives. I've also used Google face [a computer program]. There are ears and a face, and where I put the ears are the addends, and the whole face is that total.

Abigail also mentioned similar ways of teaching using more than the curriculum and tools associated with the curriculum. However, she taught in a class- within-a-class setting - meaning that she taught her students with disabilities mostly in the general education teacher's classroom - and was limited to what she personally could do in that setting. She was clear that if she had her own self-contained class, and could teach the way that she wanted, she would use videos and manipulatives.

Abigail: If I taught self-contained special education math groups, I would use manipulatives, I would use videos. But [I'm] in the CWC, which is class within a class co-taught classroom, which is what I'm doing now. So, the last couple years, we do not have time to pull out manipulatives and do that, when the pacing guidance is so fast. So we don't have the time to do that with these kids who are struggling.

However, Abigail also expressed her frustration with not being able to use the tools to meet student need in the class within a class setting in mathematics that she would use in her own self-contained classroom. She mitigated this frustration by considering the needs of the students beyond their mathematics class, including statements about what the students would need to be successful in their future. She 
believed even though she could not teach them in the way that she preferred, for these students to be successful as adults in this society, they needed to be educated in the "class within a class" with other general education students so that they have access to language and societal norms.

Abigail: I think they need to be in the CWC classroom just to acquire that language. Okay. I think that's in their best interest. I know they struggle in math. They may not get a passing grade. However, for them to function in our society language wise, it's best for them, cause I'm looking ahead to when they're grown and they're out of school, what are they going to do?"

Robyn used both the special education and some of the general education curriculum to meet the needs of her students. For example, she used a curriculum, meant for special education and ELL students, which removed complex language for the students and made it more accessible in terms of understanding the content. She also combined the special education curriculum with the computer technology portion of the general education curriculum. Even though Robyn expressed frustration at teaching the topic of fractions, she used different methods to try to teach the content to her students.

Robyn: We were doing fractions so we did a lot of things, even up on the smart board cause I could go into the general ed math website. And they even have math tools on there that you can drag over and manipulate-very visual. And so they have fraction strips that you can drag over to compare fractions, which is really nice. And then, um, there's also sheets for the kids that we cut out and made our own fraction strips and that really helped and we just put them in little envelope and they could carry it back and forth to class with them. So, I use a lot of things with blocks. I even write on my table.

Robyn differed from Margaret and Michelle in that she found materials beyond the given curriculum. She used virtual manipulatives on a smart board, and physical manipulatives that the students could carry with them. Robyn further assisted students by writing on her table to help them make meaning. She attended to the task of mathematics 
by using a variety of techniques. When asked how she assists ELLs with disabilities who may be struggling with the language, or vocabulary, she said:

Robyn: Some of my kids, you know, they'll highlight the word and then they might write something off to the side. Just as a reminder to themselves. So if some kids that had to know a strategy.... So you'll see some of them write a multiplication sign to the side.

\section{Harmful factors related to superficial teaching strategies. Superficial}

strategies refers to strategies to help students get the answer, but not attend to deeper conceptual meaning. These strategies included choosing not to teach a particular concept at all or just restating a memorized procedure, without any attempt to develop more conceptual meaning. By comparison, teachers who used more sophisticated teaching methods taught more for meaning, and thought ahead to the bigger picture of the students' lives.

One superficial strategy included choosing just not to teach a particular concept; and is illustrated in how Margaret feels about teaching word problems.

Interviewer: Do you ever teach word problems or anything?

Margaret: We haven't gotten into a lot of the word problems, um, partly because there's so much information in a word problem... and they get lost...

Interviewer: Is there anything that you do differently for your students who are ELL than you do for your other students?

Margaret: Not really. I just try and um, make sure that they understand and encourage them to ask questions whenever they don't understand something.

Another example of a superficial strategy included simply depending upon the general education mathematics teacher to provide student instruction and resources. Michelle depended upon the general education teacher, and taught her students the provided assignments. She only explained the procedures in a step-by-step fashion as 
opposed to focusing on the concept being taught. Michelle made no mention of using any methods, including technology to make mathematics more meaningful for the students.

Interviewer: How do you teach mathematics to your students?

Michelle: Um, depending on the students, normally in the math classroom, the (gen-ed) teacher would, you know, present the lesson, show them how to do three or four of them on the sheet, and then it's a worksheet because math is practice.

Interviewer: How do you differentiate your instruction for your ELL students with disabilities in math?

Michelle: I just remember I generally teach in different way because I learned it differently. But at the same time I, I'm more able to go by step by step instead of saying, Oh, that's wrong. It's like, okay, do step one.... lot of it is just plain mathematical error. They either punch it into a calculator wrong or they don't know their math facts.

Interviewer: How do you help your students who are struggling with language, how do you help make that bridge? What are some strategies that you are using?

Michelle: I try taking the directions and ask them to tell me what we need to do. Okay. This says find a product. What are you doing? ... Product means you multiply. So now what do you need to do there?..

Michelle did not mentioning offering students instruction using manipulatives, visual representations, use of technology or real world examples to help students make meaning of the mathematics. When asked about using making word problems more accessible to students by using everyday language, this is what Michelle had to say:

Michelle: And there are so many different words that you don't think about being in a math problem. And I understand introducing other terminology because when you start doing things like word problem and real life problems, you don't think in terms of product and sum, and you know, you think in terms of how many of these and differences and that sort of thing.

Interviewer: So when you're given a word problem, like from a text, or from a curriculum, do you retell the word problem in more everyday language? 
Michelle: Well, a lot of them are in everyday language and I think that's part of the problem because they're expecting to see math words, and it doesn't [have any]. They're expecting to see a math problem. [I have to ask them] 'What are they asking for?' 'Why are they, you know, what are they giving you?' And I try to take out the fluff if you would.

Michelle's comments suggest that she views mathematics as procedural, and best taught with a focus on certain words, but void of mathematical context.

\section{Theme 4 - Building Culture}

The fourth theme referred to the building culture, and anything related to the expectations of the building, including overall regard for administration and peers, teacher's autonomy in teaching, statements about time, and parent relationships.

Helpful Factors-Building Culture. When speaking about administration, teachers shared the level of support that they received and whether or not they felt they had the autonomy to change their methods of teaching according to accommodate the needs of their students. Abigail had positive statements toward her administration. She believed that her administration was helpful, and allowed teachers to meet their students' needs.

Abigail: Our administrators are the best for the whole district because the junior high, they're so chill about stuff. They're like, Oh, whatever you got to do and let me know how it goes. Okay. And then we have to follow up with them...So super supportive. They give us a lot of leeway. They do not micromanage us and it's just really wonderful. So we feel like that we have a lot of creative influence in the educational process of our ELL learners.

Cheyenne specifically gave credit to her administration for her confidence in teaching content and in teaching mathematics to ELLs. She reported having unique support because her school is ESOL (English as a Second Language) certified and her principal teaches ESOL classes that are paid for by her school district. 
Cheyenne: Oh, it's an ESOL building. So most of the staff, you know, they have that endorsement, so they have that training. So my principal teaches ESL [ELL] classes and I am taking those classes with her. Um, so like I have a student that struggles, or with any student in particular. I always know I'll go talk to the principal or somebody in the building. Like my principal, she said like it doesn't matter that they're in special ed, the ELL strategies also benefit them, she says to give ESOL strategies to try.

When Cheyenne was asked if she had the autonomy to change the curriculum or lessons to meet student needs, she said, "My principal is one of those you do what you got gotta do to teach the kids, you know, you go down to their level and try to get them up, build them."

A subtheme of building culture was the help and availability of peers. All of the teachers told of the importance of peers, especially ELL teachers and bilingual paras who helped the special education teacher to teach the students. Although not all peer assistance was created equal. For some, peers were helpful to their practice. For others, better peer relationships were desired. Margaret found that having the ESL teacher was helpful for her to communicate to a student who was having behavior concerns related to not understanding the language.

Margaret: She's [A student who is ELL] Vietnamese and she isn't always is able to communicate in English for us. And so sometimes when she gets really upset, can throw a fit. I want to try and find out what's wrong and so I'll get a lady that works primarily with the ESL students, to come down and try and talk with her. I just don't think that the girl understands what's wrong. So she doesn't know how to explain it. But yeah, I can usually ask around and get some support if I need it.

Robyn felt like when it came to receiving help from the ESOL [ELL] teacher to help with vocabulary or language, the ESOL teacher was available and helpful, and offered meaningful contributions to her lessons.

Robyn: I'm right next door to our ESL teacher in the building and it's like, it's worked out good... Either I'm asking, you know, a question about like what would go on the IEP, but just like "What would you do? I'm getting ready to 
teach this lesson. What, do you have any good ideas? And there's always something that's easy to do, you know, into my lessons. It's never anything I have to go out of the way to teach. So, um, you know, she knows the students like the back of her hand and we share them. So, it makes it really easy.

Robyn specifically expressed the desire to co-teach with other ELL teachers (instead of just content teachers) by saying, "I would like to co-teach. You know, it'd be great with these schools that, got all these ESL kids to have ESL teachers to help to teach a class like that."

Abigail spoke about her relationship with the ELL teachers in providing the necessary testing accommodations for students that are shared. She said she had a close relationship with the ELL teachers in the building and that they give her support when she needs it.

Abigail: They [ELL teachers] let me know just how far I need to go with the kids as far as interpreting. The district has hired more teachers. They give targeted help to our students. They teach us strategies, and give targeted help. We work together closely.

Abigail seemed somewhat satisfied with her relationship with the ELL teachers in the building.

Harmful Factors- Building Culture. Harmful factors related to building culture included not having supportive administration, autonomy to change their teaching or desireable peer relationships. Additionally, teachers also lamented their frustration with teaching expectations and time constraints. Lastly, teachers found relationships with the parents of ELLs with disabilities to be a barrier to their practice.

Margaret explained that her administration did not understand what her needs were, however, she believed that they would be responsive if she needed them.

Margaret: They do what's called a walk-through once a week and pretty much that's the only time we see them. But if I would need something, they would make 
sure that I got it. But as far as the challenges that we face each and every day, I don't think they realize what happens in there.

Margaret believed that the administration was doing their best to be supportive to her, but did not understand special education or how to support her as a teacher. She had a student who had significant learning and behavioral concerns, and felt that administration was not helpful in finding solutions.

Michelle discussed her administrators in more negative terms. Michelle did not believe that she had the autonomy to do what was necessary when it came to teaching the students. When asked about the support of the administrators, Michelle talked about both her special education coordinator and her principal.

Michelle: Um, and in the last year we've gotten a very, a more aggressive process coordinator who's who I answer to... Well, we have a brand new principal this year...and um, I don't think he's going to do anything to rock any boats coming from central office, and central office is the one that pushes new curriculum.

Michelle added that she did not believe that she had the permission from her adminstrators to change the curriculum or to use more innovative methods to teach her students. Whereas Amanda, reported that her administration does not allow her to have teacher autonomy in teaching her students.

Amanda- We adopted new math curriculum this year and so my administration has been very heavily persuaded to have all of us use that curriculum and only that curriculum this year... Every year we have to come up with a passion project that we do on our own. And mine was going to be doing some research with mathematics and finding ways to help kids who have been kept back. And she would not allow that because of the new math curriculum adoption.... And that has been frustrating for me because I have some things that I've done that have been very effective. 
Michelle did not seem to have a favorable relationship with the ESOL teacher in the building. They do not have a close relationship, and she did not seem to believe that her assistance was helpful.

Michelle-Instead of giving us information, which she would occasionally send us a link for an e-magazine article that no one has time to read or, or she would send out the IEP saying you've got to give them this. And they'd have almost every accommodation marked on it.

For Amanda, the ELL teachers in her building also worked with her students on language, but not math particularly. She reported feeling isolated in trying to help her students make the most meaning in mathematics saying, "Um, the ESL person does pull the kids, but she works on language, you know, a variety of language things, but not really math. And so, I've just kinda been on my own to figuring out what works."

Many of the participants discussed wanting to work with paras who spoke the language of their ELLs, and brought up the idea of co-teaching with ELL teachers. For example, Margaret said, "I would love to have paras that speak the students' native tongue and, uh, maybe be able to communicate in their native tongue so that when they have a question, they feel more comfortable to ask me."

Although Cheyenne worked at a school with a high ELL population - and her principal offers classes for certification - her exposure to ELL teachers is not what she would prefer. She also expressed interest in working along-side the ELL teachers because she feels isolated in her own classroom.

Interviewer: Do you ever get to work along-side the ESOL teacher?

Cheyenne: No, not like I would like to, though. Um, I will tell you in my room it's, I mean, in my own little world, I have, you know, anywhere from autism to multi-functioning. You know, kids who are low academically to ESOL. I have a gamut. I just have different disabilities in my room, so I don't ever really 
get out of my room much...In a perfect situation for ELLs with disabilities- just have adults in the classroom to help out, more hands-on curriculum wise.

Though not explicitly asked about, every teacher with the exception of Michelle mentioned the concept of time. This concept of time was viewed as a desire-able resource. However, each teacher mentioned frustration at not having enough time to prepare, and to teach the concepts the way that they wanted to. Some expressed irritation at being expected to do so much in such little time, such as complete paperwork, and teach to students with various learning needs. One example is in how Margaret (low selfefficacy in mathematics) mentioned feeling overwhelmed by special education paperwork.

Interviewer: What are some of your challenges?

Margaret: Well, just having, it just seems like I never have enough time...You know, and all the paperwork is just insane, you know? Um, I guess I just feel overwhelmed and I don't feel like they're getting the best.

Robyn had conflicting feelings about time as a resource. She expressed appreciation in the use of time in special education by saying, "That's what's nice about special ed. You know, I can say, Oh, we need more, we need more time. I'm not going to just fly ahead like the general class.”

But later, when she was asked about what a perfect learning situation for her students would be, she expressed her desire to have more time to teach.

Interviewer- if you could design the perfect situation for you to teach these students in math, what would it look like?

Robyn: I would design it where I would have more time to teach. I always feel it's a, it's a crunch. By the time the kids get here to go over the past lesson and teach a new lesson. So, I would like to increase it by, an ideal time would be in 45 minutes instead of half an hour. But I want, you know, the time, the time 
is always a component its always a factor but I always feel very rushed and it would be nice if I could slow it down a little bit.

Both Amanda and Cheyenne, desired additional time to plan activities and find resources to teach their students.

Amanda: I teach so many things and so many kids. I have almost 6,000 minutes of services I provide every week. So it's just very difficult for me to sit down with the books and hunt out certain problems and go make copies of those. You know what I mean? ...Ideal support for Ells with disabilities would include definitely trying to make it to where there would be more time for mathematics in the special ed teachers' pocket.

Interviewer: What would be the perfect situation for teaching mathematics to ELLs with disabilities?

Cheyenne: I know for me, for the preparation more time just to plan strategies, and um, there's things you know made, and to find the picture to help them understand.

Parent relationships refer to the types of relationships that teachers reported having with the parents of students who are ELLs with disabilities. This included parent involvement in IEP meetings, parent teacher conferences and other school functions, as well as overall communication and cultural concerns. Each teacher spoke of specific frustrations in communicating with parents, encouraging parental involvement and even cultural misunderstandings between what is expected at school, and what parents expect.

Robyn spoke about her difficulty in communicating with parents regarding their child's progress in mathematics.

Robyn: For example, I just had a meeting today, IEP meeting, transition for my Mandarin Chinese boy. Mom and dad do not speak English. The student does not speak Chinese. So it's very, it's a very tough situation. So I have a hard time getting them to understand what he needs to work on [in mathematics]. You know, there's just some breakdowns in communication. 
Robyn further added that even with the interpreter there words used on the IEP that are difficult to translate to Chinese, and the child's mother spent a great deal of time on small aspects of the IEP that she does not understand.

Michelle reported that parent involvement was good for some students but not for others. The reasons that she reported poor parent/teacher relationships and involvement was because of the language concerns, illegal status of parents and cultural mismatches between the values of school, and the values of the parents.

Michelle: I think a lot of them, we will get some families who are very supportive, very helpful. They'll do what you want. A lot of them just, I can't hardly get them to come to meetings...I think the parents that the parents don't speak English, we have a lot of them who are here illegally, so they do not want to get in the middle of anything. And with many of them that where they have found jobs, they don't necessarily think education is that important.

Abigail reported similar feelings as Michelle. She agreed with Michelle that parents do not come to school because they are trying not to draw attention to their status. However, Abigail differered from Michelle in saying that peers help us communicate with parents, and for her students, parents are mostly responsive. This is especially true for behavioral concerns.

Amanda expressed concern for her inability to communicate with parents and the hardships that parents had.

Amanda: Sometimes it's overwhelming to them or the parents will cry during an IEP meeting saying they just don't understand what we're saying and they, they feel like what we're saying is that about the child or something and they just, they just want to understand that they can't. And it's really, really hard because [IEP's] are full of those technical terms, you know? And it's so hard to break that down. A lot of our words are not even in their language.

Amanda also agreed with Michelle in saying that it seems as if education is not a real priority for some parents, and that she struggled to get them to come to school at all. 
Cheyenne had similar challenges with communicating with parents, but she mentioned two ideas that helped her. These two ideas were (1) she had relatively easier access to peers in the building who helped her communicate with parents, and (2) she found that her relationship with her students mitigated the challenge of not having a strong relationship with the students' parents.

Cheyenne: There's a big, big gap of communication. Um, usually there's somebody in school that speaks Spanish. There's several people who speak Spanish. So, if I need to contact the parents, I usually go through one of them...Um, I do feel like relationship building is, is like the most important thing with, with my kiddos and my parents. And so I don't necessarily know a lot of my ESOL parents, but I do have a really strong relationship with their child. And I think that when parents realize that how much you care about the child and know this about you, that changes their view on you. But also the kids, once they, you know, they got to know they care and they're going to perform a little bit better.

Five of the six teachers mentioned difficulty in communicating with parents. Some used other bilingual people, such as ELL teachers, or district interpreters to communicate with parents. However, even when words were translated for parents, there were still some parents who did not understand special education or the expectations that teachers had for their child.

Although some teachers regarded their administration favorably, others spoke about their administration in more negative terms, including feeling isolated by administration and having lower levels of autonomy in teaching. Half of the teachers felt somewhat satisfied with their working relationships with peers who could assist them in teaching the students, including giving the teachers access to the students' home language. However, the other half of teachers reported desiring better working relationships with peers, particularly the ELL teachers in the building. Interestingly, the idea of co-teaching with the ELL teacher was shared by more than one teacher. Every 
teacher mentioned time as a barrier to their self-efficacy in teaching mathematics to ELLs with disabilities. For five out of six teachers, parent relationships also seemed to be a barrier to their practice due to communication and cultural mismatches between the parent and teacher.

\section{Theme 5- Overall Teacher Disposition}

Overall, teacher disposition refers to statements that the teacher made about their opinion toward ELLs with disabilities, mathematics, or any other aspect of their job as it relates to these students. Teacher disposition included statements that attended to teacher empathy and overall positive and negative regard for the students.

Helpful Factors- Empathy and Positive Regard. Empathy and positive regard for students is a quality that teachers demonstrated by making comments that showed that they cared about their students as people, and were genuinely concerned about their future. Some teachers made comments that demonstrated their concern for their students beyond helping students learn the intended curriculum. Others were concerned only about whether students made progress now. One teacher had nothing positive to say about students at all. In considering empathy for the students, five teachers, with the exception of Michelle, made statements that addressed the care that they had for their students.

Margaret, expressed a desire to do a better job meeting the needs of her students.

Margaret: I just try and um, make sure that they understand and encourage them to ask questions whenever they don't understand something. If I see one other struggling or something, I'll go up and say, "Okay, what's wrong? What can we do to help?" And a lot of times they'll say, I just don't get it. And I'd say, "okay, let's work on this together" because I want to give him so much more and I, I want to be able to meet every single possible need, you know.

Also, Robyn demonstrated her empathy for her students with this quote: 
Robyn: Um, I think sometimes as teachers we don't, don't always stop and say, do you really understand this? Are you getting it? If you don't, please let me know. Cause I think sometimes they just don't sit there and not saying anything cause they might be embarrassed. And you know [thinking], "I should know this".

Both Margaret and Robyn demonstrated a concern for helping their students to learn the content at hand. They seemed genuinely concerned about meeting their students' needs and were thoughtful to check in with their students to ask about their level of understanding.

Examples of teachers' statements relating to issues of empathy for their students attended to more than just improving instruction for the students for today, but rather to the bigger picture of the students' lives and ideas about solutions that may help. For example, Amanda suggested more targeted interventions in mathematics for ELLs with disabilities in the earlier grades (K-2) considering their outcomes in fourth grade.

Amanda: We have fourth graders who don't care, who are going to drop out because they've been enraged. They've had failure after failure. They've not had any success and they're done. And that's still dangerous because those kids are going to have poor outcomes for their life. You know, a lot more likely to be in poverty, to have children without being married and have a life of poverty for them and just perpetuate the poverty that they've already experienced. So, I think if we could dedicate more time and resources to the kids in those three grades (K-2) we could really help them have success. And success breeds success. And that's so important.

These statements reflect the notion that Amanda was aware of the challenges that these students face in the classroom, and she desired to provide the best level of education possible for these students. Her statement also reflects that she believed that ELLs with disabilities could be successful with the right support. Similarly, when speaking about the students, Abigail had clear high regard for the students. She believed that it was important to set high expectations for students and encourage the students with each step. 
Abigail: Just all students regardless of their color, ability level, where they're from, what language they speak, and we have to be open to everything and we have to be accepting of them where they're at. Okay. We have to set expectations very high. All right. We can't lower expectations just because they don't speak our native language. That doesn't mean that they don't understand what we're talking about because we can't understand them. So set the set the standard and enforce the standard and then understand what their disability is, and their ability and level is, that they're capable of and always praise, praise, praise, praise, praise, praise. I mean, little accomplishments in our mind are huge accomplishments in theirs.

Abigail demonstrated a high expectations for her students. Whereas Cheyenne considered the role of teachers and staff when working with ELLs with disabilities, and considered the need for the adults in the building to treat ELLs with disabilities with empathy.

Cheyenne: In a perfect situation for Ells with disabilities- I can't imagine not understanding being in a country where you don't understand people. I think that would be highly scary. Um, but for the staff ... being mindful to have a little bit more empathy and be empathetic to that.

Harmful Factors- Negative regard for students. Fortunately, out of the teachers interviewed, only Michelle demonstrated relatively low regard for teaching mathematics to students who are ELLs with disabilities.

Michelle - There's some, I want to slap them because they're sitting there counting on their fingers versus knowing any, you know, not having any math knowledge to begin with.

Michelle seemed to be frustrated with the level of mathematics knowledge that her students had. She did not give any statements connected to checking in with her students to better understand their learning needs. Michelle also did not express any desire to be a good teacher in mathematics to ELLs with disabilities, nor did she mention caring about their futures. Though Michelle is only one teacher, it is worth mentioning because teacher disposition could potentially be an impacting factor on teacher self-efficacy and on the practice of teachers who teach mathematics to ELLs with disabilities. 


\section{Theme 6 -Culturally Responsive Pedagogy}

Culturally responsive pedagogy refers to the awareness of the teacher to understand the cultural and linguistic needs of the students that attend to the identities of their students who were ELLs with disabilities. This attention could be in adding content to the curriculum that reflected the home, cultural and the linguistic needs of the students, including bringing aspects of the students' home culture into the classroom. This is considered helpful because students may have cultural and linguistic mismatches to the curriculum and teaching methods used. In teaching mathematics to ELLs with disabilities, it is considered a helpful factor to both acknowledge the existance of these mismatches exist and a need to build off of student knowledge from their home and language in order to help students make meaning. When considering factors that were helpful or harmful, although cultural and linguistic responsiveness is considered helpful, none of the teachers spoke of actually using culturally and linguistically responsive methods of teaching. However, some teachers had a stronger awareness of the need to incorporate these tenets than others.

\section{Helpful Factors - Cultural and linguistic Responsiveness awareness. Two}

teachers were deeply reflective of their teaching practice and had a strong awareness of how the curriculum and manners of teaching were not meeting the needs of their students. This deep awareness and desire to teaching using methods and curriculum more pertinent to the students was considered a helpful step in creating a culturally and linguistically responsive atmosphere.

Amanda: I wish that there are not just names of students from other nationalities, but also pictures of students from other nationalities in the book so that the kids could see kids that look like themselves in their math book. They're real great 
about putting weird names that we can't say in a word problem, but they don't show pictures of those kids. Well, I think if, you know, they can look in the book and see themselves, I think that would really help.

Cheyenne: I just think that it's important that we build into relationships, we understand their culture and I think its kind of fun to learn about different cultures. Myself, I'm always asking them things.

The two teachers also mentioned needing to be better informed about how to teach their students. Cheyenne, when asked about an ideal situation for teaching ELLs with disabilities, said it is important that teachers understand the cultural differences that students have and that they need to be prepared to understand how students may perceive information that Americans typically take for granted. She then added the following statement.

Cheyenne: That's where you [researchers] gotta prepare us, teach the teachers language too and you have to have teachers willing to attune to their needs and understanding their culture because I think that would be your biggest obstacle....But incorporating some of the cultures in the building into the curriculum. And I think the curriculum is getting better at some of that stuff, but I still think it has a long way to go.

\section{Harmful Factors-Lack of teaching in a culturally or linguistically responsive}

manner. Two teachers, Margaret and Robyn when asked if they have ever changed the context of their curriculum to include a question that draws from the students' experience, had ever tried this. Robyn acknowledged that the curriculum may be a mismatch for ELLs with disabilities, yet she did not offer any culturally and linguistic responsive practices within her teaching to her students. When speaking about her concern about the cultural mismatch between the school curriculum and the ELLs with disabilities that she serves, she said the following quote:

Robyn: Um, because a lot of times I'm just assuming they know what these words mean and they understand it, but they don't always, and they don't always tell me 
that they don't understand it or you know, they don't have that background knowledge. You know, like any of us would from living here all the time. And I know these things happen and especially when it comes to things like holidays, um, you know, that kind of different background knowledge for the kind of things that we would celebrate here.

Robyn understood that ELLs with disabilities may not have the background knowledge of common holidays that are typically celebrated in the United States. However, she did not change her teaching to accommodate for the cultural and linguistic mismatch in the curriculum.

Interviewer: Have you ever like changed the context of word problems, you know, like you said you had students from Palestine or China, China, you ever like changed the word problem and used a Palestinian or Chinese context?

Robyn:I have not done that. A lot of them have that built in. They have a lot of names that are from some other languages. I'm going to Pull one of these out and see, I can find one of the reasoning questions. Actually, [pause] no, they don't use a whole lot of names.

Overall, with the exception of Michelle, the teachers had positive regard for their students. Some teachers centered more of their comments only around helping students with learning content. However other teachers made comments that spoke to the bigger picture of the students' school experience including making recommendations for targeted early interventions specifically in mathematics for ELLs with disabilities, breaking patterns of school failure, and in developing staff to be more empathetic to student needs.

\section{Theme 7- Teacher Expectations of Student Outcomes}

Survey data showed that teachers tend to have higher outcome expectations for ELLs with disabilities as compared to other students with disabilities. To better understand the expectations that teachers had for their ELL students in mathematics, in 
the interviews, teachers were specifically asked what their expectations were for their students in terms of achievement, motivation, and engagement.

\section{Helpful Factors-High Expectations in mathematics for ELLs with}

disabilities. Five out of six teachers expressed believing their ELL students with disabilities would have the same or higher outcomes than students with disabilities in mathematics outcomes, engagement and motivation. For example, Margaret believed that her ELL students would have the same motivation and engagement in mathematics as compared to her other students with disabilities.

Interviewer: So, back to teaching math with your English language learners. Do you notice any difference in their motivation or engagement in compared to your other students?

Margaret: Um, no. They seem very, very interested. In fact, maybe, for the most part, they're more interested and they want to learn even more...I think a lot of them, because of the ESOL that they've had in the past, they're going to probably be able to do at least as well, if not better than some of the other ones.

Interviewer: Can you talk to me a little bit more about why you believe that?

Margaret: Well, because like I said, I have one young man that will be graduating next year and he does so well in math.

Robyn, Michelle, Amanda and Cheyenne all shared that they believed that their ELLs

with disabilities should have the same or higher outcomes as other students with

disabilities because they have higher motivation and engagement.

Robyn: I have that Hispanic boy, I have the Chinese boy and I have the Palestinian boy and they're all very engaged in that [mathematics]. And I would say, they're more engaged in math than they are in anything else. So even if they're not focused on the other subjects, they are for some reason in math. It's very interesting.... that's their strength for all three of them.

Amanda made it clear that she sees her students on an individual basis, and could not give a definite opinion about the achievement of ELLs with disabilities, but then she 
settled on saying that she believes that engagement is the same for her ELLs with disabilities.

Amanda- And so I try to hold each child to the highest potential that they have individually. But I can't expect them to all perform the same because they're not able, you know, able to perform the same, I wouldn't be helping them. I hope that answers your question... I think their engagements are about the same.

\section{Harmful Factors- Special education teachers deferring mathematics teaching}

to other teachers. A potentially harmful aspect of students expectations could be the possible over-reliance on other teachers in the building to provide mathematics instruction. This is evidenced by Abigail's quote, where Abigail explains that students with disabilities should have higher outcomes because the ELL teacher works with the general education teacher.

Interviewer: Do you expect them to have the same level of outcomes as other students who may be have a similar disability?

Abigail: Yeah, absolutely. I do because our ELL teacher works really closely with the content teachers and actually all teachers, not just the content teachers, not just the four core content teachers.

Abigail expects the students to have higher outcomes because of the work of the ELL teacher and the general education teacher. It is unknown how much credit that Abigail gives herself in teaching mathematics to her ELLs with disabilities. Cheyenne mentions that she has higher expectations for students who are mainstreamed into the regular classroom.

Cheyenne: I have the same expectation...I think that of the ELL population, sometimes the students I have in my classroom, um, actually don't understand a lot. So you notice that whole language barrier... but you have the kids that are called into the regular classroom and I expect them to perform higher.. getting better. 
When she says the last two words of this quote, "getting better", it raises a question about how she views her ELLs with disabilities' performance in her own classroom. It is unknown how much ownership Cheyenne takes for the mathematics learning of her students.

Five out of six teachers expressed a belief that ELLs with disabilitities could have the same or higher outcomes as other students with disabilities in terms of learning outcomes, achievement and motivation. However, it is unknown how much ownership the special education teachers take for their own teaching when instructing ELLs with disabilities as the statements of teachers may mean that they defer to the ELL teacher or the general education teacher. This reliance on both the ELL teacher and the general education teacher may be good if the special education teacher believes there is a shared ownership of student learning between themselves and the other teachers. However, this deference to others could be harmful if the special education teacher feels as though they are isolated from the other teachers and have limited influence on student outcomes.

\section{Table 10}

Summary of factors that were helpful or harmful to teachers' practice

\begin{tabular}{|lll|}
\hline & Helpful & Harmful \\
\hline Teacher background & Those who had more & All teachers reported not \\
professional training- either & having any university \\
at the university or & classes relating to ELLs \\
professional development & with disabilities. Many did \\
& in special education, & not feel prepared to teach \\
mathematics or ELLs had & these students in \\
& higher self-efficacy. & mathematics.
\end{tabular}




\begin{tabular}{|c|c|c|}
\hline Student characteristics & $\begin{array}{l}\text { Students who seemed } \\
\text { engaged in the topic of } \\
\text { mathematics. }\end{array}$ & $\begin{array}{l}\text { Barriers in language, } \\
\text { vocabulary and culture. } \\
\text { Disability related } \\
\text { characteristics such as } \\
\text { working memory concerns } \\
\text { or behavior. Confusion } \\
\text { about language and } \\
\text { learning problems. }\end{array}$ \\
\hline Teaching Pedagogy & $\begin{array}{l}\text { Teaching in a variety of } \\
\text { ways, including bringing in } \\
\text { real -life objects and using } \\
\text { technology to make } \\
\text { mathematics meaningful. }\end{array}$ & $\begin{array}{l}\text { Teaching with a limited } \\
\text { amount of methods, or not } \\
\text { adding any information } \\
\text { beyond the intended } \\
\text { curriculum. }\end{array}$ \\
\hline Building Culture & $\begin{array}{l}\text { Supportive administration, } \\
\text { supportive and available } \\
\text { peers to ask for help, } \\
\text { supportive and available } \\
\text { parents. }\end{array}$ & $\begin{array}{l}\text { Non-supportive } \\
\text { administration. Little or no } \\
\text { help from peers- especially } \\
\text { ELL professionals. Little or } \\
\text { no parent involvement. }\end{array}$ \\
\hline Overall teacher disposition & $\begin{array}{l}\text { Positive regard for ELLs } \\
\text { with disabilities, and } \\
\text { willingness to try new ideas } \\
\text { to support student learning. }\end{array}$ & $\begin{array}{l}\text { Negative regard for ELLs } \\
\text { with disabilities, and a lack } \\
\text { of attention to their learning } \\
\text { needs. }\end{array}$ \\
\hline $\begin{array}{l}\text { Culturally and linguistic } \\
\text { Responsiveness }\end{array}$ & $\begin{array}{l}\text { Awareness of the mismatch } \\
\text { between school curriculum } \\
\text { and home culture. Desire } \\
\text { for students to see } \\
\text { themselves in the } \\
\text { curriculum. Desire to build } \\
\text { relationships with students } \\
\text { to learn about their culture. }\end{array}$ & $\begin{array}{l}\text { Lack of attention to student } \\
\text { cultural and linguistic needs } \\
\text { while teaching } \\
\text { mathematics. No attempt to } \\
\text { use contexts from the } \\
\text { students'home culture in } \\
\text { mathematics problems. No } \\
\text { mention of using the } \\
\text { students'home language in } \\
\text { the classroom. }\end{array}$ \\
\hline $\begin{array}{l}\text { Factors that impact view of } \\
\text { student outcomes }\end{array}$ & $\begin{array}{l}\text { Teachers believe that ELLs } \\
\text { with disabilities can } \\
\text { achieve the same or higher } \\
\text { outcomes as other students } \\
\text { because of the support that } \\
\text { they have. }\end{array}$ & $\begin{array}{l}\text { Teachers may not be taking } \\
\text { ownership of student } \\
\text { outcomes- but rather } \\
\text { deferring to the ELL or } \\
\text { general education teachers. }\end{array}$ \\
\hline
\end{tabular}




\section{Chapter 5}

\section{DISCUSSION}

The purposes of this study was to investigate special education teacher's selfefficacy to teach mathematics to students ELLs with disabilities, and to identify helpful or harmful factors that impact teacher practice that may be influential in teaching mathematics to ELLs with disabilities. This chapter includes a discussion of the major findings related to the literature on the self-efficacy of special education teachers who teach mathematics to any student with a disability as well as those who teach mathematics to ELL students who have mild/moderate disabilities, as well as the factors that impact the teaching of mathematics of ELLs with disabilities. Then, I will discuss the limitations of the study and future research opportunities and implications of the findings in relation to higher education institutions that prepare pre-service special education and K-12 administrators.

The number of ELLs with disabilities are rapidly increasing in the K-12 environment (Kena et al., 2016). However, on national assessments such as the NAEP, they have significantly lower outcomes in mathematics than those who are non-ELL and have no disabilities (de Brey et al., 2019). More than 40 years of research has associated teacher self-efficacy to student outcomes (Armor et al., 1976; Ashton \& Webb, 1986; Brookover, et al., 1979) where a positive self-efficacy is more likely to result in positive student outcomes. The first question of this study was focused on teacher self-efficacy beliefs and and outcome expectations in teaching mathematics to (a) any student with a disability, (b) ELLs with disabilities, and (c) ELLs with disabilities in a culturally and linguistically responsive manner. 
Based on the findings from this survey, three main conclusions can be drawn. First, special education teachers reported having lower self-efficacy in teaching mathematics to ELLs with disabilities than to non ELLs with disabilities. Interestingly, Ross (2014) had a similar finding with general education mathematics teachers who consistently reported lower self-efficacy in teaching mathematics to ELL students compared to non-ELL students. Ross also found that lower levels of self-efficacy in teaching students who were ELL applied to teachers at all levels of experience, not just those who are new and beginning. Although Ross' study did not focus specifically on students with disabilities, the current study suggests that special education teachers may be similar to their general education counterparts in having lower self-efficacy in teaching mathematics to ELLs with disabilities in than teaching mathematics to non-ELL students with disabilities.

Second, although the special education teachers reported having lower selfefficacy in teaching ELL students with disabilities, they had higher mathematics achievement outcome expectations for ELL students with disabilities than for students with disabilities who were not ELLs. This finding may seem confusing, however, according to Bandura (1977), self-efficacy in being able to produce an action is not the same as the belief that those actions will affect outcomes. These two constructs (selfefficacy and outcome expectations) are not predictive of each other; however, it does not mean that outcome expectations do not influence behavior. To explain, what a person expects regarding outcomes is about their locus of control, or the type of control that a person has over a situation (Bandura, 1997). According to Bandura (1997), a person's locus of control is polarized into either internal or external control. Internal control means 
they feel as though they have ownership of what happens next, whereas external control means that the results of an outcome are apart from their influence. For a person with a low self-efficacy but high outcome expectancy, as in this study, it is possible that they may devalue their role in a situation and feel discouraged in their tasks, even though they expect higher outcomes (Bandura, 1997).

The interview data in this study may give more information about why the teachers rated themselves as having lower self-efficacy but as having higher mathematics outcome expectations for ELLs with disabilities. Five teachers in the interviews reported that they expected their ELLs with disabilities to perform at the same or better level than their peers in mathematics, not only in achievement, but also in engagement and motivation. The reasons teachers gave were because the students had access to more teachers in the building, such as the general education teachers and ELL teachers, who were there to help develop language and vocabulary skills. Therefore, with the extra support, the teachers believed that in mathematics, ELLs with disabilities should perform as good, or better than other students with disabilities. It is possible that the special education teachers believed that their control of student outcomes was external, meaning they believed that students excelled in mathematics because of the extra support provided by other teachers, but not necessarily by the special education teacher themselves.

Third, the special education teachers rated themselves as having lower selfefficacy in teaching mathematics to ELLs with disabilities in a culturally and linguistically responsive manner than on any other factor. Examples of the questions on the survey that attended to this latent variable included (a) In mathematics, I am able to use various types of assessments that are matched to English Language Learners' 
language proficiency; (b) In Mathematics, I am able to critically examine the curriculum to determine whether it appropriately represents people from different linguistic/ cultural backgrounds; and (c) In mathematics, I am able to use culturally specific context to make mathematics meaningful. This suggests that although teachers felt more comfortable teaching mathematics to ELL students with disabilities, they had difficulty doing this in a culturally and linguistically responsive manner. During the interviews, some teachers demonstrated an awareness of the need for students to see themselves in the curriculum. Additionally, teachers spoke about the use of certain names in word problems, holidays and had knowledge of cultural mismatches in communication, particularly with eye contact. However, none of the teachers mentioned using the students' home context, or intentionally allowing students to use their home language in the classroom.

The attention given to the cultural responsiveness of their students in mentioning the use of names and holidays is similar to findings of Malo-Juvera, Correll, and Cantrell, (2018) who found that many teachers are not familiar with what cultural and linguistically responsive teaching is. Similarly, Malo-Juvera, Correll and Cantrell used the Culturally Responsive Teaching Self-Efficacy scale (CRSTE) — the same measure used to create the ELL Responsive measure in this study — and found in their study that the majority of in-service elementary school teachers had low self-efficacy in implementing culturally and responsive teaching and specifically scored low on questions that attended to using cultural connection in content areas and in the ability to identify bias in the curriculum against culturally and linguistically diverse students. The findings of the current study support that this is also true of special education teachers who teach mathematics to ELL students. 
The second research question focused on identifying factors that were considered helpful or harmful to the teachers for teaching mathematics to ELLs with disabilities. Two main conclusions can be drawn from the results. First, teachers with more training in terms of certifications and degrees had better teaching methods and used more tools to teach mathematics to ELLs with disabilities. Second, building culture is important.

First, in the interviews, there seemed to be a connection between those who had more mathematics training either from their preservice training (multiple certifications which included general education or TESOL certifications) or in-service professional development tended to use more varied teaching methods, such as manipulatives, pictures and technology to help students understand the language and vocabulary of mathematics. Not only did these teachers teach mathematics to ELLs with disabilities by using more strategies, but they were also concerned with bigger picture of the students' lives, such as what would be important after students leave high school. Their teaching methods are important because ELLs with disabilities belong to a vulnerable group of students who are most impacted by the level of training and strategies that teachers use (Paneque $\&$ Barbetta, 2006). Findings from this study may support high quality preservice and inservice professional development for special education teachers in content training in mathematics, as well as working with ELLs with disabilies.

Second, building culture is important, and included relationships with administrators, peers and parents. Teachers desired to have administration that understood their needs, more time and better peer relationships with other teachersparticularly the ELL teachers in their buildings. Parent relationships were a strongly agreed upon to be a barrier to teaching mathematics to ELL students with disabilities. 
This highlights an ongoing need in the field for professional development that focuses on teaching special education teachers how to teach mathematics to ELLs with disabilities in a more culturally and linguistically responsive manner.

The impact of administrators on teacher self-efficacy is important (Skaalvik \& Skaalvik, 2010) because teachers who feel as though they have administrative support and could do what-ever it took to teach their students, had better self-efficacy in teaching their students. In the interview portion of this study, half of the teachers reported favorable administration support and autonomy to teach their students in a meaningful way. Others lamented frustration at having administration that either does not understand the needs related to teaching mathematics to ELLs with disabilities, or not having teacher autonomy to change the curriculum or their teaching methods to meet student needs.

Similarly, teachers seemed grateful for peer support, particularly ELL teachers and general education teachers. This support was viewed as helpful. However, the special education teachers seemed to defer to the ELL teacher or general education teacher for reasons to support why ELLs with disabilities should have the same or equal outcome expectations in mathematics as other students with disabilities. This deference to other teachers for the outcomes of their students may support what Bandura (1997) says about teachers who have low self-efficacy but high student outcome expectations - their locus of control may reside in external forces such as other teachers. Bandura (1997) also mentions that models (meaning people who perform a task for others to view) favorably impact self-efficacy. In other words, one's self-efficacy toward a task can be improved by watching someone else perform the task successfully. This supports the idea that special education teachers should work more closely with ELL teachers, in addition to the 
general education teachers that many of them are already working with. In this study expressed a desire to co-teach with ELL teachers, or work more closely together with them in order to better meet student needs. As most research around co-teaching in special education centers around partnerships between special education and general education (Friend, Cook, Hurley-Chamberlain, \& Shamberger, 2010; Hackett, Bang, Goulter, \& Battista, 2019; Kirkpatrick, Searle, Smyth, \& Specht, 2020), the effectiveness of special education and ELL teachers co-teaching is an area of further research.

All of the teachers identified relationships with parents and the community of the students as barriers in teaching mathematics to ELLs with disabilities. The teachers reported several barriers in their relationships including parent misunderstandings at IEP meetings and lack of engagement from parents during school related activities. Most teachers reported having access to interpreters for meetings, it was mentioned that some words and concepts did not easily translate from school to home. Also, another barrier was a cultural mismatch between school expectations and the parents' expectations of what their children should be able to do in mathematics. Most of the teachers reported desiring better relationships with the students' parents, and Cheyenne — although she admittedly had poor relationships with parents — mitigated her lacking relationships with the parents of ELLs with disabilities by building positive relationships with the students.

This finding regarding difficult parent relationships is consistent with Wassell, Hawrylak, and Scantlebury (2017) who also examined the views of teachers who worked with parents of ELL students. They found similar findings which included (a) perceived lack of trust in the school system, (b) communication, and (c) cultural mismatches. A lack of parent involvement is concerning as it may lead teachers to view parents as not as 
interested in their child's schooling (Bandura, 1997). This was certainly the case in this study. Teachers attributed lack of parent involvement and poor parent relationships to lack of parental interest in school. However the over all low self-efficacy of teachers to access culturally and linguistically responsive teaching for ELLs, may also be impacting their ability to have meaningful relationships with parents as is documented the study by Barrera, Vang, Lui and Thurlow (2005).

\section{Limitations and Future Research}

Every possible step was taken to ensure the integrity of this study, including a pilot study. However, there are some limitations. These limitations include the survey response rate, survey concerns and the demographics of the interview participants.

\section{Survey Response Rate}

The first limitation of this study is the response rate. The survey was sent to 4696 teachers and 134 administrators (administrators were given directions to send the survey on to their teachers). After accounting for undeliverable electronic mail messages, and teachers who responded saying that they did not meet the criterion, 3993 are assumed to be have been eligible to respond. Two hundred and five teachers attempted to take the survey. From 3993 who may have been eligible and the 205 who attempted to take the survey, I have calculated the response rate as $5 \%$. One hundred seventeen of those teachers supplied enough data to be used in the analyses. It is important to note that the target participants for this study were special education teachers, who teach mathematics to ELLs with disabilities and, therefore, a niche population. Researchers who survey teachers who teach mathematics to ELLs with disabilities should consider a more 
strategic approach to obtaining participants, such as limiting their study to one school district, or to preservice teachers in one institution to obtain a better response rate.

\section{Survey Concerns}

The survey did have statistical concerns, in particular, the Cronbach's alpha used in the CFA model of the total MTEBI was .67, and MTEBI Cronbach's alpha outcome variable was .62, which is less than optimal ( George \& Mallery, 2003). Another statistical concern is the skewness of the distribution of the scores on the MTEBI-selfefficacy variable. According to the Shapiro-Wilks test, normality was violated In T-test comparisons between MTEBI self-efficacy and ELL Responsive self-efficacy as well as MTEBI self-effiacy and MTEBI-outcome variables. Although this violation was corrected by using Wilcoxon T-tests, caution should be used when interpreting these findings.

Future researchers should consider replicating this study with other populations, such as preservice teachers who teach mathematics ELLs with disabilities in field placements. Or future researchers may wish to use either survey in this study to create other measures, perhaps to investigate the impact of professional development on special education teacher self-efficacy in teaching mathematics to ELLs with disabilities.

\section{Interview participants}

Lastly, the participants who participated in the qualitative portion of this study were all white, mono-lingual females from two mid-western states. These teachers readily admitted their limitations in teaching mathematics to ELLs with disabilities. Qualitative findings may have been different if the teachers had been culturally and linguistically diverse, different genders or from other regions of the United States. Future 
researchers should consider interviewing special education teachers who teach mathematics to ELLs with disabilities from a purposeful sample of teachers who do not fit the majority of the United States teaching force of white, middle-class, mono-lingual females.

\section{Implications for Future Research}

This study addressed questions regarding special education teacher self-efficacy in teaching mathematics to ELLs, and the factors that impact their level of self-efficacy. However, other questions remain that other researchers should consider. Like this study, other studies such as Siwatu (2007) and Malo-Juvera et al.,(2018) found that teachers have overall lower self-efficacy in teaching ELLs. However, this study only focused on special education teachers who teach mathematics to ELLs with disabilities, future researchers should investigate how these findings compare to general education teachers who teach mathematics to ELLs with disabilities in inclusive settings. Unlike Paneque and Barbetta (2006), an area that was not investigated in this study was the predication of which demographics of teachers were most likely to have high or low self-efficacy on either survey measure. Paneque and Barbetta (2006) found that teachers who are nonwhite, and speak more than one language had higher self-efficacy teaching ELLs with disabilities in general. Perhaps the findings would be different if the assessment of selfefficacy also included mathematics. The current study was a descriptive study of teacher self-efficacy. Future researchers may want to use these survey measures to compare teacher self-efficacy in teaching mathematics to ELLs with disabilities to those students' achievement outcome measures. The findings could tell us which is more related to student achievement scores, (a) self-efficacy in teaching mathematics, or (b) self-efficacy 
in teaching mathematics to ELLs, particularly in culturally and linguistically responsive ways.

Secondary analyses from this study indicated that special education teachers tend to have higher self-efficacy in teaching mathematics to any student with a disability in comparison to their outcome expectations for students with disabilities. However, the MTEBI portion of this study did not use every question from the original study, and the reliability of this study was not as high as the original study. Researchers should replicate this study by using the entire MTEBI assessment by Enoch Smith, and Huinker (2000), with special education teachers to see if this finding occurs again. If the same finding happens again, this will support the need for a follow up study to examine why special education teachers have higher self-efficacy in teaching mathematics to students with disabilities, but lower outcome expectations for them.

\section{Implications for Teacher Preparation}

The findings in this study revealed that special education teachers reported having lower self-efficacy in teaching mathematics to ELL students with disabilities as compared to other students with disabilities and having lower self-efficacy in teaching in a culturally and linguistically responsive manner. Likewise, teachers reported not receiving any university training related to teaching mathematics to ELLs. This suggests the need for teacher preparation courses within the university setting and in-service professional development that should address teaching mathematics to students who identify both as ELL and having a disability.

At the university, preservice courses should attend to critical issues in education, including special education for culturally and linguistically diverse students, and teach in- 
service special education teachers how to work with peers who speak the language of the students, and how to learn more about the students' cultural and linguistic background. This manner of teaching includes helping preservice teachers to identify aspects of the students' home life and community and use this knowledge to empower students to use mathematics to have a say in their lives. Moreover, there should be more intentional instruction related to teaching students with disabilities who are also acquiring the English Language to have better access to learning concepts in mathematics. These strategies include the encouragement and support of the home language in the classroom (Moschkovich, 2005, 2012), language scaffolds (Orosco, 2014; Orosco, Swanson, O'Connor, \& Lussier, 2013), and using the context of the students' background in creating mathematics tasks (Orosco \& Abdulrahim, 2017).

When considering in-service teachers, there is a need for professional development that focuses on research-based methods for helping teachers support ELLs with disabilities in mathematics in the K-12 environment. The number of ELL students has drastically increased in the United States K-12 environment over the past 15 years, and is expected to continue increasing (Kena et al., 2016). For many in-service K-12 teachers, this increase has taken place while they have been teaching. From both the survey results and the teachers' own words, there is a both (a) lack of understanding, and (b) attention to cultural and linguistic responsiveness in teaching ELLs with disabilities in mathematics.

Orosco and Abdulrahim (2017b) examined the practice of one bilingual special education teacher who taught mathematics after receiving professional development that attended to teaching mathematics word problems in a culturally and linguistically 
responsive manner. The one teacher in their study had favorable results, and her students performed better after she implemented the newly learned methods. Orosco and Abdulrahim's study focused on one teacher in one school school district. The results of the current study further support the idea that more teachers could benefit from similar professional development opportunities. Additional research should investigate whether these professional development sessions have the same or different results for other teachers (who are white and mono-lingual) as it did for the Latina bilingual teacher in Orosco and Abdulrahim's (2017b) study.

\section{Implications for K-12 Administrators}

For administrators, the findings from this study suggest that teachers have low self-efficacy in teaching mathematics to students who are ELLs with disabilities, and are in need of more opportunities to work with their colleagues when planning or implementing instruction to ELL students with disabilities. Further, when considering the culture of the school building, administrators should consider how special education teachers, ELL teachers, and general education teachers can work together more strategically. More time may be needed to be provided to the teachers to plan and organize opportunities to collaborate together. This suggestion is not new. For example, Gersten and Baker (2000) found that special education teachers who teach ELL students also mentioned needing more time to teach and plan lessons.

It may be necessary for administrators to consider different types of co-teaching situations — beyond only having special education teachers co-teach with general education teachers the predominant model in special education (e.g., DeMartino \& Specht, 2018; Friend, Cook, Hurley-Chamberlain, \& Shamberger, 2010; Hackett, Bang, 
Goulter, \& Battista, 2019; Kirkpatrick, Searle, Smyth, \& Specht, 2020). Interestingly, during the interviews in this study, the special education teachers wanted to co-teach with ELL or bilingual teachers in order to both have access to the student's home language and to learn strategies in building vocabulary in order to help students make meaning.

One other important finding in this study that administrators may need to take into consideration is that the majority of the special education teachers in the qualitative portion of this study, reported having negative or absent relationships with the parents of their ELL students. This is concerning because parent involvement is related to improved student achievement (Arias and Morillo-Campbell, 2008). Arias and Morillo-Campbell, (2008) recommend to address this concern of poor parent teacher relationships by including: (a) support culturally relevant programs for parents of ELL students (e.g., programs that ask parents to lead a lesson and teach a skill or tell stories to the students, and that offer bilingual interpreters), (b) design reciprocal actions between the parents and the school and community (e.g., a community garden), (c) professional development to teachers to learn about the community of their students, and (d) use this knowledge for classroom learning and reaching out to parents. In other words, teachers should learn about the language and culture of the parents of the students that they serve and have access to intepreters when necessary. Then teachers should be encouraged to use this knowledge of culture and language to reach out to parents, and find ways to make school more accessible based upon the parents' needs, so that they can be more involved.

\section{Conclusion}

Forty years of self-efficacy research has linked teacher self-efficacy to student outcomes in not only achievement, but also in engagement and motivation. ELL students 
are increasing in the K-12 population, and the underperformance of ELL students with disabilities on national assessments (e.g., NAEP, 2017) have made it necessary to investigate special education teacher self-efficacy in teaching mathematics to ELLS with disabilities. Significant findings in this study revealed that special education teachers have significantly lower self-efficacy in teaching mathematics to students who are ELL with disabilities, than any student with a disability, and lower self-efficacy in teaching a culturally and linguistically responsive manner. However, findings also revealed that special education teachers had higher outcome expectations for ELLs with disabilities than for any student with a disability. Qualitative data added more nuance to these findings, and further revealed that teacher experience, building culture and parent relationships were all factors that were either helpful or harmful to the teachers' teaching practice in mathematics to ELLs with disabilities. This findings from this study highlight a need in the field to better educate both preservice and in-service teachers in researchbased practices to teach mathematics to ELLs with disabilities while emphasizing culturally and linguistically responsive methods of teaching. 


\section{REFERENCES}

Abedi, J. (2004) The no child left behind act and English language learners: Assessment and accountability issues. Educational Researcher, 33(1), 4-14. doi.org/10.3102/0013189X033001004

Abedi, J., \& Gándara, P. (2006). Performance of English language learners as a subgroup in large-scale assessment: Interaction of research and policy. Educational Measurement: Issues and Practice, 25(4), 36-46. https://doi.org/10.1111/j.17453992.2006.00077

Abedi, J., \& Herman, J. (2010). Assessing English language learners’ opportunities to learn mathematics: Issues and limitations. Teachers College Record, 112(3), 723746.

Allinder, R. (1994). An examination of the relationship between teacher efficacy and curriculum-based measurement and student achievement. Remedial \& Special Education, 16(4), 247-254.

Arias, M. B., Arizona S. U., \& Morillo-Campbell, M. (2008). Promoting ELL parental involvement: Challenges in contested times. Great Lakes Center for Education Research \& Practice, (480), 1-22. Retrieved from http://greatlakescenter.org/docs/Policy_Briefs/Arias_ELL.pdf\%5Cnhttp://www.grea $\underline{\text { tlakescenter.org }}$

Armor, D. J., Conry-Oseguera, P., Cox, M., King, N., McDonnell, L., Pascal, A., ... Zellman, G. (1976). Analysis of the school preferred reading program in selected Los Angeles minority schools. Los Angeles, Ca. Retrieved from http://www.rand.org/pubs/reports/R2007.html 
Aronson, B., \& Laughter, J. (2016). The theory and practice of culturally relevant education: A synthesis of research across content areas. Review of Educational Research, 86(1), 163-206. https://doi.org/10.3102/0034654315582066

Ashton, P. T., \& Webb, R. B. (1986a). Making a difference-teacher's sense of efficacy and student achievement. New York: Longman.

Bandura, A. (1986). The explanatory and predictive scope of self-efficacy theory. Journal of Social and Clinical Psychology, 4(3), 359-373.

Bandura, A. (1977). Self-efficacy: Toward a unifying theory of behavioral change. Psychological Review, 84(2), 191-215. https://doi.org/10.1037/0033-295X.84.2.191

Bandura, Albert. (1993). Perceived self-efficacy in cognitive development and functioning. Educational Psychologist. 28(2), 117-148. https://doi.org/10.1207/s15326985ep2802_3

Bandura, Albert. (1997). Self-efficacy: The exercise of self-control. W.H. Freeman and Company. https://doi.org/10.1007/SpringerReference_223312

Barrera, M., Vang, H., Lui, K., \& Thurlow, M. (2005). ELL parents perceptions on instructional strategies for their children with disabilities (ELLs with Disabilities Report 12). Minneapolis, MN.

Bates, A. B., Latham, N., \& Kim, J. (2011). Linking preservice teachers' mathematics self-efficacy and mathematics teaching efficacy to their mathematical performance. School Science and Mathematics, 111(7), 325-333. https://doi.org/10.1111/j.19498594.2011.00095.

Braun, V., \& Clarke, V. (2006). Qualitative research in psychology using thematic analysis in psychology. Qualitative Research in Psychology, 3(2), 77-101. 
http://www.tandfonline.com/action/journalInformation?journalCode=uqrp20\%5Cnh ttp://www.tandfonline.com/action/journalInformation?journalCode=uqrp20

Brookover, W., Beady, C., Flood, P., Schweitzer, J., \& Wisenbaker, J. (1979). School social systems and student achievement-schools can make a difference. New York: J.F. Bergin Publishers, Inc.

Bull, R., \& Lee, K. (2014). Executive functioning and mathematics achievement. Child Development Perspectives, 8(1), 36-41. https://doi.org/10.1111/cdep.12059

Caprara, G. V., Barbaranelli, C., Steca, P., \& Malone, P. S. (2006). Teachers' selfefficacy beliefs as determinants of job satisfaction and students' academic achievement: A study at the school level. Journal of School Psychology, 44(6), 473490. https://doi.org/10.1016/j.jsp.2006.09.001

Cardimona, K. (2018). Differentiating mathematics instruction for secondary-level English language learners in the mainstream classroom. TESOL Journal, 9(1), 1757. https://doi.org/https://doi-org.proxy.mul.missouri.edu/10.1002/tesj.303

Chu, S.Y. C., \& Garcia, S. (2014). Culturally responsive teaching efficacy beliefs of inservice special eduation teachers. Remedial \& Special Education, 35(4), 218-232. https://doi.org/10.1177/0741932513520511

Civil, M., Khan, L. H. (2001). Mathematics instruction developed from a garden theme. Teaching Children Mathematics, 7, 400-405.

Cramer, E, D., Gonzalez, L.\& Pellegrini-Lafont, C. (2014). From classmates to inmates an integrated approach to break the school to prison pipeline. Equity \& Excellence in Education, 47(5), 461-475.

Darling-Hammond, L. (2016). Research on teaching and teacher education and its 
influences on policy and practice. Educational Researcher, 45(2), 83-91. https://doi.org/10.3102/0013189x16639597

Darling-Hammond, L., Chung, R., \& Frelow, F. (2002). Variation in teacher preparation: How well do different pathways prepare teachers to teach? Journal of Teacher Education, 53(4), 286-302. https://doi.org/10.1177/0022487102053004002

de Araujo, Z., Smith, E., \& Sakow, M. (2016). Reflecting on the dialogue regarding the mathematics education of English learners. Journal of Urban Mathematics Education, 9(2), 33-48.

de Brey, C., Musu, L., McFarland, J., Wilkinson-Flicker, S., Diliberti, M., Zhang, A., ... Wang, X. (2019). Status and trends in the education of racial and ethnic groups 2018 (NCES 2019-038). Retrieved from http://eric.ed.gov/ERICWebPortal/recordDetail?accno=ED510909

DeMartino, P., \& Specht, P. (2018). Collaborative co-teaching models and specially designed instruction in secondary education: A new inclusive consultation model. Preventing School Failure, 62(4), 266-278. https://doi.org/10.1080/1045988X.2018.1446413

Diaz-Rico, L. T., \& Weed, K. Z. (2006). The crosscultural language, and academic development handbook: A complete K-12 reference guide. Boston, MA: Pearson Education.

Dinham, S. (2006). A good teacher in every classroom. Australian Journal of Education, 50 (1), 95-96. https://doi.org/10.1177/000494410605000108

Driver, M. K., \& Powell, S. R. (2017). Culturally and linguistically responsive schema intervention: Improving word problem solving for English language learners with 
mathematics difficulty. Learning Disability Quarterly, 40(1), 41-53. https://doi.org/10.1177/0731948716646730

Ekstam, U., Korhonen, J., Linnanmäki, K., \& Aunio, P. (2017). Special education preservice teachers' interest, subject knowledge, and teacher efficacy beliefs in mathematics. Teaching and Teacher Education, 63, 338-345. https://doi.org/10.1016/j.tate.2017.01.009

Ekstam, U., Korhonen, J., Linnanmäki, K., \& Aunio, P. (2018). Special education and subject teachers' self-perceived readiness to teach mathematics to low-performing middle school students. Journal of Research in Special Educational Needs, 18(1), 59-69. https://doi.org/10.1111/1471-3802.12393

Enochs, L. G., Smith, P. L., \& Huinker, D. (2000). Establishing factorial validity of the mathematics teaching efficacy beliefs instrument. School Science and Mathematics, 100(4), 194-202. https://doi.org/10.1111/j.1949-8594.2000.tb17256.x

Every Student Succeeds Act of 2015, Pub. L. No. 114-95 § 114 Stat. 1177 (2015-2016)

Faul, F., Erdfelder, E., Lang, A.-G., \& Buchner, A. (2007). G*Power 3: A flexible statistical power analysis program for the social, behavior, and biomedical sciences. Behavior Research Methods, 39(2), 175-191.

Field, A., Miles, J., \& Field, Z. (2012). Discovering Statistics Using R. London: Sage Publications Limited.

Flores, M. M., Thornton, J., Franklin, T. M., \& Hinton, V. M. (2014). Elementary general and special education teachers' mathematics skills and efficacy. Journal of Research in Education, 24(1), 69-82.

Gay, G. (2002). Preparing for culturally responsive teaching. Journal of Teacher 
Education.53(2),106-116. https://doi.org/10.1177/0022487102053002003

Geary, D.,Hoard, M., Nugent, L., \& Bailey, D. (2012). Mathematical cognition deficits in children with learning disabilities and persistent low achievement: A five-year prospective study. Journal of Educational Psychology, 104(1), 206-223. https://doi.org/10.1038/nrg3575.Systems

George, D., \& Mallery, P. (2003). SPSS for Windows step by step: A simple guide and reference. 11.0 update (4th ed.). Boston: Allyn \& Bacon. Allyn \& Bacon.

Gersten, R., \& Baker, S. K. (2000). What we know about effective instructional practices for ELLs. Exceptional Children, 66(4), 454-470.

Giles, R. M. M., Byrd, K. O., \& Bendolph, A. (2016). An investigation of elementary preservice teachers' self-efficacy for teaching mathematics. Cogent Education, 3(1). https://doi.org/10.1080/2331186X.2016.1160523

Gutiérrez, R. (2002). Beyond essentialism: The complexity of language in teaching mathematics to Latina/o students. American Educational Research Journal Winter, 39(4), 1047-1088. https://doi.org/10.3102/000283120390041047

Hackett, J., Bang, M., Goulter, A., \& Battista, M. (2019). Crossing risky boundaries: Learning to authentically and equitably co-teach through design and practice. Teaching and Teacher Education, 86, 1-20. https://doi.org/10.1016/j.tate.2019.102889

Hattie, J., \& Yates, G. C. R. (2013). Visible learning and the science of how we learn. Visible Learning and the Science of How We Learn. Routledge. https://doi.org/10.4324/9781315885025

Hinton, V., Burton, M., Flores, M., \& Curtis, R. (2015). An investigation into pre-service 
special education teachers' mathematical skills, self-efficacy, and teaching methodology. IUMPST: The Journal, 1, 1-13.

Holzberger, D., Philipp, A., \& Kunter, M. (2013). How teachers' self-efficacy is related to instructional quality: A longitudinal analysis. Journal of Educational Psychology, 105(3), 774-786. https://doi.org/10.1037/a0032198

Hoy, A. W., \& Spero, R. B. (2005). Changes in teacher efficacy during the early years of teaching: A comparison of four measures. Teaching and Teacher Education, 21(4), 343-356. https://doi.org/10.1016/j.tate.2005.01.007

Hoy, W. K., \& Woolfolk, A. E. (1990). Socialization of student teachers. American Educational Research Association, 27(2), 279-300.

Individuals with Disabilities Education Act, 20 U.S.C. § 1400 (2004)

Kena, G., Hussar, W., McFarland, J., de Brey, C., Musu-Gillette, L., Wang, X., ... Ossolinski, M. (2016). The Condition of Education - 2016. U.S. Department of Education, National Center for Education Statistics, 4-29. https://doi.org/10.1037/e492172006-019

Kim, K. R., \& Seo, E. H. (2018). The relationship between teacher efficacy and students' academic achievement: A meta-analysis. Social Behavior and Personality: An International Journal. https://doi.org/10.2224/sbp.6554

Kim, S. A., Wang, P., \& Michaels, C. A. (2015). Using explicit C-R-A instruction to teach fraction word problem solving to low-performing Asian English learners. Reading and Writing Quarterly, 31(3). https://doi.org/10.1080/10573569.2015.1030999

Kirkpatrick, L., Searle, M., Smyth, R. E., \& Specht, J. (2020). A coaching partnership: 
Resource teachers and classroom teachers teaching collaboratively in regular classrooms. British Journal of Special Education, 47(1), 24-47. https://doi.org/10.1111/1467-8578.12296

Ladson-Billings, G. (1995). But that's just good teaching! The case for culturally relevant pedagogy. Theory Into Practice, 34(3), 159-165.

Malo-Juvera, V., Correll, P., \& Cantrell, S. (2018). A mixed methods investigation of teachers' self-efficacy for culturally responsive instruction. Teaching and Teacher Education, 74, 146-156. https://doi.org/10.1016/j.tate.2018.05.003

Martiniello, M. (2008). Language and performance of English-language learners in math word problems. Harvard Educational Review, 78(2), 333-369. https://doi.org/10.2307/1510642

Martiniello, Maria. (2009). Linguistic complexity, schematic representations, and differential item functioning for English language learners in math tests. Educational Assessment, 14(3-4), 160-179. https://doi.org/10.1080/10627190903422906

McFarland, J., Hussar, deBrey, S. (2016). The condition of education. National Centre for Education Statistics, xxxi-347. https://doi.org/10.1037/e492172006-019 McLeskey, J., Barringer, M.D., Billingsley, B., Brownell, M., Jackson, D., Kennedy, M., ... Ziegler, D. (2017). High-leverage practices in special education : foundations for student success. (J. McLeskey, B. Maheady, M. T. Brownell, \& T. J. Lewis, Eds.) (1st ed.). Routledge.

Midgely, C., Anderman, E., \& Hicks, L. (1995). Differences between elementary and middle school teachers and students: A goal theory approach. Journal of Early 
Adolescence, 15(1), 90-113.

Mojavezi, A., \& Tamiz, M. P. (2012). The impact of teacher self-efficacy on the students' motivation and achievement. Theory and Practice in Language Studies, 2(3), 483-491. https://doi.org/10.4304/tpls.2.3.483-491

Moll, L. C., Amanti, C., Neff, D., \& Gonzalez, N. (1992). Funds of knowledge for teaching using a qualitative approach to connect homes and classrooms. Theory Into Practice: Qualitative Issues in Educational Research, 31(2), 132-141.

\section{https://doi.org/10.1017/S0047404500009039}

Moore, W. P., \& Esselman, M. E. (1994). Exploring the context of teacher efficacy: The role of achivement and climate. Paper Presented at the Annual Meeting of the American Educational Research Association, New Orleans.

Moschkovich, J. (2002). A situated and sociocultural perspective on bilingual mathematics learners. Mathematical Thinking and Learning, 4(2\&3), 189-212. https://doi.org/10.1207/S15327833MTL04023

Moschkovich, J. (2012). Mathematics, the core, and language: Recommendations for mathematics instruction for ELs aligned with the common core. In K. Hakuta \& M. Santos (Eds.), Understanding language: Language, Literacy, and Learning in the Content Areas (pp. 17-31). Commissioned papers on Language and Literacy Issues in the Common Core State Standards and Next Generation Science Standards. Stanford, CA: Stanford University Press.

Nasir, N. S., Hand, V., \& Taylor, E. V. (2008). Culture and mathematics in school: boundaries between "cultural" and "domain" knowledge in the mathematics classroom and beyond. Review of Research in Education. 
https://doi.org/10.3102/0091732X07308962

NCTM (2000). Principles and standards for school mathematics. Reston, VA: NCTM.

Orosco, M. (2014). Word problem strategy for Latino English language learners at risk for math disabilities. Learning Disability Quarterly, 37(1), 45-53. https://doi.org/10.1177/0731948713504206

Orosco, M. J., Swanson, H. L., O’Connor, R., \& Lussier, C. (2013). The effects of dynamic strategic math on English language Learners' word problem solving. Journal of Special Education, 47(2), 96-107. https://doi.org/10.1177/0022466911416248

Orosco, M. J. (2014). A math intervention for third grade Latino English language learners at risk for math disabilities. Exceptionality. https://doi.org/10.1080/09362835.2013.865535

Orosco, M. J., Swanson, H. L., O’Connor, R., \& Lussier, C. (2013). The effects of dynamic strategic math on English language learners' word problem solving. Journal of Special Education, 47(2), 96-107. https://doi.org/10.1177/0022466911416248

Orosco, M. J., \& Abdulrahim, N. A. (2017)a. Culturally responsive evidence-based practices with English language learners with learning disabilities: A qualitative case study. Educational Borderlands, 1, 27-45.

Orosco, M. J.,\& Adulrahim, N.A. (2017)b. Culturally responsive professional development for one special education teacher of Latino English language learners with mathematics learning disabilities. Insights into Learning Disabilities 14(1), 7395. 
Paneque, O., \& Barbetta, P. (2006). A study of teacher efficacy of special education teachers of English language learners with disabilities. Bilingual Research Journal, 30(1), 173-193. https://doi.org/DOI: 10.1080/15235882.2006.10162871

Paneque, O. M. (2004). Teacher efficacy of special education teachers of English Language Learners with disabilities. Dissertation Abstracts International Section A: Humanities and Social Sciences, 65(4-A), 1319. Retrieved from http://ezproxy.lib.utexas.edu/login?url=http://search.ebscohost.com/login.aspx?direc

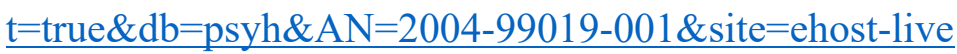

Paris, D. (2012). Culturally sustaining pedagogy: A needed change in stance, terminology and practice. Educational Researcher, 41(3), 93-97. https://doi.org/10.3102/0013189x12441244

Podell, D., \& Soodak, L. (1993). Teacher efficacy and bias in special education referrals. Journal of Education Research, 86(4), 247-253.

Revelle, W. R. (Photographer). (2017). Psych: Procedures for personality and psychological research. Software.

Roberts, S. A. (2009). Supporting English language learners' development of mathematical literacy. Democracy \& Education, 18(3), 29-36. Retrieved from http://vnweb.hwwilsonweb.com/hww/jumpstart.jhtml?recid=0bc05f7a67b1790e65c 1743845f24026c6fc2eb573aa85f201e787f325420a5a5a5498afb1412b2d\&fmt=H\%5 $\mathrm{Ct} \% 5 \mathrm{Ct} \% 5 \mathrm{Ct} \% 5 \mathrm{Ct}$ http://vnweb.hwwilsonweb.com/hww/jumpstart.jhtml?recid=0bc05f7a67b1790e65c $1743845 f 24026 \mathrm{c} 6 \mathrm{fc} 2 \mathrm{eb} 573$

Ross, K. E. L. (2014). Professional development for practicing mathematics teachers: A 
critical connection to English language learner students in mainstream USA classrooms. Journal of Mathematics Teacher Education, 17(1), 85-100. https://doi.org/10.1007/s10857-013-9250-7

Rosseel, Y. (2012). lavaan : An R Package for Structural Equation. Journal of Statistical Software. https://doi.org/10.18637/jss.v048.i02

Schiefele, U., \& Schaffner, E. (2015). Teacher interests, mastery goals, and self-efficacy as predictors of instructional practices and student motivation. Contemporary Educational Psychology, 42, 159-171. https://doi.org/10.1016/j.cedpsych.2015.06.005

Merriam, S. B. \& Tisdell, E. J. (2016). Qualitative research- A guide to design and implementation. San Francisco: Jossey-Bass A Wiley Brand.

Siwatu, K. O. (2007). Preservice teachers' culturally responsive teaching self-efficacy and outcome expectancy beliefs. Teaching and Teacher Education, 23(7), 10861101. https://doi.org/10.1016/j.tate.2006.07.011

Siwatu, K. O. (2011). Preservice teachers' culturally responsive teaching self-efficacyforming experiences: A mixed methods study. Journal of Educational Research, 104(5), 360-369. https://doi.org/10.1080/00220671.2010.487081

Skaalvik, E. M., \& Skaalvik, S. (2010). Teacher self-efficacy and teacher burnout: A study of relations. Teaching and Teacher Education, 26(4), 1059-1069. https://doi.org/10.1016/j.tate.2009.11.001

Sleeter, C. E. (2012). Confronting the marginalization of culturally responsive pedagogy. Urban Education, 47(3), 562-584. https://doi.org/10.1177/0042085911431472

Swanson, H. L., Orosco, M. J., \& Lussier, C. M. (2014). The effects of mathematics 
strategy instruction for children with serious problem-solving difficulties. Exceptional Children. https://doi.org/10.1177/001440291408000202

Team, R. C. (2018). R Core Team R. R: A Language and Environment for Statistical Computing. Vienna, Austria. Retrieved from http://www.r-project.org/

Téllez, K., \& Manthey, G. (2015). Teachers’ perceptions of effective school-wide programs and strategies for English language learners. Learning Environments Research, 18(1), 111-127. https://doi.org/10.1007/s10984-015-9173-6

Toll, S. W. M., van der Ven, S. H. G., Kroesbergen, E. H., \& van Luit, J. E. H. (2011). Executive functions as predictors of math learning disabilities. Journal of Learning Disabilities. https://doi.org/10.1177/0022219410387302

van Garderen, D., Scheuermann, A., Poch, A., \& Murray, M. M. (2018). Visual representation in mathematics: Special education teachers' knowledge and emphasis for instruction. Teacher Education and Special Education: The Journal of the Teacher Education Division of the Council for Exceptional Children, 41(1), 7-23. https://doi.org/10.1177/0888406416665448

Van Uden, J. M., Ritzen, H., \& Pieters, J. M. (2013). I think I can engage my students. Teachers' perceptions of student engagement and their beliefs about being a teacher. Teaching and Teacher Education, 32, 43-54. https://doi.org/10.1016/j.tate.2013.01.004

Verzosa, D. B., \& Mulligan, J. (2013). Learning to solve addition and subtraction word problems in English as an imported language. Educational Studies in Mathematics, 82(2), 223-244. https://doi.org/10.1007/s10649-012-9420-z

Wassell, B. A., Hawrylak, M. F., \& Scantlebury, K. (2017). Barriers, resources, 
frustrations, and empathy: Teachers' expectations for family involvement for Latino/a ELL students in urban STEM classrooms. Urban Education, 52(10), 12331254. https://doi.org/10.1177/0042085915602539

Zuya, H. E., Kwalat, S. K., \& Attah, B. G. (2016). Pre-service teachers' mathematics self-efficacy and mathematics teaching self-efficacy. Journal of Education and Practice, 7(14), 93-98. 


\section{APPENDICES}

\section{Appendix (A): New MTEBI/ELL Responsive Measure (Survey instrument)- Current study}

What is your name?

What is your email address?

What state do you teach in?

Screening Questions ("No" to any of the next 3 questions will end the survey)

Are you a special education teacher?

Yes or No

Do you teach students with mild/moderate disabilities?

Yes or No

Do you teach mathematics to English Language Learners?

Yes or No

Currently, to how many English Language Learners do you teach mathematics?

How would you classify the community in which you teach? Please report the approximate population.

Urban

Suburban

Rural

I'm not sure

Other

How would you rate the community that you teach in?

Upper Class

High Middle Class

Middle Class

Lower Middle Class

Lower/poverty class 
What is your ethnicity? (Check all that apply)

Latino/a

White

Black

Asian

Pacific-Islander

Prefer not to say

Other

Gender Identity

Female

Male

Non-Binary

Prefer not to say

Other

What is your age?

Besides English, how many other languages do you speak?

0

$1-2$

$3+$

In which grades do you teach? (Check all that apply)

$\mathrm{K}-5$

6-8

9-12

Other

What is your highest level of education?

Bachelor's Degree

Master's Degree

Educational Specialist Degree

Ph.D. or E.D.

Other 
What professional licenses do you hold?

Cross-Categorical Mild Moderate K-12

General Elementary School

Secondary- Content (if so, which content)

Content Specialist (if so, which content)

Other

Do you have ESOL English to Speakers of Other Languages certification, or similar certification?

Yes

No

How many years have you taught in your entire career?
A. $0-1$ year
B. 2-5 years
C. 6-10 years
D. $11+$ years

How many years have you taught Special Education?
$0-1$ year
B. 2-5 years
C. $6-10$ years
D. $11+$ years

How many years have you taught English Language Learners with disabilities?
A. $0-1$ year
B. 2-5 years
C. $6-10$ years
D. $11+$ years

What are the ethnicities of your English Language Learners? Please report all that apply, as well as the number of students for each. For example (European 5)

European

African

Hispanic/Latino/a/x

Asian

Native American

Other please specify 
How many years have you taught students at risk for math disabilities?

$0-1$ year

$2-5$ years

6-10 years

$11+$ years

How many ELL students do you serve at each of the following levels of English?

Beginning slider

Intermediate slider

Advanced slider

How much professional development have you received on teaching students who are English Language Learners in mathematics?

0 hours

$2-5$ hours

6-10 hours

$11+$ hours

MTEBI/ELL Responsive- Using a Sliding Scale from 0-10, (strongly disagree- neutralstrongly agree)

\begin{tabular}{|l|l|l|}
\hline 1. & MTEBI5 & $\begin{array}{l}\text { I know how to teach mathematics concepts } \\
\text { effectively. }\end{array}$ \\
\hline 2. & MTEBI11 & $\begin{array}{l}\text { I understand mathematics concepts well enough to } \\
\text { be effective in teaching elementary mathematics. }\end{array}$ \\
\hline 3. & MTEBI16 & $\begin{array}{l}\text { I am not sure if I have the necessary skills to teach } \\
\text { mathematics. }\end{array}$ \\
\hline 4. & MTEBI15 & $\begin{array}{l}\text { I am typically able to answer students' questions } \\
\text { about mathematics concepts. }\end{array}$ \\
\hline 5. & MTEBI18 & $\begin{array}{l}\text { When a student has difficulty understanding a } \\
\text { mathematics concept, I am usually at a loss as to } \\
\text { how to help the student understand. }\end{array}$ \\
\hline 6. & MTEBI14 & $\begin{array}{l}\text { I find it difficult to use manipulatives to explain to } \\
\text { students why mathematics work. }\end{array}$ \\
\hline 7. & MTEBI8 & I generally teach mathematics in-effectively. \\
\hline & \multicolumn{2}{|l}{} \\
\hline
\end{tabular}




\begin{tabular}{|c|c|c|}
\hline 8. & MTEBI10 & $\begin{array}{l}\text { When a low-achieving student progresses in } \\
\text { mathematics, it is usually due to extra attention } \\
\text { given by the teacher. }\end{array}$ \\
\hline 9. & MTEBI12 & $\begin{array}{l}\text { The teacher is generally responsible for the } \\
\text { achievement of students in mathematics. }\end{array}$ \\
\hline 10. & MTEBI13 & $\begin{array}{l}\text { Students' achievement in mathematics is directly } \\
\text { related to their teacher's effectiveness in } \\
\text { mathematics teaching. }\end{array}$ \\
\hline 11. & MTEBI4 & $\begin{array}{l}\text { When the mathematics grades of students improve, } \\
\text { it is often due to their teacher having found a more } \\
\text { effective approach to teaching. }\end{array}$ \\
\hline 12. & ELL7 & $\begin{array}{l}\text { In mathematics, I am able to use various types of } \\
\text { assessments that are matched to proficiency } \\
\text { of English Language Learners with disabilities. }\end{array}$ \\
\hline 13. & ELL12 & $\begin{array}{l}\text { In mathematics, I am able to use culturally specific } \\
\text { context to make mathematics meaningful to } \\
\text { students who are English Language Learners with } \\
\text { disabilities. }\end{array}$ \\
\hline 14. & ELL13 & $\begin{array}{l}\text { In mathematics, I am able to implement } \\
\text { interventions that reflect cultural/ linguistic } \\
\text { matches for English Language Learners with } \\
\text { disabilities. }\end{array}$ \\
\hline 15. & ELL8 & $\begin{array}{l}\text { In mathematics, I am able to critically examine the } \\
\text { curriculum to determine whether it appropriately } \\
\text { represents people from different linguistic/ cultural } \\
\text { backgrounds such as English Language Learners } \\
\text { with disabilities. }\end{array}$ \\
\hline 16. & ELL11 & $\begin{array}{l}\text { In mathematics, I am able to use the students' } \\
\text { language to make mathematics meaningful for } \\
\text { English Language Learners with disabilities. }\end{array}$ \\
\hline 17. & ELL3 & $\begin{array}{l}\text { In mathematics, I am able to create a caring, } \\
\text { supportive environment for English Language } \\
\text { Learners with disabilities. }\end{array}$ \\
\hline
\end{tabular}




\begin{tabular}{|c|c|c|}
\hline 18. & ELL5 & $\begin{array}{l}\text { In mathematics, I am able to develop appropriate } \\
\text { Individual Education Plan (IEP) goals for English } \\
\text { Language Learners with disabilities. }\end{array}$ \\
\hline 19. & ELL15 & $\begin{array}{l}\text { In mathematics, I am able to create a supportive } \\
\text { environment for my English Language Learners } \\
\text { with disabilities. }\end{array}$ \\
\hline 20. & ELL18 & $\begin{array}{l}\text { In mathematics, I am able to help my English } \\
\text { Language Learners with disabilities develop } \\
\text { positive interactions with their peers. }\end{array}$ \\
\hline 21. & ELL17 & $\begin{array}{l}\text { I am able to identify how mathematics } \\
\text { standardized tests may be biased against students } \\
\text { who are English Language Learners with } \\
\text { disabilities. }\end{array}$ \\
\hline 22. & ELL19 & $\begin{array}{l}\text { In mathematics, I am able to gather information } \\
\text { about how my English Language Learners with } \\
\text { disabilities learn best. }\end{array}$ \\
\hline 23. & ELL6 & $\begin{array}{l}\text { In mathematics, I am able to use prior knowledge } \\
\text { related to their backgrounds to help make learning } \\
\text { meaningful for English Language Learners with } \\
\text { disabilities. }\end{array}$ \\
\hline 24. & ELL23 & $\begin{array}{l}\text { In mathematics, I believe that using culturally } \\
\text { relevant examples will enhance the learning } \\
\text { outcomes of English Language Learners with } \\
\text { disabilities. }\end{array}$ \\
\hline 25. & ELL25 & $\begin{array}{l}\text { In mathematics, I believe that English Language } \\
\text { Learners with disabilities' learning outcomes can } \\
\text { be enhanced when their native languages/ cultures } \\
\text { are valued by teachers. }\end{array}$ \\
\hline 26. & ELL26 & $\begin{array}{l}\text { In mathematics, I believe that changing learning } \\
\text { environments to be compatible with students' home } \\
\text { culture increases English Language Learners with } \\
\text { disabilities' learning outcomes to learn. }\end{array}$ \\
\hline 27. & ELL24 & $\begin{array}{l}\text { In mathematics, I believe encouraging the use of } \\
\text { the native language of English Language Learners } \\
\text { with disabilities will help enhance their learning } \\
\text { outcomes. }\end{array}$ \\
\hline
\end{tabular}


Appendix B: Cronbach's Alphas for each item in the MTEBI/ ELL Responsive Survey Instrument organized by latent variable ( as identified by the pilot study)

\begin{tabular}{|c|c|c|c|}
\hline Latent Variable & $\begin{array}{l}\text { Survey } \\
\text { Measure }\end{array}$ & Question & $\begin{array}{l}\text { Item } \\
\text { Cronbach's } \\
\text { alpha }\end{array}$ \\
\hline MTEBI - Efficacy & MTEBI5 & $\begin{array}{l}\text { I know how to teach } \\
\text { mathematics concepts } \\
\text { effectively. }\end{array}$ & 0.72 \\
\hline MTEBI - Efficacy & MTEBI11 & $\begin{array}{l}\text { I understand } \\
\text { mathematics concepts } \\
\text { well enough to be } \\
\text { effective in teaching } \\
\text { elementary } \\
\text { mathematics. }\end{array}$ & 0.79 \\
\hline MTEBI - Efficacy & MTEBI16 & $\begin{array}{l}\text { I am not sure if I have } \\
\text { the necessary skills to } \\
\text { teach mathematics. } \\
\text { (reverse coded) }\end{array}$ & 0.88 \\
\hline MTEBI - Efficacy & MTEBI15 & $\begin{array}{l}\text { I am typically able to } \\
\text { answer students' } \\
\text { questions about } \\
\text { mathematics concepts. }\end{array}$ & 0.79 \\
\hline MTEBI - Efficacy & MTEBI18 & $\begin{array}{l}\text { When a student has } \\
\text { difficulty } \\
\text { understanding a } \\
\text { mathematics concept, } \\
\text { I am usually at a loss } \\
\text { as to how to help the } \\
\text { student understand. } \\
\text { (reverse coded) }\end{array}$ & 0.85 \\
\hline MTEBI - Efficacy & MTEBI14 & $\begin{array}{l}\text { I find it difficult to } \\
\text { use manipulatives to }\end{array}$ & 0.38 \\
\hline
\end{tabular}




\begin{tabular}{|c|c|c|c|}
\hline & & $\begin{array}{l}\text { explain to students } \\
\text { why mathematics } \\
\text { work. (reverse coded) }\end{array}$ & \\
\hline MTEBI - Efficacy & MTEBI8 & $\begin{array}{l}\text { I generally teach } \\
\text { mathematics in- } \\
\text { effectively. (reverse } \\
\text { coded) }\end{array}$ & 0.56 \\
\hline MTEBI- Outcome & MTEBI10 & $\begin{array}{l}\text { When a low-achieving } \\
\text { student progresses in } \\
\text { mathematics, it is } \\
\text { usually due to extra } \\
\text { attention given by the } \\
\text { teacher. }\end{array}$ & 0.82 \\
\hline MTEBI- Outcome & MTEBI12 & $\begin{array}{l}\text { The teacher is } \\
\text { generally responsible } \\
\text { for the achievement of } \\
\text { students in } \\
\text { mathematics. }\end{array}$ & 0.84 \\
\hline MTEBI- Outcome & MTEBI13 & $\begin{array}{l}\text { Students' } \\
\text { achievement in } \\
\text { mathematics is } \\
\text { directly related to } \\
\text { their teacher's } \\
\text { effectiveness in } \\
\text { mathematics teaching. }\end{array}$ & 0.76 \\
\hline MTEBI- Outcome & MTEBI4 & $\begin{array}{l}\text { When the } \\
\text { mathematics grades of } \\
\text { students improve, it is } \\
\text { often due to their } \\
\text { teacher having found } \\
\text { a more effective } \\
\text { approach to teaching. }\end{array}$ & 0.70 \\
\hline \multicolumn{4}{|l|}{$\begin{array}{l}\text { ELL- LCR } \\
\text { (linguistically/culturally } \\
\text { responsive) }\end{array}$} \\
\hline $\begin{array}{l}\text { ELL- LCR } \\
\text { (linguistically/culturally } \\
\text { responsive) }\end{array}$ & ELL7 & $\begin{array}{l}\text { In mathematics, I am } \\
\text { able to use various } \\
\text { types of assessments }\end{array}$ & 0.77 \\
\hline
\end{tabular}




\begin{tabular}{|c|c|c|c|}
\hline & & $\begin{array}{l}\text { that are matched to } \\
\text { proficiency of English } \\
\text { Language Learners } \\
\text { with disabilities. }\end{array}$ & \\
\hline $\begin{array}{l}\text { ELL- LCR } \\
\text { (linguistically/culturally } \\
\text { responsive) }\end{array}$ & ELL12 & $\begin{array}{l}\text { In mathematics, I am } \\
\text { able to use culturally } \\
\text { specific context to } \\
\text { make mathematics } \\
\text { meaningful to } \\
\text { students who are } \\
\text { English Language } \\
\text { Learners with } \\
\text { disabilities. }\end{array}$ & 0.83 \\
\hline $\begin{array}{l}\text { ELL- LCR } \\
\text { (linguistically/culturally } \\
\text { responsive) }\end{array}$ & ELL13 & $\begin{array}{l}\text { In mathematics, I am } \\
\text { able to implement } \\
\text { interventions that } \\
\text { reflect cultural/ } \\
\text { linguistic matches } \\
\text { for English Language } \\
\text { Learners with } \\
\text { disabilities. }\end{array}$ & 0.80 \\
\hline $\begin{array}{l}\text { ELL- LCR } \\
\text { (linguistically/culturally } \\
\text { responsive) }\end{array}$ & ELL8 & $\begin{array}{l}\text { In mathematics, I am } \\
\text { able to critically } \\
\text { examine the } \\
\text { curriculum to } \\
\text { determine whether it } \\
\text { appropriately } \\
\text { represents people } \\
\text { from different cultural } \\
\text { /linguistic } \\
\text { backgrounds such as } \\
\text { English Language } \\
\text { Learners with } \\
\text { disabilities. }\end{array}$ & 0.72 \\
\hline $\begin{array}{l}\text { ELL- LCR } \\
\text { (linguistically/culturally } \\
\text { responsive) }\end{array}$ & ELL11 & $\begin{array}{l}\text { In mathematics, I am } \\
\text { able to use the } \\
\text { students' language to } \\
\text { make mathematics } \\
\text { meaningful for } \\
\text { English Language } \\
\text { Learners with } \\
\text { disabilities. }\end{array}$ & 0.70 \\
\hline
\end{tabular}




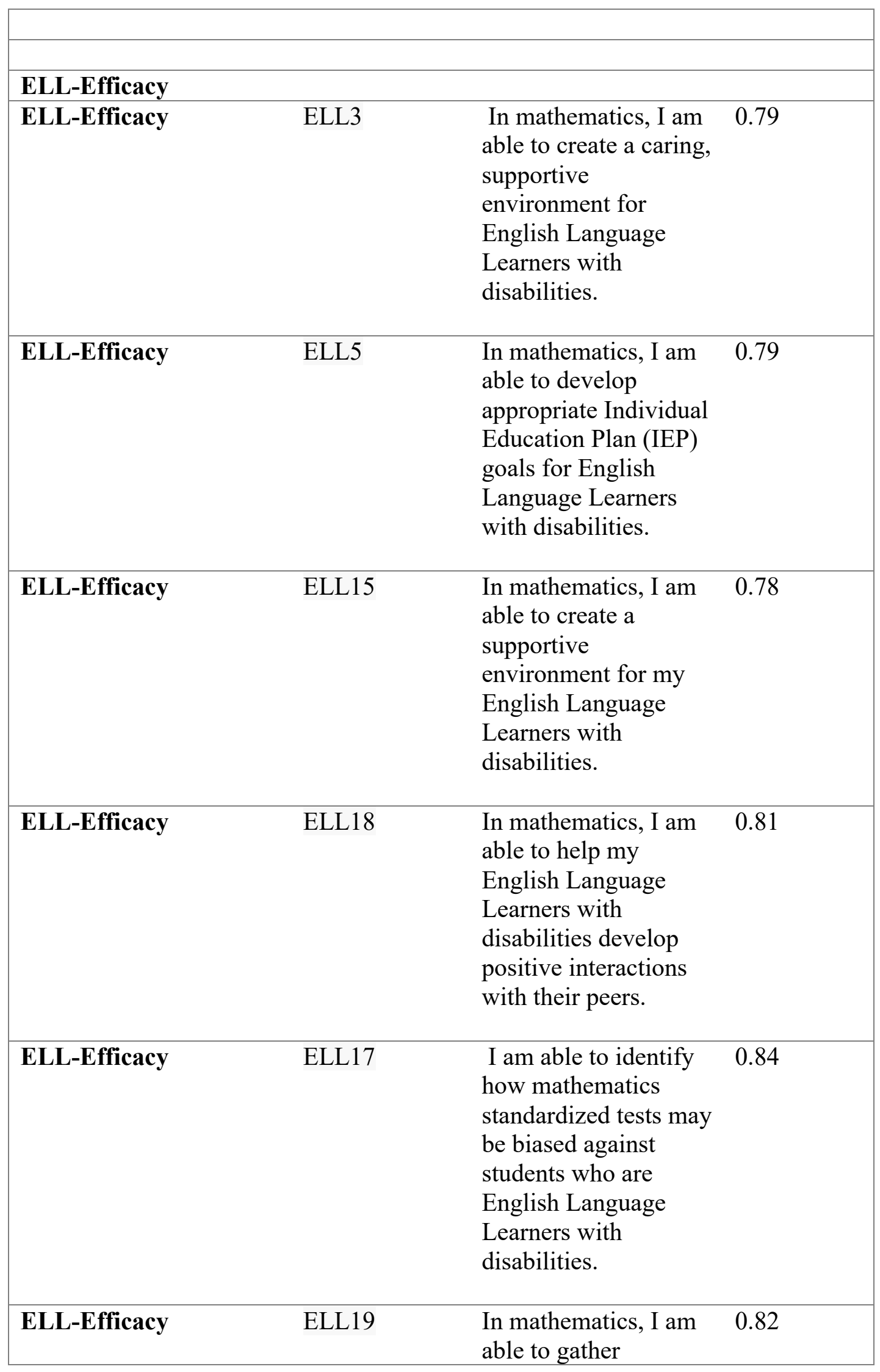




\begin{tabular}{|c|c|c|c|}
\hline & & $\begin{array}{l}\text { information about } \\
\text { how my English } \\
\text { Language Learners } \\
\text { with disabilities learn } \\
\text { best. }\end{array}$ & \\
\hline ELL-Efficacy & ELL6 & $\begin{array}{l}\text { In mathematics, I am } \\
\text { able to use prior } \\
\text { knowledge related to } \\
\text { their backgrounds to } \\
\text { help make learning } \\
\text { meaningful for } \\
\text { English Language } \\
\text { Learners with } \\
\text { disabilities. }\end{array}$ & 0.82 \\
\hline \multicolumn{4}{|l|}{ ELL- Outcome } \\
\hline ELL- Outcome & ELL23 & $\begin{array}{l}\text { In mathematics, I } \\
\text { believe that using } \\
\text { culturally relevant } \\
\text { examples motivate the } \\
\text { learning of English } \\
\text { Language Learners } \\
\text { with disabilities. }\end{array}$ & 0.79 \\
\hline ELL- Outcome & ELL25 & $\begin{array}{l}\text { In mathematics, I } \\
\text { believe that English } \\
\text { Language Learners } \\
\text { with disabilities' self- } \\
\text { esteem can be } \\
\text { enhanced when their } \\
\text { native languages/ } \\
\text { cultures are valued by } \\
\text { teachers. }\end{array}$ & 0.88 \\
\hline ELL- Outcome & ELL26 & $\begin{array}{l}\text { In mathematics, I } \\
\text { believe that changing } \\
\text { learning environments } \\
\text { to be compatible with } \\
\text { students' home culture } \\
\text { increases English } \\
\text { Language Learners } \\
\text { with disabilities' } \\
\text { motivation to learn. }\end{array}$ & 0.87 \\
\hline
\end{tabular}




$\begin{array}{|ll|}\text { ELL- Outcome } \quad \text { ELL24 } & \text { In mathematics, I } \\ & \text { believe encouraging } \\ & \text { the use of the native } \\ & \text { language of English } \\ & \text { Language Learners } \\ & \text { with disabilities will } \\ & \text { help to maintain their } \\ & \text { cultural identity. }\end{array}$




\section{Appendix C- Interview Question Protocol}

\section{Qualitative Questions:}

Interview Protocol for 6 teachers: (approximately 30- 45 minutes)

The first parentheses demonstrate how each question ties back to Bandura's theory of self-efficacy. The second parentheses give hints to further probe the participant.

a. Tell me your experiences teaching ELLs with disabilities. (Probe for ethnicities, English levels, numbers of students, current teaching caseload)

b. Tell me about your experiences teaching mathematics with ELLs with disabilities.

(Probe for ethnicities, English levels, numbers of students, current teaching caseload)

c. Talk about how well prepared you feel you are to teach mathematics to ELL students with learning disabilities in mathematics?

1. Talk about how this compares to other content areas.

2. Talk about any preparation you've had specific to teaching mathematics to ELLs, with learning disabilities.

(Probe for ELL-specific, SWD specific, etc. for university classes, professional development, experience with working with ELL students with disabilities, comfort level with teaching ELL students with disabilities, ability to use the students' home language)

c. Talk about strategies you use when teaching mathematics to ELL SWD.

d. Talk about strategies you use for those students if they are struggling with mathematics specifically.

(Assets to self-efficacy)

(Probe for building support, curriculum, pedagogy, content knowledge,

personal interactions with others, personal knowledge, strategies used)

Secondary Question: Of these supports, which is most effective?

d. How would you describe the outcomes that you expect for your students who are ELL with disabilities? What factors impact your expectations for ELLs with disabilities? What influences your factors and challenges? (Beliefs about outcomes for students)

(Probe for previously mentioned supports, barriers, strategies, and ask for any additional outside factors which may either positively or negatively impact teacher expectations for their students.)

e. Talk about the challenges you encounter when teaching mathematics to ELLs with disabilities? (Barriers to Self-Efficacy) In what ways are these challenges, different if at all, from their non-ELL peers? 
Secondary question, how is teaching mathematics to ELLs w/disabilities different from teaching other students, if at all.

(Probe for building support, curriculum, pedagogy, content knowledge, personal interactions with others, personal knowledge)

f. Consider this instead, which aspects of the school classroom, school community, in what ways does each of the following serve as either an asset or barriers in supporting ELLs with disabilities:

-curriculum- is this an asset or barrier explain (if barrier- how much power to do you have to change or adapt the curriculum to meet the needs of learners)

-Sped resources/staff- asset or barrier (how much power do you have to change or adapt this barrier)

-Administrators- asset or barrier (how do you negotiate this situation)

-School district resources- (generic) (such as professional development, data, funding)

-Students family or community-

- Are there any other assets and barriers that influence their ability to teach ELLs.

If you were able to design an ideal support system for ELL SWD, what would it look like?

\section{g. How do the factors previously mentioned impact your confidence in teaching?}

mathematics ELLs with disabilities? (Power to impact personal self-efficacy)

-curriculum- is this an asset or barrier explain if barrier- how much power to do you have to change or adapt the curriculum to meet the needs of learners)

-Sped resources/staff- asset or barrier (how much power do you have to change or adapt this barrier)

-Administrators- asset or barrier (how do you negotiate this situation)

-School district resources- (generic) (such as professional development, data, funding)

-Students family or community-

- Are there any other assets and barriers that influence their ability to teach ELLs.

(Probe: So, you told me about Can you tell me how this impacts your confidence in teaching mathematics to ELLs with disabilities?)

h. Is there anything I should have asked you but didn't?

i. Is there any other information that you would like to share? 


\section{Appendix D}

Interview Code Book, with accompanying categories and codes

\begin{tabular}{|c|c|c|}
\hline \multicolumn{3}{|c|}{ Categories: Teacher Experience } \\
\hline Codes: & $\begin{array}{l}\text { Citations from } \\
\text { literature: }\end{array}$ & Definition: \\
\hline $\begin{array}{l}\text { Years of teaching } \\
\text { ELLs with } \\
\text { Disabilities }\end{array}$ & $\begin{array}{l}\text { Hoy and } \\
\text { Spero, (2005); } \\
\text { Tschannen- } \\
\text { Moran, (2007) }\end{array}$ & $\begin{array}{l}\text { Years teacher reports teaching students at all, and the } \\
\text { number of years of teaching Ells with disabilities in total. } \\
\text { Also consider how many years the teacher has been } \\
\text { teaching mathematics. }\end{array}$ \\
\hline $\begin{array}{l}\text { Professional } \\
\text { training }\end{array}$ & $\begin{array}{l}\text { Maccini \& } \\
\text { Gagnon } \\
(2006)\end{array}$ & $\begin{array}{l}\text { Any training related to college/university training as well } \\
\text { as any professional development in practice in teaching } \\
\text { mathematics, ELL students, and students with disabilities. }\end{array}$ \\
\hline $\begin{array}{l}\text { Background with } \\
\text { language/cultural } \\
\text { aspects of } \\
\text { students }\end{array}$ & $\begin{array}{l}\text { Paneque and } \\
\text { Barbetta } \\
\text { (2006), Chu \& } \\
\text { Garcia (2014) }\end{array}$ & $\begin{array}{l}\text { This refers to any familiarity that the teacher reports in } \\
\text { their experience or lack of experience with cultural and } \\
\text { linguistic aspects of their students. (Examples- I am } \\
\text { bilingual. I have worked with XXXX students before in } \\
\text { summer camp. Or I am not bilingual. Many of their } \\
\text { parents are migrants, I have no idea what their life is like.) }\end{array}$ \\
\hline \multicolumn{3}{|r|}{ Student Concerns } \\
\hline Student placement & & $\begin{array}{l}\text { Placement refers to special education placement. } \\
\text { Examples- itinerant, co-teaching, class within a class } \\
\text { (CWC), self-contained, flexible (some self-contained } \\
\text { students, some itinerant). }\end{array}$ \\
\hline $\begin{array}{l}\text { ELL vs. Special } \\
\text { Education }\end{array}$ & $\begin{array}{l}\text { Roberts } \\
(2009)\end{array}$ & $\begin{array}{l}\text { This refers to concerns that the teacher explicitly says } \\
\text { referring to separating ELL concerns from Special } \\
\text { education concerns. }\end{array}$ \\
\hline $\begin{array}{l}\text { Student learning } \\
\text { needs (math) }\end{array}$ & $\begin{array}{l}\text { Bull \& Lee, } \\
\text { 2014; Geary, } \\
\text { Hoard, Nugent } \\
\text { \& Bailey, } \\
\text { 2012; Toll, } \\
\text { van der Ven, } \\
\text { Kroesbergen, } \\
\text { \& van Luit, } \\
2011\end{array}$ & $\begin{array}{l}\text { Needs that students have connected to learning } \\
\text { mathematics. These needs could be concerns with } \\
\text { memory, ability to make meaning, attention span etc. }\end{array}$ \\
\hline $\begin{array}{l}\text { Student learning } \\
\text { needs (ELL } \\
\text { needs) }\end{array}$ & $\begin{array}{l}\text { Gersten\& } \\
\text { Baker, 2000; } \\
\text { Orosco, 2013; } \\
\text { 2014; } \\
\text { Paneque \& }\end{array}$ & $\begin{array}{l}\text { Needs that students have connected to language } \\
\text { acquisition. This could be learning needs related to } \\
\text { language, vocabulary, cultural context of the mathematics. }\end{array}$ \\
\hline
\end{tabular}




\begin{tabular}{|c|c|c|}
\hline & $\begin{array}{l}\text { Barbetta } \\
(2006), \text { Chu \& } \\
\text { Garia (2014), } \\
\text { Moschkovich } \\
\text { (2013), }\end{array}$ & \\
\hline $\begin{array}{l}\text { Student behavior, } \\
\text { motivation, } \\
\text { engagement } \\
\text { concerns }\end{array}$ & $\begin{array}{l}\text { Mojavezi \& } \\
\text { Tamiz, 2012; } \\
\text { Schiefele \& } \\
\text { Schaffner, } \\
\text { 2015; Van } \\
\text { Uden, Ritzen, } \\
\text { \& Pieters, } \\
2013\end{array}$ & $\begin{array}{l}\text { This refers to student behaviors, including motivation and } \\
\text { engagement during mathematic tasks. }\end{array}$ \\
\hline $\begin{array}{l}\text { Other student } \\
\text { characteristics }\end{array}$ & & Other characteristics not captured by other codes. \\
\hline & & Teaching Pedagogy \\
\hline Math pedagogy & $\begin{array}{l}\text { Guskey } \\
\text { (1988) -Try } \\
\text { new methods; } \\
\text { NCTM (2014) } \\
\text { standards, } \\
\text { Gersten et al. } \\
\text { (2009) } \\
\text { Explicit } \\
\text { instruction... }\end{array}$ & $\begin{array}{l}\text { This refers to how the teacher presents mathematics to the } \\
\text { students. This could be explicit direct instruction (I do, we } \\
\text { do, you do), or using hands on methods, drawing on the } \\
\text { desk etc to show mathematics. }\end{array}$ \\
\hline ELL pedagogy & $\begin{array}{l}\text { Orosco(2013, } \\
2014) \\
\text { Moschkovich } \\
(2013)\end{array}$ & $\begin{array}{l}\text { Refers to how the teacher provides linguistic scaffolding } \\
\text { in the way of sentence starters, vocabulary support, } \\
\text { pictures to aid in comprehension, drawings to show } \\
\text { vocabulary, gestures, videos, real world tangible } \\
\text { examples. }\end{array}$ \\
\hline $\begin{array}{l}\text { Culturally } \\
\text { responsive } \\
\text { pedagogy }\end{array}$ & $\begin{array}{l}\text { Ladson- } \\
\text { Billings } \\
\text { (1995); } \\
\text { Siwatu } \\
\text { (2007); Chu } \\
\text { and Garcia } \\
\text { (2014), } \\
\text { Aronson and } \\
\text { Laughter } \\
\text { (2016) Sleeter } \\
(2012)\end{array}$ & $\begin{array}{l}\text { This refers to any mention of the cultural needs of the } \\
\text { students in relation to teaching mathematics. This could } \\
\text { be using the students' own cultural background in word } \\
\text { problems, or using their language or cultural ideas in a } \\
\text { mathematics lesson. }\end{array}$ \\
\hline $\begin{array}{l}\text { Student outcome } \\
\text { expectations }\end{array}$ & $\begin{array}{l}\text { Allinder } \\
(1994) \\
\text { Ashton and } \\
\text { Webb (1986) }\end{array}$ & $\begin{array}{l}\text { This is what teachers believe that ELL students with } \\
\text { disabilities will be able to accomplish - as compared to } \\
\text { other students with disabilities - in achievement, } \\
\text { engagement and motivation in mathematics. }\end{array}$ \\
\hline
\end{tabular}




\begin{tabular}{|c|c|c|}
\hline & \multicolumn{2}{|l|}{$\begin{array}{l}\text { Enoch \& } \\
\text { Huinker } \\
(2000) \text { and } \\
\text { Siwatu (2007) }\end{array}$} \\
\hline \multicolumn{3}{|r|}{ Building Climate } \\
\hline Peers & $\begin{array}{l}\text { Caprera et al. } \\
(2006)\end{array}$ & $\begin{array}{l}\text { Peers are anyone in the building who helps the teacher } \\
\text { instruct their ELLs with disabilities. This could be the } \\
\text { ELL (or ESOL) teacher. This could be a para, or others in } \\
\text { the building. }\end{array}$ \\
\hline $\begin{array}{l}\text { SES of school/ } \\
\text { student } \\
\text { demographics }\end{array}$ & $\begin{array}{l}\text { Hoy \& Spero, } \\
\text { 2005; } \\
\text { Midgley et al., } \\
\text { 1989; Téllez } \\
\text { \& Manthey, } \\
\text { 2015) }\end{array}$ & $\begin{array}{l}\text { This comes from any mention of the student population } \\
\text { and school demographics. }\end{array}$ \\
\hline Administration & $\begin{array}{l}\text { Hoy\& Spero } \\
(2005)\end{array}$ & $\begin{array}{l}\text { This refers to the level of Administrative support and } \\
\text { whether it is positive or negative. }\end{array}$ \\
\hline $\begin{array}{l}\text { Curricula/teaching } \\
\text { resources }\end{array}$ & $\begin{array}{l}\text { Hoy \& Spero } \\
(2005)\end{array}$ & $\begin{array}{l}\text { Type of curricula, access to technology, manipulatives etc. } \\
\text { Special attention to the availability of materials and to the } \\
\text { appropriateness of the curricula to the students' needs. }\end{array}$ \\
\hline $\begin{array}{l}\text { Students as peers } \\
\text { to help each other }\end{array}$ & $\begin{array}{l}\text { Podell \& } \\
\text { Soodak, 1993; } \\
\text { Sharma, } \\
\text { Loreman, \& } \\
\text { Forlin, 2012 } \\
\text { Kong \& } \\
\text { Orosco, 2016; } \\
\text { Orosco, 2014; } \\
\text { Orosco, } \\
\text { 2014), }\end{array}$ & $\begin{array}{l}\text { Any mention of students working together to help each } \\
\text { other either with mathematics or with cultural/linguistic } \\
\text { concerns. }\end{array}$ \\
\hline $\begin{array}{l}\text { Time as a } \\
\text { resource }\end{array}$ & $\begin{array}{l}\text { (Gersten \& } \\
\text { Baker, 2000) }\end{array}$ & $\begin{array}{l}\text { Any mention of time- as in "I have the luxury of time to } \\
\text { teach all of my students." Or "I wish that I had more } \\
\text { time." }\end{array}$ \\
\hline $\begin{array}{l}\text { Teacher } \\
\text { autonomy }\end{array}$ & $\begin{array}{l}\text { Ashton \& } \\
\text { Webb, 1986; } \\
\text { Moore \& } \\
\text { Esselman, } \\
\text { 1994) }\end{array}$ & $\begin{array}{l}\text { This refers to teachers specifically mentioning having or } \\
\text { not having the ability to change their teaching methods to } \\
\text { meet the needs of their students. }\end{array}$ \\
\hline $\begin{array}{l}\text { Community and } \\
\text { Parents as } \\
\text { resources }\end{array}$ & $\begin{array}{l}\text { Caprera et al. } \\
(2006)\end{array}$ & $\begin{array}{l}\text { This refers to how the teacher views parents and } \\
\text { community members as sources of help in teaching their } \\
\text { students. This could include parent involvement, or } \\
\text { community member involvement (eg. churches). }\end{array}$ \\
\hline School Climate & $\begin{array}{l}\text { Somech and } \\
\text { Drach-Zahavy } \\
\text { (2000) }\end{array}$ & $\begin{array}{l}\text { This refers to any aspect of school climate not covered by } \\
\text { another code. Some teachers may refer to an unfriendly }\end{array}$ \\
\hline
\end{tabular}


environment for ELLs, or the whole school is ELL friendly.

\section{Inherent Teacher Characteristics}

\begin{tabular}{|c|c|c|}
\hline $\begin{array}{l}\text { Positive vs. } \\
\text { negative regard } \\
\text { for ELLs with } \\
\text { disabilities }\end{array}$ & $\begin{array}{l}\text { Woolfolk, } \\
\text { Rosoff, \& } \\
\text { Hoy (1990), } \\
\text { Brouwers and } \\
\text { Tomic (2000). } \\
\text { Bandura } \\
\text { (1997), Flores } \\
(2007)\end{array}$ & $\begin{array}{l}\text { This refers to overall statements made about Ells with } \\
\text { disabilities, such as, "They are really as bright as other } \\
\text { students, they just need more time to learn the } \\
\text { language."(positive), Or "In their parents' culture, they } \\
\text { don't really care about education, what can you expect } \\
\text { from the kids?" (negative) }\end{array}$ \\
\hline $\begin{array}{l}\text { Desire for } \\
\text { relationships both } \\
\text { students and } \\
\text { parents- } \\
\text { Including } \\
\text { culturally } \\
\text { responsive } \\
\text { relationships }\end{array}$ & & $\begin{array}{l}\text { This refers to the mention of the teacher's feelings about } \\
\text { learning more about the language and the culture of their } \\
\text { students including building deeper relationships with their } \\
\text { parents in order to gain more understanding. }\end{array}$ \\
\hline $\begin{array}{l}\text { Having a } \\
\text { "Whatever it } \\
\text { takes" type of } \\
\text { attitude toward } \\
\text { teaching students } \\
\text { vs. an "It's not my } \\
\text { job" attitude }\end{array}$ & $\begin{array}{l}\text { Bandura } \\
\text { (1993) }\end{array}$ & $\begin{array}{l}\text { Any statement that refers to teachers going above or } \\
\text { beyond to reach their students. Or any statement where a } \\
\text { teacher says "I follow the curriculum- script, I don't } \\
\text { change it", "Or, I try to find other resources to help my } \\
\text { students learn. I have to adjust my teaching for these } \\
\text { students..." }\end{array}$ \\
\hline
\end{tabular}




\author{
Appendix E \\ Recruitment Letter for Administrators
}

Dear Administrator,

Hello. I am a doctoral candidate at the University of Missouri-Columbia, and I need your help! I am looking for Special Education teachers who teach Math to English

Language Learners to complete a survey about their beliefs and expectations. Their responses will be extremely helpful as I plan future university courses and professional development for teachers.

About the survey:

- 15-20 minutes to complete

- All teachers who complete it will be entered into a raffle to win a \$25 Amazon gift card (out of 10 cards)

- If teachers participate in an interview (outside school hours), they will receive a $\$ 25$ gift card

- Identifiable information will be kept confidential

Please send this email with the link below to all of your special education teachers:

https://missouri.qualtrics.com/jfe/form/SV e5VcICPNSMzusxn

When you forward the email, please email me back to let me know the number of teachers it was sent to. This helps me keep track of who has access to this survey.

Thank you so much,

Jessica Kamuru

University of Missouri-Columbia

Special Education- Mathematics Emphasis

Doctoral Candidate

Project PRISM

If you have any questions or concerns about this study, please contact the principal investigator: Jessica Kamuru at the Department of Special Education, University of Missouri, 311Townsend Hall, Columbia, MO, 65211 (phone number: 816-682-0558); jgc7vc@mail.missouri.edu or Delinda van Garderen at the Department of Special Education, University of Missouri, 311 Townsend Hall, Columbia, MO, 65211 (phone number: (573) 884-7075) (email: vangarderend@,missouri.edu). 
If you have any questions or concerns regarding the study and would like to talk to someone other than the researcher(s), contact the University of Missouri Institutional Research Board, 482 McReynolds and phone (573) 882-3181.

\section{Appendix F}

\section{Interview Consent Script}

Independent Study Interview Consent Script:

Thank you for agreeing to participate in this interview. This interview will be used for research purposes only, and the results will not be reported to your place of employment. In this interview, I will ask you questions about your beliefs and perceptions related to teaching mathematics to students who are English Language Learners and have a learning disability in mathematics. Participation in this interview is voluntary. You can stop at any time.

This is just a reminder; you will receive a $\$ 25$ Amazon gift card following the completion of your interview(s).

If you would like to contact me after this interview, my name is Jessica Kamuru, and my phone number 816-682-0558. My email is jgc7vc@mail.missouri.edu. I can also email you this information if you would like. 


\title{
Appendix G
}

\author{
Survey Consent Script
}

Dear Educator,

I am a doctoral candidate in the Special Education Department at the University of Missouri-Columbia. I am asking you to participate in a study examining your beliefs and perceptions regarding teaching mathematics to English Language Learners. Your participation would include completion of a survey and 1-2 possible follow-up interviews.

\section{Responsibilities}

If you agree to participate in this study, you will complete a survey so I can gather information regarding your background, your experiences and beliefs about teaching mathematics, particularly with English Language Learners. The survey should take about 20 minutes to complete.

\section{Risks and Benefits of Being in the Study}

There are no potential risks involved with your participation in this study.

\section{Compensation}

Upon completion of the survey you will be included in a drawing for a $\$ 10$ Amazon gift card. Participants who are chosen for the follow up interview(s) will receive a \$25 Amazon gift card following the completion of their interview(s).

\section{Confidentiality}

This is a confidential survey. Once your survey is complete you will be assigned a pseudonym and that pseudonym will be used for all data storage. If you choose to participate in the follow-up interview(s), your survey data will be associated with your name only to match your survey and interview information. Once the interview is complete, your identifiable information will not be stored with survey data. The records of this study will be kept private, and will not be shared with employers. In any type of report that is published, I will not include any information that will make it possible to identify a participant. Research records will be kept on a password protected server; only researchers will have access to the records.

\section{Voluntary Nature of the Study}


Your decision whether or not to participate will not affect your current or future relations with the University of Missouri.

\section{CONTACTS AND QUESTIONS}

If you have any questions or concerns about this study, please contact the principal investigator: Jessica Kamuru at the Department of Special Education, University of Missouri, 311Townsend Hall, Columbia, MO, 65211 (phone number: 816-682-0558); jgc7ve@mail.missouri.edu or Delinda van Garderen at the Department of Special Education, University of Missouri, 311 Townsend Hall, Columbia, MO, 65211 (phone number: (573) 884-7075) (email: vangarderend@missouri.edu).

If you have any questions or concerns regarding the study and would like to talk to someone other than the researcher(s), contact the Campus Institutional Research Board, 482 McReynolds and phone (573) 882-3181.

\section{Statement of Consent}

I have read the above information and do not have any further questions. I consent to participate in the study.
Yes
No 


\section{Appendix H}

Recruitment Letter for Teachers

Dear Fellow Special Education Teacher,

Hello. I am a doctoral candidate at the University of Missouri-Columbia, and I need your help! I am looking for Special Education teachers who teach Math to English

Language Learners with Mild/Moderate Disabilities to complete a survey about their beliefs and expectations. If this is you, your input will be extremely helpful as I plan future university courses and professional development for teachers.

About the survey:

- 10-15 minutes to complete

- Teachers who complete the survey will be entered into a raffle to win a one of 10 Amazon gift cards for $\$ 25$.

- If you are chosen to participate in an interview (outside school hours), you will receive a $\$ 25$ Amazon gift card.

- Identifiable information will be kept confidential

\section{This is the survey link}

\section{- https://missouri.qualtrics.com/jfe/form/SV_1A1wtwxOBYmYiX3}

If you get this email, could you email me back just to let me know that you received it?

Thank you so much,

Jessica Kamuru

University of Missouri-Columbia

Special Education- Mathematics Emphasis

Doctoral Candidate

Project PRISM

If you have any questions or concerns about this study, please contact the principal investigator: Jessica Kamuru at the Department of Special Education, University of Missouri, 311Townsend Hall, Columbia, MO, 65211 (phone number: 816-682-0558); jgc7vc@mail.missouri.edu or Delinda van Garderen at the Department of Special Education, University of Missouri, 311 Townsend Hall, Columbia, MO, 65211 (phone number: (573) 884-7075) (email: vangarderend@missouri.edu).

If you have any questions or concerns regarding the study and would like to talk to someone other than the researcher(s), contact the University of Missouri Institutional Research Board, 482 McReynolds and phone (573) 882-3181. 


\section{Appendix I}

Survey Descriptives for each question asked on the (current study) survey (means, median, standard deviation, range)

\begin{tabular}{|c|c|c|c|c|}
\hline Survey Questions & Mean & Median & SD & Range \\
\hline $\begin{array}{l}\text { MTEBI 4- When the mathematics grades of } \\
\text { students improve, it is often due to their teacher } \\
\text { having found a more effective approach to } \\
\text { teaching. }\end{array}$ & 7.43 & 6.00 & 1.56 & 7.00 \\
\hline $\begin{array}{l}\text { MTEBI } 5 \text {-I know how to teach mathematics } \\
\text { concepts effectively. }\end{array}$ & 7.79 & 7.00 & 1.33 & 6.00 \\
\hline $\begin{array}{l}\text { MTEBI 8- I generally teach mathematics } \\
\text { ineffectively. }\end{array}$ & 7.82 & 7.00 & 2.36 & 10.00 \\
\hline $\begin{array}{l}\text { MTEBI } 10 \text { - When a low-achieving student } \\
\text { progresses in mathematics, it is usually due to } \\
\text { extra attention given by the teacher. }\end{array}$ & 6.97 & 6.00 & 1.68 & 9.00 \\
\hline $\begin{array}{l}\text { MTEBI } 11-\text { I understand mathematics concepts } \\
\text { well enough to be effective in teaching elementary } \\
\text { mathematics. }\end{array}$ & 8.30 & 8.00 & 1.31 & 6.00 \\
\hline $\begin{array}{l}\text { MTEBI 12- The teacher is generally responsible } \\
\text { for the achievement of students in mathematics. }\end{array}$ & 6.36 & 5.00 & 1.76 & 8.00 \\
\hline $\begin{array}{l}\text { MTEBI 13- Students' achievement in mathematics } \\
\text { is directly related to their teacher's effectiveness in } \\
\text { mathematics teaching. }\end{array}$ & 6.86 & 6.00 & 1.78 & 10.00 \\
\hline $\begin{array}{l}\text { MTEBI 14- I find it difficult to use manipulatives } \\
\text { to explain to students why mathematics work }\end{array}$ & 7.31 & 5.00 & 2.75 & 10.00 \\
\hline $\begin{array}{l}\text { MTEBI } 15-\text { I am typically able to answer students' } \\
\text { questions about mathematics concepts }\end{array}$ & 8.30 & 8.00 & 1.89 & 10.00 \\
\hline $\begin{array}{l}\text { MTEBI 16- I am not sure if I have the necessary } \\
\text { skills to teach mathematics }\end{array}$ & 8.10 & 8.00 & 2.24 & 8.20 \\
\hline $\begin{array}{l}\text { MTEBI 18- When a student has difficulty } \\
\text { understanding a mathematics concept, I am } \\
\text { usually at a loss as to how to help the student } \\
\text { understand. }\end{array}$ & 8.09 & 8.00 & 2.15 & 9.00 \\
\hline $\begin{array}{l}\text { ELL 3- In mathematics, I am able to create a } \\
\text { caring, supportive environment for my students } \\
\text { from different linguistic/cultural backgrounds. }\end{array}$ & 8.88 & 8.00 & 1.34 & 8.00 \\
\hline $\begin{array}{l}\text { ELL 5- In mathematics, I am able to develop } \\
\text { appropriate Individual Education Plan (IEP) goals } \\
\text { for my students who are English Language } \\
\text { Learners. }\end{array}$ & 8.80 & 8.00 & 1.27 & 6.00 \\
\hline
\end{tabular}




\begin{tabular}{|c|c|c|c|c|}
\hline $\begin{array}{l}\text { ELL 6- In mathematics, I am able to use my } \\
\text { English Language Learner's prior knowledge } \\
\text { related to their backgrounds to help make learning } \\
\text { meaning. }\end{array}$ & 7.88 & 7.00 & 1.73 & 8.00 \\
\hline $\begin{array}{l}\text { ELL } 7 \text { - In mathematics, I am able to use various } \\
\text { types of assessments that are matched to English } \\
\text { Language Learners' language proficiency. }\end{array}$ & 7.16 & 6.00 & 2.11 & 9.00 \\
\hline $\begin{array}{l}\text { ELL 8- Mathematics, I am able to critically } \\
\text { examine the curriculum to determine whether it } \\
\text { appropriately represents people from different } \\
\text { linguistic/ cultural backgrounds. }\end{array}$ & 6.47 & 5.00 & 2.35 & 9.00 \\
\hline
\end{tabular}

\begin{tabular}{lllll}
$\begin{array}{l}\text { ELL 11- In mathematics, I am able to use } \\
\text { students' language to make mathematics } \\
\text { meaningful for students. }\end{array}$ & 5.99 & 4.00 & 2.63 & 10.00 \\
$\begin{array}{l}\text { ELL 12- In mathematics, I am able to use } \\
\begin{array}{l}\text { culturally specific context to make mathematics } \\
\text { meaningful. }\end{array}\end{array}$ & 6.13 & 4.00 & 2.62 & 10.00 \\
\hline
\end{tabular}

$\begin{array}{lllll}\text { ELL 13- In mathematics, I am able to implement } & 6.13 & 5.00 & 2.34 & 9.00\end{array}$ interventions that reflect linguistic/cultural matches for English Language Learners.

$\begin{array}{lllll}\text { ELL 17- In mathematics, I am able to identify how } & 6.87 & 5.00 & 2.39 & 10.00\end{array}$ mathematics standardized tests may be biased against students who are English Language Learners.

$\begin{array}{lllll}\text { ELL 18- In mathematics, I am able to help my } & 8.37 & 8.00 & 1.49 & 8.00\end{array}$ English Language learners develop positive interactions with their peers.

$\begin{array}{llllll}\text { ELL 19- In mathematics, I am able to gather } & 7.74 & 7.00 & 1.73 & 9.00\end{array}$ information about how my ELL students learn best
ELL 22- In mathematics, I believe students'
$\begin{array}{llll}8.52 & 8.00 & 1.39 & 5.00\end{array}$

learning becomes meaningful when teachers are aware of the linguistic needs of their English Language Learners with disabilities.

$\begin{array}{lllll}\text { ELL 23- In mathematics, I believe that using } & 8.28 & 7.00 & 1.82 & 7.00\end{array}$ culturally relevant examples enhance the learning outcomes of English Language Learners with Disabilities.

ELL 24- In mathematics, I believe that $\begin{array}{llll}7.35 & 6.00 & 2.11 & 8.00\end{array}$ encouraging the use of native language for English Language Learners will enhance their learning outcomes.

ELL 25- In mathematics, I believe that students' learning outcomes can be enhanced when their native languages/cultures are valued by teachers. 
$\begin{array}{lllll}\text { ELL 26- In mathematics, I believe that changing } & 7.30 & 6.00 & 2.00 & 9.00\end{array}$ learning environments to be compatible with students' home culture increases students' learning outcomes. 


\section{Appendix J}

MTEBI EFA Latent Factor Table -(variances)

\begin{tabular}{|lllllll|}
\hline $\begin{array}{l}\text { Latent } \\
\text { Factor }\end{array}$ & Indicator & B & SE & Z & Beta & Sig \\
\hline M.Efficacy & MTEBI 8 & 2.208 & 0.523 & 4.22 & 0.402 & 0.00 \\
M.Efficacy & MTEBI 14 & 4.820 & 0.849 & 5.678 & 0.664 & 0.00 \\
M.Efficacy & MTEBI 16 & 1.784 & 0.476 & 3.747 & 0.352 & 0.00 \\
M.Efficacy & MTEBI 18 & 2.519 & 0.507 & 4.970 & 0.501 & 0.00 \\
M.Outcome & MTEBI 4 & 1.872 & 0.347 & 5.398 & 0.765 & 0.00 \\
M.Outcome & MTEBI 12 & 1.66 & 0.458 & 3.629 & 0.585 & 0.00 \\
M.Outcome & MTEBI 13 & 1.29 & 0.564 & 2.297 & 0.440 & 0.02 \\
\hline
\end{tabular}

\section{Appendix K}

ELL Responsive Factor Loadings Variances

\begin{tabular}{|lllllll|}
\hline $\begin{array}{l}\text { Latent } \\
\text { Factor }\end{array}$ & Indicator & B & SE & Z & Beta & Sig \\
\hline E. Efficacy & ELL 17 & 3.261 & 0.537 & 6.072 & 0.566 & 0.00 \\
E. Efficacy & ELL 18 & 1.023 & 0.178 & 5.754 & 0.506 & 0.00 \\
E. Efficacy & ELL 19 & 1.264 & 0.257 & 0.00 & 0.399 & 0.00 \\
E. outcome & ELL 23 & 1.040 & 0.259 & 4.012 & 0.319 & 0.00 \\
E. outcome & ELL 24 & 1.708 & 0.361 & 4.726 & 0.379 & 0.00 \\
E. outcome & ELL 26 & 1.626 & 0.326 & 4.987 & 0.404 & 0.00 \\
E. CLR & ELL 7 & 1.449 & 0.293 & 4.942 & 0.333 & 0.00 \\
E. CLR & ELL 8 & 2.370 & 0.411 & 5.761 & 0.437 & 0.00 \\
E. CLR & ELL 12 & 2.219 & 0.440 & 5.047 & 0.344 & 0.00 \\
\hline
\end{tabular}


Appendix L

\section{MTEBI CFA Graph}

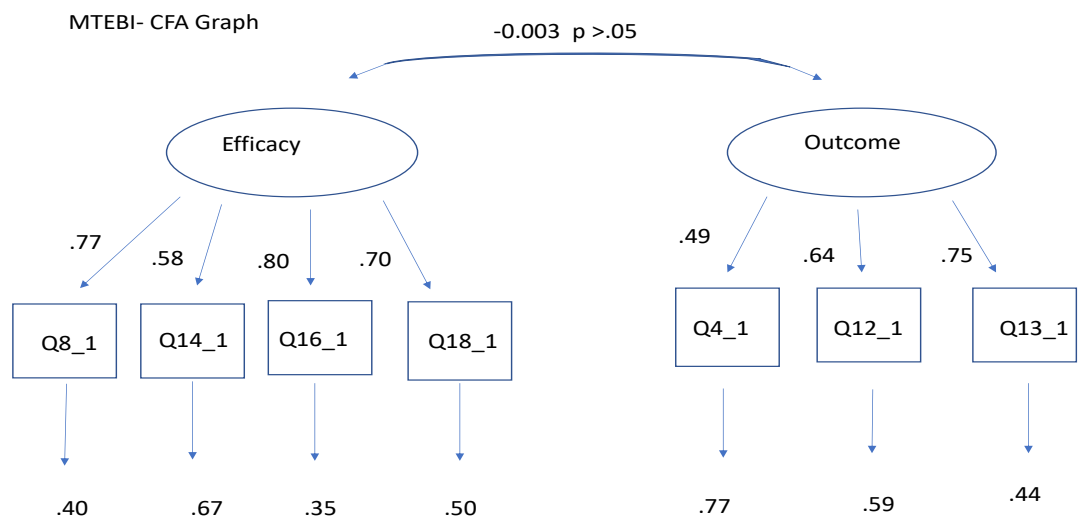

Note: Items are in the order as presented in the text. All modeled path coefficients are significant $(p<.05$, however the correlation between efficacy and outcome was not significant).

\section{Appendix M}

\section{ELL Responsive CFA Graph}

ELL-Responsive CFA graph

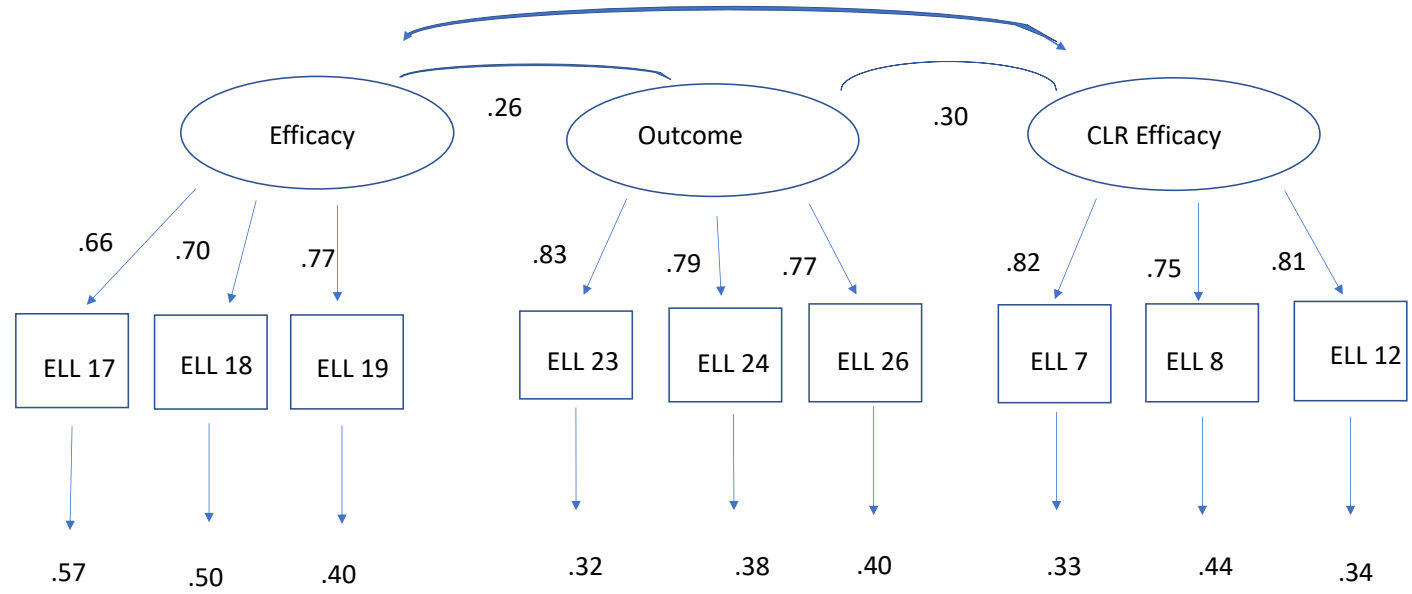

Note: Items are in the order as presented in the text. All modeled correlations and path coefficients are significant $(p<.05)$. 


\section{Appendix N}

CFA Psychometric Properties for the latent variables of the MTEBI and ELL Responsive Measure

\begin{tabular}{|lcccccc|}
\hline Scale & $\mathrm{N}$ & Mean & SD & Median & Range & Cronbach's alpha \\
\hline M. Total & 117 & 7.37 & 1.19 & 7.57 & 5.16 & .62 CI- [.55-.74] \\
M.Efficacy & 112 & 7.85 & 1.97 & 8.50 & 8.10 & .81 CI- [.77-.86] \\
M.Outcome & 117 & 6.90 & 1.32 & 7.00 & 6.67 & .67 CI- [.57-.77] \\
E.Total & 113 & 7.29 & 1.35 & 7.44 & 7.22 & .83 CI- [.78-.86] \\
E. Efficacy & 113 & 7.66 & 1.53 & 7.67 & 7.00 & .71 CI- [.63-.80] \\
E. outcome & 112 & 7.64 & 1.70 & 8.00 & 8.00 & .82 CI- [.76-.88] \\
E. CLR & 113 & 6.59 & 2.03 & 7.00 & 9.00 & .83 CI- [.77-.88] \\
efficacy & & & & & & \\
\hline
\end{tabular}

M.Total- MTEBI Total

M. Efficacy-MTEBI Efficacy

E.Total- ELL Responsive Total

E. Efficacy- ELL Responsive Efficacy

E. Outcome- ELL Responsive Outcome

E. CLR efficacy- ELL Responsive Cultural and Linguistically Responsive Efficacy 


\section{VITA}

Jessica Collins Kamuru taught for 13 years in the inner city of Kansas City, Missouri for a large urban school district. While teaching in this district, she had opportunities to educate students from many different countries such as Mexico, Burma and Vietnam. This lead her on a quest to learn better ways to instruct her students because she realized that she needed to do more than just teach the intended curriculum. She needed to attend to her students as people and teach them in a way that was meaningful in their lives. Upon coming to the University of Missouri-Columbia, she made that her mission — to learn ahow to better serve the students who identify as both ELL and having a disabilit. She plans to continue finding ways to empower underserved communities through outreaches, research and education. 